

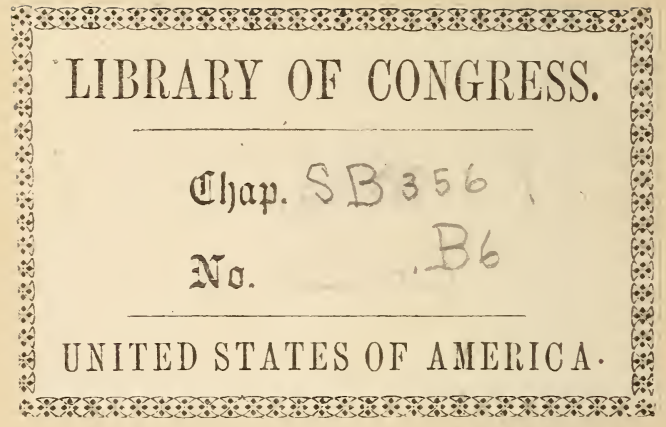





THE

\section{FRUIT GROWER'S INSTRUCTOR,}

BEIXG

A PRACTICAL TREATISE

ON THE

CULTIVATION AND TREATMENT

$O F$

FRUIT TREES:

TO WHICH IS ADDED,

FULL INSTRUCTIONS FOR FORCING,

WITH

A LIST AND DESCRIPTIVE ACCOUNT OF ALL THE BEST FRUITS CULTIVATED IN GREAT BRITAIN;

ALSO DIRECTIONS FOR

\section{HOTHOUSE BUILDING,}

WITH THE MOST APPROVED MODES OF HEATING BY FIRE AND HOT WATER.

THIS WILL BE FOUND A SUCCESSFUL GUIDE TO THE CULTIVATION AND FORCING OF FRTIIS IN EVERY DEPARTMENT, FROM THE PINE DOWNWARDS, AS IT COMPREHENDS THE.

MANAGEMENT OF THE PINERT, VINERY, PEACHERY, AND OTHER FRUIT-TREE

FORCING HOUSES; WITH SORTS PROPER FOR FORCING. AISO DIRECTIONS FOR FORCIYG CHOICE PLAXTS, \&C.THEREIN. TOGETHER WITH FULI INSTRUCTIONS FOR GROWING MELONS, EARLY STRAWBERRIES, \&C.

THE WHOLE WRITTEN FROM PRACTICE, BY GEORGE BLISS.

SECOND EDITION, GREATLY ENLARGED.

LONDON :

JAMES RIDGWAY, 169, PICCADILLY. ] $84 \mathrm{~L}$. 


$$
5^{33^{56}} \cdot 86
$$




\section{PREF A C E.}

IT is necessary to prefix a Preface to a work of this nature, to give the reader such information as may be useful during its perusal; to explain and point out the nature and arrangements of its principal parts; likewise to duly prepare him for what the work contains, which is of great advantage both to the author and himself.

It often happens in works of this sort, as well as in many others, that quotations are made from other authors, in order to sanction and glòss over their own productions, sometimes of 
praise, sometimes of ridicule, just as it may suit the passage or parts alluded to; but by caution. ing my readers against inexperienced authors, I do not intend throughout this publication to call any one name in particular in question, as, perhaps, much which has been written has been to the best of the writer's judgment. But when a person is about to become a fruit grower, (particularly on an extensire scale,) he ought to be cautious how he follows the advice of inexperienced or theoretical persons; for I have read many works professing to treat on horticultural and gardening subjects, which are more calculated to amuse than enlighten. There is a difference between rules of treatment by which certain effects can be insured, and hereditary customs, (if I may use the term) by which advantages may accidentally follow; yet the sticklers, nay almost worshippers, of these latter, will not hesitate to attack the experienced man, because, in one instance out of a hundred, he 
has happened to succeed contrary to the advice of the former.

But the treatment of fruit trees altogether requires long practice and close application; and I intend in this small treatise to explain so clearly the necessary treatment of fruit trees, that every one who is able to read it may understand. I might fill three volumes twice the size, and not convey more practical information to the reader than will be found in this small book; and those who follow its instructions need not fear success, as I do not intend to speak of anything which I have not fully proved. This work will be confined to that profitable and beautiful part of horticulture, the most leading fruits cultivated in this country; among which I shall treat largely on apples, they being of all fruits the most profitable and useful, and I may add the most beautiful, for the bloom in spring is extremely handsome, and the fruit when ripe the same. Indeed it may be denominated with 
strict propriety, a truly British fruit, being the most staple commodity of the kind grown in England; and unlike any other, may be obtained in perfection during any month throughout the year.

It is impossible to write a book that will apply. to every particular case, and as this is not intended as an introduction to Botany, or a Gardener's Dictionary, I think it would be wrong to confuse the reader with more than is stated in the title page. I am certain there is great room for improvement in England, were the soils and situations properly studied, after the following treatise. I should not speak so confidently, were it not from a long series of practice; for when I say there are thousands, and tens of thousands of apple and other trees, in different parts of England, which have been grafted and managed by my own hands till they have been sent to their respective places of destination, together with the opportunity of fruit- 
ing and improving all the best sorts now in cultivation-the confidence in attempting this work will not be surprising.

In addition to the treatise on fruits, budding, and the various modes of grafting trees, with interesting observations thereon, I have given a list of all the leading fruits now in cultivation, both alphabetical and explanatory, which will be found very useful to those who are unacquainted with them.

The work is divided into chapters and paragraphs, each paragraph beginning and ending with the subject it relates to, without being confused with extraneous matter; and as the index refers to paragraphs as well as pages, any subject may be found with the greatest facility.

I now feel the greatest gratification in knowing that the first edition of this work has had the most beneficial results, by causing a vast quantity of fruit trees (particularly apples) to be be planted in various parts of the kingdom; 
and what is still more satisfactory, the finest sorts have taken the place of those of inferior quality, which the markets of the metropolis and most other large towns now bear ample testimony. 


\section{INTRODUCTION TO PART II.}

Amongst the diversified branches of utility pointed out for our pursuits, both in practice and theory, there is none that can class with gardening; it must stand foremost in estimation, and ever be acknowledged the basis of the glory of every country; England, then, which is not second to any other nation in the world, whose navy rides triumphant on the ocean, is more indebted to arboricultural gardening than any other country; it is to our timbers we are mainly indebted for the comforts we enjoy in this highly favoured isle. 
The nobleman and the peasant can rest secure in the mansion or the cot, and in peace partake of luxuries which Providence has so bountifully, through skilful hands, supplied for our use, and without such security we could not expect long to see our highly-favoured fertile soil studded in all directions with seats of more or less consequence, the gardens in many instances forming the most interesting part, and from which the principal vegetable luxuries of life are produced.

Apart from the luxuries thereof, the importance of agriculture, which has been long duly appreciated, the scientific principles thereof, may be likewise traced to have sprung from gardening; and when blended together, we may trace not only all the blessings we possess, and comforts we enjoy, but also health, riches, and prosperity ; nay more, not only has agriculture a right to claim gardening for its foundation, but every art, trade and profession, indeed every 
individual article of life, may be traced to the same source.

With a view to avoid confusion, which often occurs by subjects of this nature, following in one continued narrative, I have also arranged the second part in chapters and paragraphs, so that the reader may refer with ease to any subject he may have immediate cause to consult. The paragraphs, it will be perceived, are for the most part concise, at the same time giving ample instructions on each subject under separate heads.

The chapters, as a whole, will contain a sufficiently elaborate account of the principal fruits for forcing, in which their general management will be so explained as to render the contents not only of use to the practical man as a reference for his general guide, but will also, by the clearness of the rules laid down, be found of such service to young practitioners in gardening, and even to the amateur, that by perseverance and application they may attain the height of 
their profession as fruit-growers in the forcing departments, from the pine down to the strawberry.

The forcing and management of grapes, and such other tree fruits which are best suited to the forcing house, is clearly explained, with some useful remarks relative to the stocks which peaches, nectarines, \&c., should be budded upon, when they are intended for forcing, which I would impress on the minds of such of my readers who would wish to excel in the profession, not to pass over too lightly.

As this is intended as a general guide to the forcing fruit-grower, not any one thing of importance has been omitted, in order to render the work as intelligible and useful as possible, not neglecting or rejecting the ancient for the modern, nor the modern for the ancient.

While I am writing from an extensive practical knowledge on these subject, let me avail myself of this opportunity to confess that since the first publication of the Fruit Grower's In- 
structor, which was my first essay on these matters, that I am under great obligations to many eminent authors, and more particularly to those friends in the horticultural world who have furnished me privately with invaluable information on very many important subjects relative to gardening; at the same time, should I differ from any of my gardening friends, I trust they will not consider it done wilfully to offend, or discourage, but having had such vast opportunities to put anything connected with the subject to the test, I think I should act wrong to flatter any one by stating as authentic in this work anything which has been merely experimental, and which cannot be supported by tried practice, and knowledge derived from a fundamental source.

My having for some years past been engaged in suggesting alterations, and improvements in different parts of the country, it has brought me into contact with men of the first abilities as regards gardening pursuits, and has led me to a field for great observation, which greatly 
stimulated me to write these sheets; although nothing but a long and great former practice, attended with great application on my own part, could have given me confidence to attempt a work of this nature, and through which means I am enabled to form a contrast between ancient and modern improvements, and to recommend such portions of each that may lead to beneficial results and ultimate success. 


\section{N D E X.}

Page Par.

Os the Propagation of Apples

Quartering Stocks

Grafting

Tying Graft

Management of Grafts • . $\quad$. $15 \quad 5$

Snagging of Grafts • • $\quad 16 \quad 6$

Pruning and Management while in the Nursery. $\begin{array}{lll}17 & 7\end{array}$

Observations before the general cultivation of Apples $22 \quad 8$

Cultivation of Dwarf Apples . $\quad \begin{array}{lllll} & & 23 & 9\end{array}$

Directions for planting in bad soils . $\quad \begin{array}{lll}25 & 10\end{array}$

$\begin{array}{lll}\text { Cultivation of Standard Apples } \quad ~ & 26 & 11\end{array}$

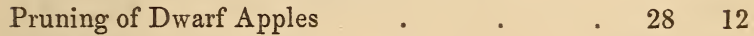

$\begin{array}{llll}\text { Pruning of Standard Apples } & 32 & 13\end{array}$

Pruning of Trained Apples, with Observations . $34 \quad \begin{array}{ll} & \mathbf{1 4}\end{array}$

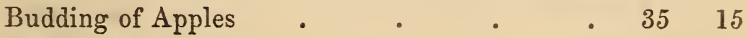

Description of Budding • • $\quad$ • $\quad \begin{array}{lll}37 & 16\end{array}$

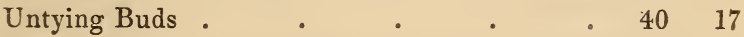

Heading down Stocks which are Budded $\quad \begin{array}{lll}40 & 18\end{array}$

$\begin{array}{llll}\text { Tying and Suckering of Buds } & \text {. } & 41 & 19\end{array}$

Observations before the Explanatory List of Sorts $\quad 41 \quad 20$ 
EXPLANATORY LIST OF SORTS.

Page Par.

Ribston Pippin .

Court of Wyck Pippin

$\begin{array}{ll}42 & 21\end{array}$

Scarlet Nonpareil

Old Nonpareil .

Downton Pippin

Sykehouse Apple

Yellow Ingestry Pippin

Hick's Fancy

Old Golden Pippin

Franklin's Golden Pippin

Early Oslin Apple

Scarlet Pearmain

Royal Pearmain

Margaret Apple

Duchess of Oldenburgh

Golden Reinet

King of the Pippins

Wellington Apple

Kerry Pippin

Wheeler's Russet

Powell's Russet

Deronshire Whitesour

Margell

Cristy's Pippin

Beauty of Kent .

Emperor Alexander

Keswick Codlin

Luccomb's Seedling

Northern Greening

Scarlet Admirable

Royal Russet .

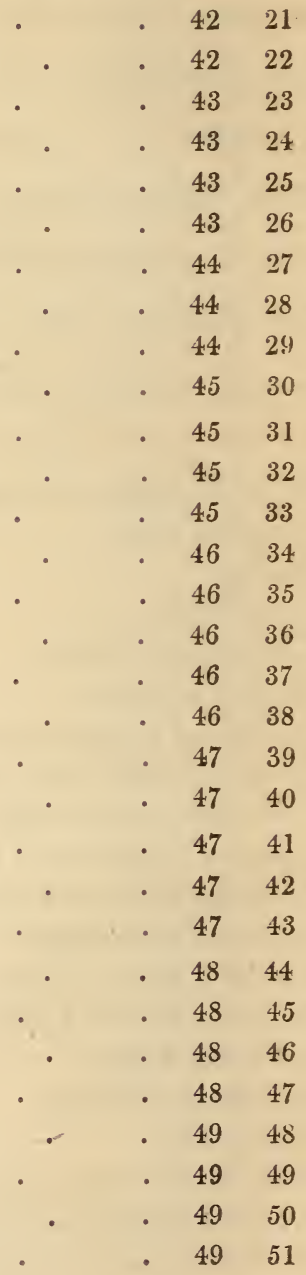


INDEX.

Cockagee

Page Par.

Shepherd's Newington

Striped Holland Pippin

Dutch Codlin .

Kentish Codlin

Norfolk Storing

Norfolk Beefin

Lemon Pippin

Loan's Pearmain

Hawthorne Dean

Hertfordshire Pearmain

Kirke's Lord Nelson

French Crab

Nonsuch

Norfolk Paradise

Woodstock Pippin

Mank's Codlin .

Pile's Russet

Braddick's Nonpareil

Observations

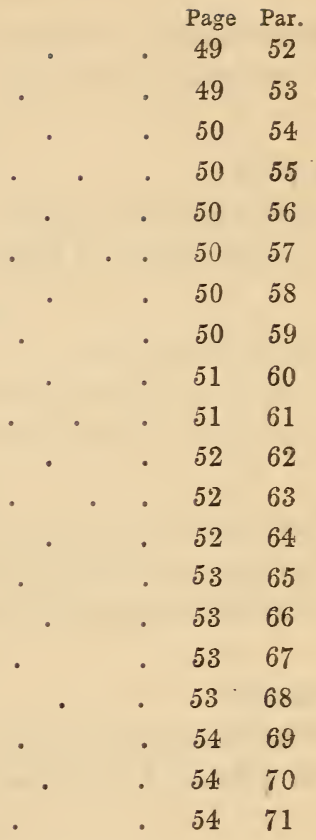

ALPHABETICAL LIST OF APPLES NOW GENERALLY

CULTIVATED

Cider Apples

Apples recommended for small Gardens

The mode of producing new kinds of Apples

Observations on the different modes of Grafting

CHAPTER II.

PEARS. 
Explanatory List of Pears

PLUMS.

Remarks

$$
\text { PLoms. }
$$

Explanatory List of Plums

Alphabetical List of Plums

CHERRIES.

Useful Observations

Explanatory List of Cherries .

Alphabetical List of Cherries

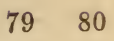

$\begin{array}{ll}79 & 81\end{array}$

$84 \quad 82$

APRICOTS.

Remarks on the Stocks for Budding, \&c. $\quad$. $\quad 89 \quad 86$

$\begin{array}{lllll}\text { Explanatory List of Apricots } \quad ~ & \text {. } & 90 & 87\end{array}$

Alphabetical List of Apricots . . . $92 \quad 88$

PEACHES.

Remarks

Explanatory List of Peaches .

$92 \quad 89$

Alphabetical List of Peaches

$94 \quad 90$

NECTARINES.

Explanatory List of Nectarines

- $99 \quad 92$

Alphabetical List of Nectarines

- 10193

GRAPE VINES.

Remark's

GRAPE VINES.

Explanatory List of Grapes .

Alphabetical List of Grapes $\quad$ • $108 \quad 96$

FIGS.

$\begin{array}{lllll}\text { Explanatory List of Figs } \quad \text {. } & 109 & 97\end{array}$

Alphabetical List of Figs _ . . . 11198

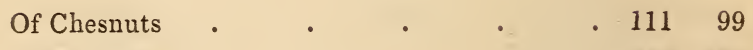

Of Barberries • . $\quad$. $\quad$. $112 \quad 100$ 
INDEX.

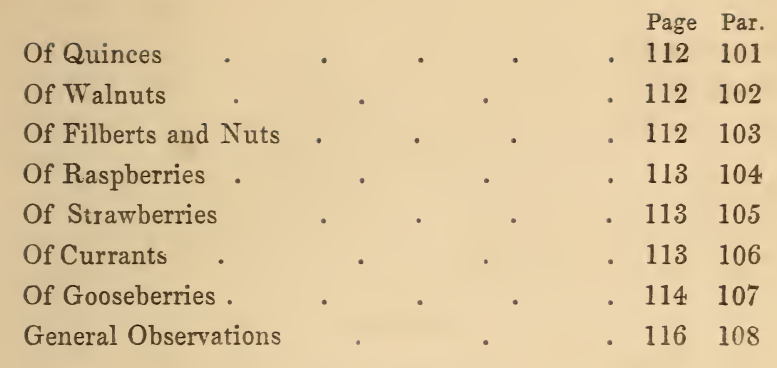




\section{PART II.}

\section{CHAPTER I.}

ON THE CULTURE OF PINES, WITH INSTRUCTIONS FOR BUILD. ING, AND GENERAL DESCRIPTION OF HOTHOUSES, METHODS OF HEATING, \&c.

General description of Hothouses intended for

Page Par.

Pines, including situations, aspects, \&c.; also

Instructions for Pits and Hotbeds $\quad$. $123 \quad 1$

Description of Soils . . . . . 144 2

Methods of raising Pine plants ․ . $145 \quad 3$

General culture of Pines . . . . . 1514

At full growth, order of Fruiting, \&c. • $157 \quad 5$

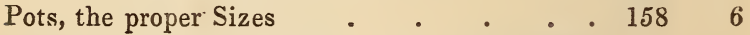

Different varieties of Pines, with Observations

relative to their nature and culture $\quad$. 1597

Method of making the Bark-bed, its general

Management and Utility . • . $\quad$. $162 \quad 8$

Sorts of fuel for Fire-heat . . . . . 164 9

Regulation of heat, thermometer, \&c. $\quad$ - 16410 
Of Bark-bed and Fire-heat $\quad$. $\quad$, . . $167 \quad 11$

$\begin{array}{llll}\text { Giving Air and Water at different seasons } & 169 & 12\end{array}$

Hot Water and Steam, the general uses thereof in Forcing, with Explanatory Remarks $\quad \begin{array}{lll}170 & 13\end{array}$

Raising Pines in Hotbeds . . . . $178 \quad 14$

Management of the Bark-bed in the Pinery - $179 \quad 15$

Occasional Revival of the Bark-bed _ . $183 \quad 16$

Winter Management of Pines _ . . 184 17

Spring Management of Pines . . • . 18518

Summer Management of Pines • • • . 18619

Observations on Shifting Pines, including directions for Autumn Management . . 19020

Insects, remarks thereon, with Instructions how to prevent them from being injurious . . 19521

Early Grapes in the Pinery a . . . $200 \quad 22$

Choice varieties of Fruits, Flowers, \&c., in the Pinery . . . . . . . 20223

Useful Remarks relative to the Chapter on Hothouse Building, \&c. • . • • . 20324

\section{CHAPTER II.}

ON FORCING PEACHES, NECTARINES, AND APRICOTS, CHERRIES, GRAPES, AND OTHER CHOICE FRUITS.

Observations relating to Peacheries, Vineries, and other Forcing Houses, with Introductory Remarks on raising different sorts of Fruits, Vegetables, and Flowers therein - . . 207.25

Description of the different plans for Forcing Houses, methods of Heating, with general Observations . . . . . . 21026

Nescription of a general Forcing House - . $214 \quad 27$ 
Preparing Borders for the trees, and the different

Page Par.

Sorts proper for Forcing, including Grape Vines

Proper Seasons and Methods of Planting trees for Forcing . . . . . . . 223

Narrow Glass-houses for Forcing principally by

Fire-heat, or Hot Water . . . . 228

Forcing Frames, for forcing Fruit trees by Barkbed heat alone

Vinery or Hothouse, principally for Forcing Grapes ; methods of obtaining the Plants, with useful Observations

How to obtain Fruit trees intended for Forcing, with a neces. . ry Caution . . . . 233 33

Management of Vines, and Seasons for Forcing 234 34 Green-house, or Cold Glass house for Vines $240 \quad 35$

Peach-house, its culture and general utility for Forcing . . . . . . . 24

Forcing-house for Cherries, with its further Uses $\quad 244 \quad 37$

Observations relative to the Season, and Methods of Forc generally . . . . . 245

Admitting ir, with Instructions for Watering in the different Forcing houses $\quad$ • $\quad$ • $\quad 248 \quad 39$

Pruning Fruit trees in Forcing houses, with Instructions for Training . • • . 25140

Blights and Insects on Trees, how to prevent and destroy in Forcing houses . . . . 254

The Seasons the different varieties of Fruit generally attains maturity in Forcing-houses . 25542 Treatment of Fruit Trees after Forcing . $256 \quad 43$ 


\section{CHAPTER III.}

CONTAINING DIRECTIONS FOR GROWING MELONS, WITH INSTRUCTIONS HOW TO RAISE EARLY STRAWBERRIES; ALSO, MANY USEFUL AND ORNAMENTAL PLANTS IN FORCINGHOUSES.

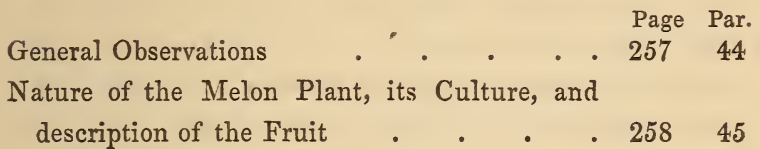

Different varieties of the Melon, with Observations . . . . . . . . 25946

Soil proper for growing Melons _ . . $261 \quad 47$

Preparing dung, \&c., for the Hotbeds, for raising

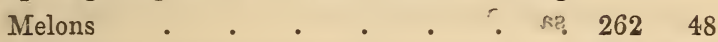

Seed proper for Sowing . . . . . 26349

Observations on raising Melons in different ways, the times for Sowing the Seed, with remarks thereon . . • . • 26350

Method of Making Hotbed for raising Melon plants, with their Management therein - , $-265 \quad 51$

Making the Fruiting Hotbeds for early and general crops of Melons, with their Management therein, copiously laid down • • • $268 \quad 52$

Manner of Treating Melons when in bloom $\quad 275 \quad 53$

Instructions for Renewing the Heat of the Hot. bed by linings $\quad$ • . . . . $276 \quad 54$

Remarks relative to Melons while Ripening • $278 \quad 55$

Late Crops of Melons under Hand-glasses, \&c. $279 \quad 56$

Raising Melons in Oiled-paper Frames, with

Directions for making the Frames ․ $282 \quad 57$

Growing Melons by Bark-bed Heat . . $285 \quad 58$

How to save and preserve Melon Seed $\quad$. $\quad 288 \quad 59$ 
Strawberries, Introductory Remarks on growing

Page Par. them . . . . . . . . 28960

Different Sorts of Strawberries proper for Forcing $\quad 290 \quad 61$

Manner of Raising, and Culture of Strawberry

Plants intended for Forcing • • . $292 \quad 62$

Forcing Strawberries in the Pinery . . . $294 \quad 63$

Forcing Strawberries in Peach and other Fruit

Tree Forcing-houses, including Vineries $296 \quad 64$

Forcing Strawberries in Hotbeds, with Useful

Remark's . . . . . . 29765

Forcing Raspberries . . . . . . 30066

Raising Kidney Beans in Forcing-houses • . $303 \quad 67$

Growing Cucumbers in Forcing-houses . . $305 \quad 68$

Early Lettuces in Forcing-houses . . $306 \quad 69$

Peas and Beans in Fruit-tree Forcing-houses . $307 \quad 70$

Raising early, various useful articles for culinary purposes in Forcing-houses . . . . $308 \quad 71$

Observations on Forcing different varieties of choice Flowers in Forcing-houses $\quad$ • $\quad$. $309 \quad 72$ 
THE

\section{FRUIT GROWER'S INSTRUCTOR.}

\section{PART THE FIRST.}

\section{CHAPTER I.}

On the Propagation, $\mathrm{Cu}$ ition, Pruning, and General Management of Apple Trees; also, Instructions for Budding, the various modes of Grafting, \&c.

ON THE PROPAGATION OF APPLES.

PAR. 1.-The propagation of apples is, of all other fruits, the most easy; and yet no tree requires more care and good management in its general cultivation. 
The reason why it is more easy is, because the grafts are, if put on in the proper season, and made to touch the bark, almost sure to grow; but although so easy, it is generally attended with more dangerous consequences than any other tree, if the grafting part is not properly attended to, which will be hereafter explained.

The general method of propagating apples, is by grafting on the Crab stock, which stock should be raised from the seed of the true Crab; the seed may be procured from those who make verjuice; when a large quantity is wanted, it is the best way, as you can generally depend on having seed from the true Crab; but this is not the case with many stock-growers, for they often sow the seed from apples made into cider, which will produce various sorts of stocks; some will grow large and vigorous, others of so weak a nature that they will scarcely ever make a standard tree.

The best method is to wash the seed from the pulp, and let it get rather dry, for its own pulp is very apt to rot the pip; mix it with 
some light mould or sand, not too damp; then, the following February, or beginning of March, as the weather may suit, you may sow your seed in beds or in drills; but beds are best, for when you have taken your mould out the proper depth, which should be about an inch, you will be able, when you have sown your seed, to cover it all over alike, which you cannot do so correctly in drills: the beds should be about four feet wide, leaving two feet between each bed for a path, to be able to walk between them to weed and keep the beds clean, as that is most material to all young seedlings; you take the mould out about one inch deep with the spade, and put it into the path or alley; make the bottom of your beds perfectly level, then sow your seed (just as it is mixed, with mould or sand), as near as you can judge about one inch apart all over the ground, which will be much better for the plants than if you sow. them thicker, for Crabs when drawn up very weak, seldom do much good after: then take the mould you have thrown into the alleys, and sift it over them about one inch; but if the 
ground is strong and binding, about three quarters of an inch will be quite enough.

The seed will then remain in the ground till the following spring, before you get your general crop, although some few may come up the first year; during that period, the beds should be kept carefully clean, while the weeds are in a young state, in order that the mould may not be disturbed so deep as the seed.

The following Autumn you may take up the seedlings, having had one summer's growth, and transplant them into beds, putting them about one foot row from row, and about three inches apart in the rows: let them stand two years, then they will be strong to plant out into quarters for grafting, or if the plants are not too close together in the seed beds, they may stand two years, and the greater part will be then strong enough to plant out for grafting, without being first bedded.

QUARTERING STOCKS FOR GRAFTING.

Par. 2.-Where you quarter or plant out Crab stocks, being intended to grow strong 
to throw up standard trees, it is necessary to select a piece of deep loamy soil, which should be well trenched two spades deep; this should be done as early in autumn as you can, in order to get your stocks planted early in November, then they will immediately draw root, which will make a considerable deal of difference in their growth the following summer; for if you do not get them planted till late in December, the coldness of the ground, even if the weather is mild, will prevent them drawing fresh root, and they would be better to remain in the beds till February, when they would soon begin to vegetate; for when the stocks remain in the ground for some months, after being removed and all regetation ceased, the small fibres are very apt to rot, and the large roots get in a mildewed, stagnant state, which I have proved has been so far injurious to the plants, that it often takes them the following summer to recover themselves, while those planted in February will make a good growth.

If your ground is very poor, it will be ne- 
cessary to give it plenty of good rotten manure, to make them throw up standards quick.

The distance for quartering out the stocks for grafting should be two feet six inches row from row, and about ten inches apart in the rows. Some will give two feet ten inches, or three feet row from row; but that I think unnecessary, as two feet six inches is quite suffcient to get between them for all purposes, and quite room enough for them to grow so long as they ought to remain in the nursery.

When you plant your stocks you should prune the roots, cutting the strong roots shorter, and take away as many of the superfluous fibres as you can; trim up the stock clean at the bottom, but be sure to leare buds to break from the top, then cut off the top, leaving the stock long enough to be about sixteen or eighteen inches out of the ground when planted; the stocks should remain two years, and then they will be in good order for grafting, during which time they will require very little care or trouble, more than digging between and keeping them clean from weeds. 
GRATING。

Par. 3.-We next come to grafting, which is one of the most important branches in propagation, particularly of the apple, it being so subject to the canker, and so apt to be injured where the graft' is put on the stock, which, if it once takes place, is almost sure to destroy the tree.

Grafting appears to those who may see others performing it, very easy, like looking at another who may write a fine hand, but it requires much practice to become a clean grafter, as well as it does to write a clean hand; at the same time I shall endeavour so fully to explain it, that it may be of considerable advantage to the pupil.

There are various ways to graft, but the best and usual method for stocks, planted as before described, is what is commonly called whipgrafting, for which we must first make the necessary preparation. In the first place, some strong loam, such as will stick well together, should be dug and laid in a heap, if in the dry 
the better; for if you can run it through a sieve you will free it from all stones or lumps, which will make it mix the better.

In the next place there must be provided a sufficient quantity of horse-dung (I mean the clean droppings from the horse, quite clear from straw, for it is the best thing to keep the clay from cracking,) to allow about one-fourth to three fourths of loam; this must be mixed well together, to make it smooth and fine enough for plastering, and sufficiently moist to be able to mix it about easy in the hands; but not too moist, otherwise it would slip off the stock, but that would soon be found out by those who are using it.

The next thing to prepare is some bass or matting for tying on the grafts. For stocks of the age and size before-mentioned, it should be cut about one foot and a half long, and tied in small bundles ready for the man who is to tie the grafts.

Now having all ready, we must watch our season for grafting: where there is a great quantity to do, it is necessary to begin as early 
as the season will admit; and as apples are not so early as cherries, plums, or pears, (where you have these to graft) your apples must wait till they are done; but if you can begin your apples about the middle of March, and finish by the second week in April, it is very rare that it is too late for them, for I have grafted apples with success in the last week in April, when the stocks have been out in full leaf; but this is a dangerous practice, for if the weather sets in very dry, it will so dry up the juices of the stocks that many cannot be expected to grow, and what do will be very weak, and scarcely ever make handsome standards.

In the next place must be got ready the scions or cuttings, which should be of one year's growth, and as firm and strong as you can get them, so that they are not too large for the stocks; for although weak cuttings will grow, they will not make near the growth as the strong cuttings, neither will they bear a dry harsh spring so well. Now we proceed to grafting. In the first place you cut down your stocks within four or five inches from the 
ground, which in large nurseries is done by a man before the grafter. After the grafter a man to tie the grafts; then follow two boys, the one to what is commonly called dabb, or put the clay on the graft, and the other to close the clay: in this way you may get through much grafting, if the grafter be quick. The grafter should have the scions cut in lengths about six inches long, and carry them in his apron; then taking out one at a time, he should hold it firm in his left land, then take a slice off the end of the sción, rather more than an inch long, and be careful not to let your knife cut too deep to get into the pith, till it gets near the end of the slice; - this is one reason why I recommend so short a slice, for in taking a long slice you are apt to cut along the pith, which is very injurious; although it may not signify so much with apples, it is a bad practice to follow, for in grafting cherries you will scarcely ever have a crop, or what is commonly called a good hit. Having made your slice in the manner described, you then cut a tongue or slit, which should be about a quarter of an 
inch long, (this is another material thing to pay attention to,) commencing about a quarter of an inch below the top of the slice; let your knife go in not more than half-way through the scion, for if you cut too far in when your grafts are united, you must be at the unnecessary trouble of shouldering or tying them again round the top, otherwise those cut too far through when they have grown any size, the winds will blow down, even after tying them a second time.

Having got your scion ready, you take a slice of your stock the length of the slice on your scion, make a tongue or slit about the same length as that on your scion, beginning nearly at the top of the slice, letting your knife slope gradually into the stock. If your stock is much larger than your scion, do not make your slice too deep into the stock, in order that your scion may touch the inner rind of the stock on both sides as well as the bottom; but be careful to let your scion just touch the bottom of the slice on the stock, as that is necessary both for its making a good growth 
the first summer, and likewise for its healing well over, for the graft derives by far more nourishment from the bottom than the side; but be sure do not let your scion go below the slice on the stock. By this practice you put on the graft in the centre of the stock, which is much better than putting it on the side, and by this practice you need not tie your grafts a second time.

TYING OF GRAFTS.

Par. 4.-Having given the necessary instructions for the grafter, tying of grafts is the next consideration: the tying is done by a man who follows the grafter; he must have his bass or matting cut in lengths about one foot and a half long, or if the stocks are large, it may be longer; this tied in small bundles should be taken one at a time, (after dipping it in water to make it tough) and tied in the string of the apron, putting one end in the apron to keep it moist: the bass should be strong, otherwise should it break, if the grafter be quick, he will have to wait for the man 
who ties : the man being now prepared, he should begin to tie about four stocks behind the grafter, and keep about that distance, which will give the grafter room.

The bass should be placed firm against the bottom of the scion, and not let slip, which will prevent the scion from being put out of its place; this is very necessary to be observed, for if the scion is removed by the tying, it is useless for the grafter to be particular about putting the grafts on; he should then tie it tight round till it comes to the top of the stock, where it should have a tight hitch to fasten off, then cut the end of the bass close off, for if the end is left an inch long, which I have often seen, it prevents the clay from being properly closed, consequently admitting the air to the graft, which.often proves fatal.

The next thing is putting on the clay, commonly called dabbing : this is done by a boy who follows the man who ties; having put his clay into something to carry it with him, he must take a small piece of clay sufficient to cover the whole of the incision, and to come about half an inch 
above the top of the stock, in order that it may hang well on the shoulder; this he should roll up in his hands nearly in the form of an egg, then make a hollow in one side of it with one hand, sufficiently deep, that when it is put on the stock, it will enclose it all round alike.

After the dabber follows another boy, called the closer; he follows with a pot of dry ashes, or dust, to rub his hands with to keep them from sticking to the clay, and closes up every crack, squeezing it tight round the bottom of the clay to keep it from slipping; then making it perfectly smooth, nearly in the form of an egg, it finishes the grafting.

The above is the general way of grafting in large nurseries about London; but where small quantities only are wanted to be grafted, the grafter may tie his own grafts, and one boy will serve both to dab and close.

I have treated as fully as possible on grafting of "apples, as it will serve for most other fruits, for this practice of grafting is far preferable to saddle or rind grafting for fruit trees. 
MANAGEMENT OF GRAFTS.

Par. 5.-We next proceed to the management of grafts, which it is necessary to pay great attention to.

The grafts will not require anything to be done to them till they have grown five or six inches long, unless suckers should break out from the stock before the graft shoots, which must be carefully cut off and not pulled off, for by pulling them off, you leave holes in the stock which the insect is very fond of getting into, and of course the bottom is the most dangerous part of the tree to get the canker in; therefore they should be cut off as clean as possible, and when the grafts have grown five or six inches long, you should watch your opportunity after rain and the clay is wet, to go over your grafts and take off those clays which have grown out that length, as they will then come off easy, and leave those which have not grown out sufficient till another time; for if you take thern off too soon, and hot dry weather should ensue, they are very apt to wither up; if the weather should continue 
dry, and your grafts grow too long, you must then get the clays off by knocking them with the handle of your knife, or anything that will answer the purpose; but be sure to hold the graft as steady as you can with one hand, to keep it from being removed out of its place, for that would be sure death to the graft; therefore as this is so much more trouble, it is necessary to take every opportunity after rain.

The day after the clays are removed, you may untie the bass, observing that you cut your bass at the back of the stock; and by following the above practice, they will require no more tying, nor any further attention through the summer, than keeping them free from suckers, and cutting off the small piece of wood at the top of the stock, commonly called snagging; but this must be carefully done.

SNAGGING OF GRAFTS.

Par. 6.-When you commence this work, which you may do at any time after midsummer, it is necessary to have a sharp knife with a smooth edge to aroid the knife slipping and cutting the 
stem of the graft, which it is very apt to do if your knife has a bad edge; and by making those cuts in the summer season, it leaves a place where the insect is very fond of getting in and causing the tree to canker.

It is necessary your knife should be strong, and held very tight in the hand: after a little practice, if your stocks are not very strong, you will be able to take the snag off with one cut, and after this work is performed, they will require no further attention through the summer. I shall hereafter make some interesting observations on grafting generally, with other methrods.

PRUNING AND MANAGEMENT OF APPLES WHILE IN THE NURSERY.

Par. 7.-The next thing to explain is the pruning and management while they remain in the nursery. The first autumn after grafting, they are what are called maiden trees, and they generally produce from one to three shoots, and are by many preferred in this state for general planting, where dwarf trees are required, which, 
in some instances, are to be recommended ; for where the tree has thrown out three shoots from the alternate buds (but not twin buds from the same joint,) the three shoots will be quite sufficient to form the bottom of the tree, and those shoots will often throw out quite wood enough for the tree to support, which will be hereafter explained under the general head of pruning.

But I shall now confine myself to the general management while they remain in the nursery. Dwarf trees, as well as standards, being now in general request, it is necessary, when the pruning season commences, to reserve those for dwarfs which are not likely to make standards; therefore, after having drawn or taken away as many maiden trees as you may require, all those you intend for standards you must take off all shoots but one, leaving the strongest and most upright.

Those intended for dwarfs should be those where the shoots are not upright or strong: in this case you ought to cut all off but two shoots, and cut those shoots down to about three buds; or where one shoot is much weaker than the 
other, in order to form a handsome tree, it is better to take off the weak shoot and cut down the strong one to four or five buds, which will produce quite a sufficient quantity of shoots, and prevent the tree growing strong on one side and weak on the other; this having been performed, will be all the pruning they will require till the following summer, when those intended for standards will require what is called spurring in,that is, while they are in a growing state, soon after Midsummer, the young shoots which they throw out from the side of the tree should be cut off within about an inch from the stem, except about five or six at the top, which will cause a general circulation of the sap, and make the trees grow evidently stronger and taller during the summer; but unless they are taken before they have done growing, it will be of no use, but had better cut them close off to the stem towards autumn, which it is necessary should be done to form a head with five or six shoots.

The trees at this age being generally about three or four feet high in the stem, and commonly called half standards, those wishing to plant half 
standards, cannot plant them at a better age, if the trees have made a strong growth, for the shoots are alternately formed, and consequently never crowd or injure each other, which is often the case where a tree has been headed down, unless it is carefully pruned; but this the reader will be more fully furnished with under the head of pruning.

The dwarfs, likewise, after one year's heading down, will have formed shoots enough, and will never be at a better age for planting.

Although a few trees may have grown five or six feet high, and make tolerable good standards the second year, you seldom find many; therefore after taking away as many half standards as you may have occasion for, the March following begin to make your half standards into standards, by cutting off all the side shoots, leaving the upright shoot, cutting that off about five feet six inches high, and some six feet, but trees are none the better for being too high in the stem.

After the next summer's growth, if the trees are tolerably strong, and have formed a head of 
five or six shoots, they cannot be in a better state for general planting, for their shoots likewise are formed alternately from the stem, which, when they get large, causes every limb to receive free and equal, nourishment from the main stem.

As the trees will not be all fit this season, it is necessary to be careful how those are pruned which are left, in order to keep their heads young, free, and flourishing; if the stem of the tree should not be higher than you may wish it, the best way will be to trim the lower shoots clean off, learing only the two top ones, and cut those two down to about three or four buds each; or if you wish the tree lower, you must cut it down to the two bottom shoots, and be careful when you are pruning at this season, to cut as close as you can to a bud; for what wood you leave above the bud becomes a dead substance, and if it does no other injury it greatly disfigures the tree, besides making it awkward to remove after the tree has formed a head.

The above instructions are from the time 
of planting the stocks. I have allowed them to remain six years in the quarters before the ground is cleared, which I think quite long enough; therefore shall not give any further instructions for pruning while they remain in the nursery, for they would not pay for standing; neither would I recommend old trees for planting; for although old trees may grow and perhaps bear almost immediately, the fruit. would not be near so fine as those produced from young trees, neither would they succeed so well in future.

OBSERTATIONS BEFORE THE GENERAL CULTIVATION OF APPLES.

Par. 8.- It is both necessary and important to make some observations on the cultivation of apples, as it more or less affects fruit growers generally; for it is too often the case, (some for want of thought, others for want of experience) to go upon one broad plan, without studying the situation, the soil, or the different sorts of fruit which would best suit the different situations, which I shall endeavour to explain; at 
the same time confine myself to a limited number of sorts, such as are most esteemed]; for to introduce two or three hundred sorts of apples, two-thirds of which are not worth growing, would only confuse the reader, and render it difficult to choose.

I shall therefore confine myself to fifty sorts, giving each their true character; for it is very necessary when you plant either in large quantities for the market, or in gardens for the use of the family, to plant such sorts as will come in succession all the year round, which will be here explained, and the different seasons when each sort is held in its highest perfection.

CULTIVATION OF DWARF APPLES.

Par. 9.-As dwarf apples are now so much cultivated, we will commence with planting untrained dwarfs in gardens. Having first selected your sorts, you must get such trees from the nursery as described in paragraph the seventh; but before you plant, you should study the situation and the soil; for although many persons are afraid to plant apples, because those of their 
neighbours do not flourish, and the land does not appear to suit them, I should not be afraid of failing to have fine trees and fine fruit in any soil, with my treatment.

Apples are fond of a deep loamy soil, and a situation where they will have plenty of sun, and where the soil is naturally good; you need not take any further trouble (where the ground is in the habit of being dug) than opening a hole sufficiently large to take the root in easily, loosening the bottom of the hole about a spade deep, and having pruned the roots, plant them in the same soil; and these you may plant in any convenient corner of the garden, the same as you would a currant or gooseberry tree, and if required will not take up more room by being properly pruned; and the same rule may be followed in the shrubbery, at such convenient distances where you can find an open place for the sun to get at the fruit; or if a piece of ground is set apart for a plantation of dwarf apples, the distance I should recommend would be about twelve feet apart, and then by keeping them properly pruned, they would have plenty 
DIRECTIONS FOR PLANTING IN BAD SOIL 25

of room to grow and receive the nourishment of the sun and air.-See Pruning.

DIRECTIONS FOR PLANTING IN BAD SOIL.

Par. 10. I shall now give directions for planting where the apples are not fond of the soil, say the soil is of a gravelly nature, or nearly a bed of gravel.

You must open a hole at least three feet square and three feet deep, bring in some soil bordering on clay, and put at bottom (which will keep cool) about one foot thick, then fill up the other two feet with rich loam, and plant yourr tree right in the centre.

This it may be said is a great deal of trouble, but what is a garden without an apple tree?-and when once done they will last for many years, either in gravelly or sandy soil, in neither of which apples will do well alone.

It is under the above treatment indispensably neeessary to study the sort of stock your apple is grafted on; it should be the small Paradise stock, for apples grafted on these stocks will bloom beautifully and produce fruit even in pots, 


\section{6}

DIRECTIONS FOR PLANTING IN BAD SOIL.

as the root is of a fine fibrous nature, and will remain in a small compass; but the crab is naturally a strong-rooted tree, and would soon overrun the boundaries of the hole made for it, and consequently not flourish after: in fact, apples grafted on paradise stocks are greatly recommended as dwarfs, where you do not want the trees to grow large, for they generally bear very freely on those stocks; and although the fruit will come very fine, they do not produce near such strong wood as those grafted on the crab; in all cases in planting of apples be careful noi to plant them too deep, but merely cover the roots well.

CULTIVATIOY OF STANDARD APPLES.

Par. 11.-The culture of standard apples is so generally known in this country, that it is not necessary to make many observations; at the same time a few may not be considered superfluous.

In the first place, when you select your trees from the nursery, be careful there is no blemish on the stem caused by the canker; and when orchards are planted the trees should stand at 
least sixteen feet apart, but distances vary in different countries, from sixteen to forty feet: I should recommend about twenty feet, or twentyfive if the land is very good, to give room for the under crop; and as there is no fear in future of the trees decaying through the canker, it would be better than planting them nearer, for it is necessaiy for the meadow to have a free current of air, otherwise it would produce a poor sour pasturage.

It is a very good plan to plant the trees three or four years or more before the ground is laid down for grass, for keeping the ground dug about the trees while young greatly encourages their growth, and they then become strong and out of the way of cattle.

This plan is often adopted by hop-growers to plant their trees before the hop grounds are worn out; and when the meadow is laid down, there is at once a fine young orchard in bearing without further trouble, and while the trees are in that young state they do so litile injury to the under crops, that the same method may be adopted by cropping the land with regetables

$$
\text { c } 2
$$


or corn, but not too near the tree, for any thing of strong growth is very injurious; those who plant standards in gardens, must be guided by the spots they can best select to plant the trees where they will do the least injury to the vegetable crops.

It would be very wrong to plant standard apple orchards on very inferior land; and on good land I would by no means recommend very large holes, for the ground will naturally sink, thereby causing the tree to be considerably lower than it ought, which is rery injurious, particularly if sunk below the graft; at the same time they should be made sufficiently large to let the roots in easily, and the earth at the bottom of the hole finely loosened full one foot deep before the tree is put in.

PRUNING OF DWARF APPLES.

Par. 12.-The pruning of apple trees is a most important thing to attend to, and to understand, both for keeping the trees in a healthy state, and likewise for the production of fine fruit, particularly dwarfs, of which I shall first 
treat; I mean common dwarfs (called by some dwarf standards) and not dwarf trained trees.

It is necessary to commence from the maiden graft, and go on till the tree is in a state of maturity, in order to render the process as clear as possible.

Suppose your maiden tree has only one or two shoots, it is then necessary to cut them down to four or five buds, to get a sufficiency of wood to form the bottom of the tree; the following season leave about five of the most regular shoots, which will be quite sufficient, or even four, for they are none the better for being crowded with limbs from the stem.

But as apples, sometimes the first year after planting, will scarcely make any growth, they had better stand one year after planting before they are headed down; but I should prefer those trees which have been one year headed down in the nursery, having enough shoots to form the bottom of the tree; I should not leave more than six shoots at the outside, but what you take out, take out clean, and be sure not to leave any blemish, nor bruise the bark with the knife. 
I here beg leave to differ from those who recommend heading down dwarf apple trees, when they have wood sufficient to form the bottom of the tree; I prefer letting it remain, for, as the new wood will grow but little the first year, the shoots will swell and get strong, and if it is a good bearer will form bloom buds all up these young shoots: this, perhaps, will alarm some to allow the tree to bear so young, but it must be remembered that the trees while young will produce the finest fruit: besides, it is necessary to throw them into bearing early, to keep them from growing too luxuriantly. It is useless having a great fruitless tree covering a large space of ground, while by proper management you can get an equal quantity of fruit off a tree half the size, and that fruit finer, and the tree kept sufficiently strong and in perfect health, by the mode of pruning I shall adopt.

* Now the tree having stood two years without being headed down as before described, it will throw out some young side-shoots towards the top of the original shoots; these should be cut off within two buds of the bottom, allowing the ori- 
ginal shoots to grow straight up, till they get to the height you wish them, say five or six feet or higher, then cut their tops off, and keep all the young shoots spurred in every year, to about two buds, nearly the same as you would a red currant tree; by this means it will throw all those spurs into bloom buds, and I have seen by this process, the trees hanging from bottom to top with apples like ropes of onions; and by pruning away all that superfluous wood, the fruit receives the whole strength and nourishment of the tree ; and besides, by this method, you not only throw your trees into bearing, and produce more fruit, but they have the advantage of the sun, so essential both for their flavour and beauty; the trouble is no more than that of pruning your currants and gooseberries, and surely apples are worth as much attention.

When the trees begin to get old, you may occasionally leave a clean young shoot, and the following year remove an old one, and by so doing you will keep your trees in a young, healthy, bearing state.

Dwarf apples on the small Paradise stock, may 
(if required) be kept in a much less space than those described above, and by this way of pruning, the trees may be, with proper management, kept perfectly free from the canker.

\section{PRUNING OF STANDARD APPLES。}

Par. 13.-The pruning of standard apples has for many years past been attended with very dangerous consequences, on account of the canker; for where the tree has not been cut particularly clean, or left at all bruised, there the insect would be sure to get in, and keep wounding the tree further and further, till it completely ruined it; therefore, in all kinds of pruning, you ought to cut very smooth and clean, and then it will soon heal over, but if bruised or left rough, it will not.

Having selected the standards with young heads, such as are recommended in paragraph the seventh, I should plant them without touching their heads with a knife, for if you cut them down, and they do not break freely the first year, they seldom do well after; but if the head is not cut, and the tree does not grow much the first 
year, it will get strong, and the main shoots from the stem will get strong likewise, and sooner get out of the way of cattle.

But where you plant trees that have been two or three years headed down in the nursery, it is necessary to cut out any cross shoots, or where two shoots are close together to take away one; for although they might not injure while young, they would when they grew old, and the tree not grow so handsome.

I must add another reason for not cutting down the heads of fresh planted standard apples: I have often seen them when they have been cut down, instead of making fine young heads, throw out short shoots two or three inches long, and those (if they are good bearers) formed into bloom, which stagnates the tree, and seldom forms a good head after.

Standard trees planted, and their heads left in this state, will require no pruning till the trees get large and too full of wood, except an occasional cross branch, and taking out all dead pieces.

But old trees should occasionally be thinned 
where they grow too thick of wood, and this should be performed with a saw where the branches are large, but be sure to saw them off without splitting or injuring the bark, and as the saw will leave it rough, the part where it has been sawed off should be made smooth with a sharp knife, otherwise it will not heal so well or so soon.

\section{PRUNING OF TRAINED APPLES.}

Par. 14.-As trained apples are not so much in request since the introduction of common Dwarfs, and as the pruning of them has been so fully explained, it is necessary only to state after the tree has been properly trained in the nursery, the pruning it will require, will be similar to the pruning and management of dwarf apples, in paragraph the twelfth.

There is one great benefit arising from trained apples; while young the wind has not the puwer of shaking them about so much, and consequently the fruit is not so likely to fall; likewise, if they have no other trees to shade them, the fruit is sure to receive the benefit of the sun. 
The season I should recommend for pruning apples, is from the middle of January till the middle of March; some will prune through April, and so late as May; but my opinion is by causing the sap to flow, and the tree to bleed too freely when the bloom is tender, often causes the fruit not to set well.

Another thing should be observed in pruning of dwarf and trained apple trees: there are some sorts which bear principally at the end of the young shoots; where that is the case, you should always leave plenty of the young one year shoots; for want of a knowledge of this many fail in their crops on trained trees, for if the bloom is cut off we cannot have fruit; this is easily discovered by leaving those sorts you are unacquainted with till March, before you prune them, you will then see where they shew their bloom, and the tree may be kept free, by taking away old wood instead of young.

BUDDING OF APPLES.

Par. 15.-Budding of apples some years back, was much more practised than at the present 
day, although in some nurseries in the country, it is still continued, and, of course they think it best: but I will here give my reasons for not approving of the general practice of budding apples.

The argument of those who approve of budding apples is, they generally grow taller for standards the first summer, there being but one shoot for the stock to support: granted; but this is often the cause of crooked, weak, stemmed trees, for having run up so tall, they frequently throw out shoots at the top the following summer, which are often too heary for the stem to support, and they consequently bend down and grow crooked.

Another very great objection to budding apples is the canker, for buds are generally untied late in summer, and there is naturally a wound in the stock, which the most scientific budder cannot prevent; and this is the season of the year, of all others the most dangerous, for the insect is fond of a wound where they can enter for their winter quarters, and that spot of 
all others, is the most dangerous in the tree for the canker to take place.

But although I do not recommend it generally, sometimes it is necessary: for if you wish to make the most of a cutting, or it might happen you would be able to get a cutting of some favourite sort at the budding season, and could not at the grafting season. I will, therefore, give as clear a description of budding, as can be given in writing, which will serve not only for budding apples, but all other fruits.

\section{DESCRIPTION OF BUDDING.}

'Par. 16.-Budding is an art which requires long practice, and close attention, to arrive at perfection in; indeed most authors have said, it is impossible to convey an accurate idea to the reader; but I will endeavour to state it so plain, that I think with attention it may be of service.

The budding of apples is what we now have before us; in the first place, it is necessary to attend to the state of the stocks you intend to bud, for some seasons are much earlier than others, and some soils will cause the stocks, 
either Crabs or Paradise, to grow much longer than others; and in budding of all kinds of fruit trees, it is very necessary to bud them before the stocks have stopped growing.

Generally the best time for apples, is late in August, but this must entirely depend on the state of the stocks, or trees, which you intend to bud.

The stocks being ready, you should endeavour to get your cuttings (which must be of the same summer's growth) as firm and ripe as you can, and having prepared some strong new matting for the purpose, you proceed to budding.

After cutting the leaves off the cutting or scion, cut off the top likewise, as low down as it is soft and too green, then with your budding knife which must have a very keen edge, take off the top bud from the scion, commencing with your knife about an inch below the bud, then hold the bud firm betwen your thumb and finger, and take out the piece of wood the reverse way of the bud, leaving nothing but the rind, this must be done clean without leaving it 
any way ragged; you then look, (and in this it is necessary to be very particular, ) to see if taking out the wood has injured the bud, which it will do in various ways; sometimes it will draw all the centre of the bud out, which renders the bud of no use whatever ; sometimes it will leave the bud very hollow; in that case they are doubtful; therefore if you are not short of cuttings, do not make use of one bud unless it is quite plump and lerel with the inside rind, and then you may almost make a certainty of its growing; on the contrary, you cannot depend on them, for they will often keep alive to all appearance even through the winter, but will not shoot in spring; in fact, this is one of the most nice points in budding; having your bud ready, you next proceed to open the incision in the stock or tree; the incision is made nearly in the form of a letter $T$, cutting through the rind first at the top about half way round the stock, ther commencing with your knife about two inches lower down, draw your knife up to the cut at the top, and before you take your knife out, gently open the rind on one side, 
which will let in the handle of your budding knife, then open the incision so that it will let in the bud to the bottom, and cut off what may remain too long for the incision; tie the bud tight round with some strong matting, observing that you do not let the bass go at all over the bud, for that is sure death; give it a tight hitch to fasten off and the budding is finished.

UNTXING OF BUDS.

Par. 17. - When the stocks or trees have been budded about six weeks, it is necessary to untie the bass from them; it is the practice of some to tie them again, but this is qnite unnecessary, except where they have been budded in very free growing young wood, but even then if the bass is not tied too tight, they need not be, or at least very seldom, tied again.

HEADING DOWN STOCKS WHICH ARE BUDDED.

Par. 18. - The heading down of stocks or trees which have been budded is the next process; they should be cut off about four inches above the bud; this may be done any time after 
Christmas, but about the end of February is a good time; they are not so well to be left much later in the season, otherwise the bud is apt to go blind, through the sap rising more up into the head of the stock or tree.

TYING AND SUCKERING OF BUDS.

Par. 19.--The next thing is the tying and suckering of buds; it is necessary when the suckers shoot out from the stocks to cut them clean off, in order to give the bud all the encouragement you can; and when the bud has grown four or five inches long, tie it gently up to the piece of the stock which is left above the bud, but be sure to leave a sufficient space between the bud and the stock for the bud to swell, after this you have no further trouble with them, except keeping them free from suckers till they want snagging, for which see snagging, Paragraph 4.

OBSERVATIONS BEFORE THE EXPLANATORY LIST OF SORTS.

Par. 20.-Having given all the necessary in- 
formation for the cultivation, pruning, and general management of apple trees, I shall next furnish the reader with an explanatory list of sorts, giving each their true character.

\section{EXPLANATORY LIST OF SORTS.}

TABLE OR DESSERT APPLES.

Par. 21.-Ribston Pippin; this is one of the most celebrated apples in cultivation; it is ripe in October, and in the months of November and December; it is considered by most superior in flavour to any apple at that season; its bloom is simple and by no means showy for the shrubbery; it is a general bearer, but will not keep late, for if the fruit does not rot, it will lose its juices and become insipid. It will also make excellent sauce, but it is generally recommended as one of the best table apples.

(22.) - Court of Wyck Pippin; this is a very handsome small table apple; it is said to be a seedling from the old golden pippin: it ripens 
in October, is a good bearer, and will keep through the winter.

(23.) - Scarlet Nonpareil; this is a very choice table apple, in high perfection at Christmas, at which season it is not excelled by any apple for beauty and flavour; it is rather larger than the old nonpareil, of very handsome form, and if the fruit stands open to the sun, it will turn of a beautiful scarlet; it produces a prodigious quantity of bloom, and generally bears well.

(24.) -Old Nonpareil; this is an apple too well known to require much explanation or recommendation; it is a fine keeping table fruit.

(25.)-Downton Pippin; this is one of the productions of Mr. Knight, of Downton Castle, and President of the Horticultural Society; it is a very handsome small yellow apple, very full of juice, of rather a tart flavour; it is a great bearer, and in high perfection in the autumn.

(26.)-Sykehouse; this is a small firm table apple of a russet colour, handsome form, and 
equal, from Christmas till May, to the old nonpareil; it is a very great bearer.

We have not a better keeping table apple in England.

(27.) - Yellow Ingestry Pippin; this is a very handsome small yellow table fruit, a good bearer, and is in perfection about October.

(28.) - Hicks Fancy; this is a most delicious dessert apple, of small size, a very great bearer, and will keep; but it is best before Christmas.

(29.)-Old Golden Pippin; this apple as a table fruit, is decidedly one of the best in this country; although there are many apples far superior to it in flavour before Christmas: it is not excelled by any after, and consequently at a season when most of our finest table apples are gone by. I cannot pass over this fruit without making a few observations, knowing an impression has been made on some gentlemen, that the Golden Pippin is entirely wearing out, and therefore useless to cultivate it; in this I must beg leave to differ: from my great practice among apples, I am satisfied they are to be kept in as flourishing a state as ever they were, for 
the cause of its early decay is entirely from the canker, which is the case with most sorts of weak growth, but the Golden Pippin is one of the insect's greatest farourites: therefore by keeping the body of the trees sound, you may depend on your Golden Pippins flourishing as well as ever.

(30.)-Franklin's Golden Pippin; this is a very good juicy table apple, a good bearer and will keep, it is in high perfection in No. vember.

(31.)-Esopus Spitzenberg Apple; this apple is said to be an American, and was first raised in Albany; it requires the protection of a wall; it is large, handsome, and of an exquisite flavour.

(32.) - Scarlet Pearmain; this is a handsome table apple of a fine scarlet colour, full of fine sweet juice, and a great bearer; ripens early in the autumn, and will keep through the winter.

(33.) - Royal Pearmain; this apple is very handsomely formed, of rather a russet red colour, and a good size for the table, the flavour is very fine, and it is generally a good bearer; 
it ripens in September, but soon becomes mealy after it is gathered.

(34.) - Margaret Apple; this a good summer apple of a red colour, with a little russet towards the eye; it is a good bearer and ripens in August.

(35.)-Kirke's Duchess of Oldenburgh; this is a table apple of a tolerable size; it is rather a flat form; the ground of the fruit when ripe is a greenish yellow, beautifully pencilled with pink and red; it is full of fine sweet juice, and may be fairly called one of our best summer table apples.

(36.) - Kirke's Golden Reinet; this is a very handsome table apple of a golden russet colour, and a fine red next the sun; the flavour is very fine; it ripens about October, and is good till after Christmas.

(37.) - King of the Pippins; this apple ripens late in the summer, and to eat it from the tree it is equal in flavour to any at that season; but a few days after it is gathered it looses its flavour, or at least is very materially diminished.

(38.) - Wellington Apple; this is a very. 
handsome keeping table fruit, and deserves to be brought into general cultivation; the fruit is of a pale green ground, of a beautiful pale red or rather pink next the sun, and is a great addition to the desserts at, and after, Christmas.

(39.)-Kerry Pippin; this is a much admired summer table apple, and is a good bearer.

(40.) -Wheeler's Russet; this apple, as a table fruit, deserves the highest character; it is rather larger than the old nonpareil, much like it in appearance and flavour; it is a great bearer, and will keep till May.

(41.)-Powell's Russet is a most excellent table apple; it is smaller than Wheeler's, very fine flavour, a great bearer, and will keep through the winter.

(42.) -Devonshire Whitesour; this is a very early summer table apple, of a whitish yellow colour ; it has fine melting flesh, with very rich juice; it is a good bearer, and is greatly admired.

(43.) - Margell is a table apple, in flavour much like the Ribston Pippin, but does not 
grow so large; it is a great bearer, and will keep till spring.

(44.)-Christy's Pippin; this is an apple not much known at present; it is one of the best table apples among the new varieties; in form much like the Nonsuch, firm and juicy, of a greenish colour, fine flavoured, is a very great bearer, and will keep through the winter.

APPLES FOR CULINARY PURPOSES.

Par. 45.-Beauty of Kent; this is one of the largest apples in cultivation; it is a most excellent apple for sauce, looks very handsome on the trees, is a great bearer, and will keep.

(46.)-Kirke's Emperor Alexander; this is a fine sauce apple, and is decidedly the most beautiful apple grown. I have known them measure sixteen inches round; and although they grow so large, they seldom fall from the trees if sound; it is a good bearer, ripe late in October, and will keep till Christmas.

(47.) - Keswick Codlin is a large yellow apple, and one of the greatest bearers we have. This is well adapted for small gardens, for it is 
a long time before it gets large through its great bearing; it ripens in September, but will not keep long after they are gathered.

(48.) - Luccumb's Seedling, is a great bearer, of a greenish yellow striped with red, will grow large; it is a very good sauce apple, and will keep through the winter.

(49.)-Northern Greening; this is a most desirable apple to plant, it is a firm green fruit, a very great bearer, and will keep sound till spring.

(50.) -Kirke's Scarlet Admirable; this is a very fine large sauce apple, of a beautiful scarlet next' the sun; is generally a good bearer, and will keep.

(51.)-Royal Russet; this is a well-known good keeping sauce apple.

(52.) - Cockagee; this apple, which is so celebrated for cider, I have merely recommended for kitchen use, on account of its fine acid for being mixed with other apples in the tart or pudding-it answers the purpose of the Quince.

(53.)-Shepherd's Newington; this is a fine large juicy sauce apple, and is a great bearer. 
(54.)-Striped Holland Pippin; this would be very handsome in the shrubbery, for the bloom which comes out early is extremely beautiful; it is a good bearer and a very good apple.

(55.)-Dutch Codlin; although I cannot recommend this as a general bearer, the fruit is so fine, and the bloom so beautiful, it deserves a place amongst a collection.

(56.) - Kentish Codlin; this is a very good bearer, not so large as the Dutch Codlin, but is a very good sauce apple.

(57.)-Norfolk Storing; this apple will keep well through the winter, and is good for sauce when most others are gone by; it is generally a good bearer.

(58.)-Norfolk Beefin; this is a well-known long keeping apple, of a dullish red colour, it is famed for baking, and is good for all culinary purposes. This apple will keep good till $\mathrm{Au}$ gust, and is a general bearer.

(59.)-Lemon Pippin; this is a very good sauce apple, of a yellow colour, is a good bearer, and will keep till March. 
(60.) -Loan's Pearmain, is an excellent sauce apple, is a good bearer, and will keep.

APPLES FOR DESSERT OR CULINARY PURPOSES,

Par. 61.-Hawthorne Dêan; this apple, for the beauty of its bloom, the beauty of its fruit, its fine flavour when in season, together with its wonderful bearing, surpasses every apple now in cultivation: if the trees stand where they can have the benefit of the sun, the fruit will look as handsome as a beautiful peach; it is handsomely formed, of a whitish yellow ground, and a brilliant pink next the sun; they are very full of 'juice, and the flavour universally admired while in season; it is generally in perfection through the month of September, although they are used much earlier, and till the end of October. If this apple would keep, there would not be such an apple in cultivation, for many of them grow large for kitchen purposes, while the small ones produce a beautiful and delicious fruit for the dessert, and it is thought by many it would . make fine cider: but to have this fruit handsome it is absolutely necessary to plant the trees 
where the fruit will receive the sun, otherwise it will be of a pale colour. I know of no plant or shrub in cultivation that would adorn the shrubbery more than this tree; for the bloom is extremely handsome in the spring, and in the summer the fruit would not be passed without being admired.

(62.) - Hertfordshire Pearmain; this is an exceedingly fine apple for winter, it is rather of a red russet colour, the small ones are handsome for the table, having a very fine flavour; the large ones are most excellent for kitchen purposes.

(63.) -Kirke's Lord Nelson; this apple is one of Mr. Kirke's finest productions, it is a great bearer, and very handsome; good for table or sauce, is in perfection in October, and will keep till spring.

(64.) - French Crab, called by some the everlasting pippin; this is a very firm green apple, it is good for culinary purposes through winter, and in spring is a very fine table fruit; it will keep good till the early summer apples come in, and may be considered one of the most useful 
apples in cultivation: it might be grown in the country to very great advantage for the London markets, for they are so firm they will not bruise like other apples, and in the spring they always fetch a great price.

65.-Nonsuch; this well-known apple deserves cultivation, it is a great bearer, and very good for kitchen purposes; and for those who are fond of a sharp juicy apple, they will do for the dessert; it ripens late in summer, but will not retain it flavour long after it is ga thered.

(66.) - Norfolk Paradise; this is a handsome apple for table, and very good for sauce ; it will keep through the winter.

(67.)-Woodstock, or Blenheim Pippin; this apple was produced at Woodstock, the seat of the Duke of Marlborough; it is a most excellent apple for all purposes; it ripens in October, and will keep good some time.

(68.)-Mank's Codlin; this is one of the greatest bearers we have; the fruit is handsomely formed, of a pale yellow colour, and where the sun can get at them they turn of a 
beautiful pale pink; it is full of fine rich juice, and good for all purposes; the bloom is not excelled by any; it is nearly as handsome as a rose; it is further to be recommended to plant as dwarfs in the shrubbery, for its great blooming and bearing prevents its growing so large as many sorts ; it is in perfection about September, but will not keep long.

(66.)--Pile's Russet; this is an old, wellknown excellent keeping apple, and good for all purposes.

(70.)-Braddick's Nonpareil ; this apple, which is rather new and not much known, deserves to be recommended; it partakes much of the old nonpareil in flavour, but is an earlier apple: it is nearly of a russet colour, fine melting flesh, and full of rich juice; some of them grow a tolerable size, which will do for culinary purposes, and the small ones afford a fine dessert; it is in perfection about November, and will keep and retain its juices; it is a great bearer.

OBSERVATIONS.

Par. 7l.-I have now furnished my readers 
with a collection of the best sorts of apples now in cultivation, for the different purposes as described in the character of each apple. Although there are more very good apples, there are a great many not worth recommending; indeed there are some I could mention superior to some of those in the list, but what a disappointment it is when your crops continually fail! Some may say, why leave out such and such a sort, where it may probably be a favourite? but there is such a confusion in the names of apples, that it is likely to be in this list under another name, for there are several among them I know to have three or four different names: but these are properly named as known by the Horticultural Society, and the principal nurserymen round London.

Some may think, if they see a tree full of fruit it must be a good bearer, but I have known some of the most shy bearers (by chance) produce a fine crop; it is therefore necessary to watch its general bearing: such fruits as I have described here I have thoroughly tried, and chosen them from a very large collection; I can 
therefore recommend them with confidence. I should also wish it to be understood, that fruit will not ripen at the same time every year; neither will apples keep so well same seasons as others. I have mentioned the time of ripening as that of our usual summers.

To confuse the reader with an explanatory list of other sorts for the above purposes, would be useless, and render it difficult to choose ; but as there are other very good apples, and every one have their favourites, I will give an alphabetical list of names of those sorts now generally cultivated.

\section{ALPHABETICAL LIST OF APPLES.}

NOW IN GENERAL CULTIVATION.

Those marked with an asterisk (*) are described in the explanatory list.

Par. 72.-

Aromatic Russet

Ashmead's Kernel

*Beauty of Kent

Beauty of Wilts
Berecourt Pippin

*Braddick's Nonpareil

Boatswain's Pippin

Biggs' Nonsuch 
Barcelona Pearmain

Benwell's Pearmain

Bedfordshire Foundling

Claggate Pearmain

*Court of Wyck Pippin

Cray Pippin

Crofton Apple

Cockle Pippin

Costard Apple

*Cockagee

*Cristy's Pippin

Carlisle Codlin

Cornish Aromatic

Custard Apple

Cobsham Apple

*Downton Pippin

*Dutch Codlin

*Duchess of Oldenburg

* Devonshire Whitesour

Duke of Beaufort's Pippin

*Emperor Alexander

Embroidered Pippin

*Esopus Spitzenberg Apple Flower of Kent

*Franklin's Golden Pippin

French Crab

Foxley Pippin

Farleigh Pippin
Fearn's Pippin

Formuse Apple

Fall Pippin

* Golden Pippin

*Golden Rennet

Gibbon's Russet

Golden Russet

Gough Apple

Grange Apple

Gray Leadington

Golden Harrey or Brandy

Apple

General Wolf

* Hawthorne Dean

*Hertfordshire Pearmain

*Hick's Fancy.

Hughes' Golden Pippin

Holland Pippin

Hall Door

Hunt's Royal Red

Jubilee Pippin

*Keswick Codlin

Kirke's Golden Pippin

Kirke's Incomparable

*King of the Pippins

*Kerry Pippin

*Kirke's Lord Nelson

*Kentish Codlin

D 5 
Kentish Fillbasket

*Luccomb's Seedling

*Lemon Pippin

*Loans' Pearmain

Lewis' Gilly Flower

* Manks Codlin or Irish

Pitcher

* Margaret Apple

Marmalade Pippin

*Margil

Minchin Crab

Memmel Pippin

*Norfold Storing

*Norfolk Beefin

*Norfolk Paradise

*Nonpareil

New Town Pippin

*Northern Greening

*Nonsuch

Oslin

Orange Pippin

Ord Apple

Potter's Apple

Pigeon's Heart or Arabian Apple

Pedley's Pippin

*Piles Russet
Peach Apple

Pomgree

*Powell's Russet

*Pomme de Violet

Quince Apple

*Ribston Pippin

* Royal Pearmain

Royal Corpendue

Red Quarentine

*Royal Russet

Ridding's Nonpareil

Red Ingestry Pippin

Red Juneting

*Scarlet Nonpareil

* Sykehouse

Scarlet Crab

Siberian Crab

Siberian Harvey

Sops of Wine

Sellswood Rennet

Scarlet Pearmain

Scarlet Queening

Southampton Pippin

*Scarlet Admirable

*Shepherd's Newington

Stubbard Apple

* Striped Holland Pippin 
Spring Grove Codlin

- Sandy's Russet

Stony Royd Pippin

Transparent Crab

* Woodstock or Blenheim

Pippin

*White Juneting

*Wellington Apple
Wormsley Pippin

*Wheeler's Russet

Winter Pearmain

Wyken Apple

White Lilly

Yorkshire Greening

*Yellow Ingestry Pippin

CIDER APPLES.

Par. 73.-As it is now become a question whether our old cider fruits are not going to decay from old age, it is necessary to say something on the subject.

I' have no doubt but many, where they have not had sufficient practice, will differ with me, but having for many years had thousands, and tens of thousands, continually under my immediate care and notice, it has given me an opportunity of becoming thoroughly acquainted with the constitution of the apple tree; and I am confident it is nothing but bad management and ill treatment which is the cause of the general decay of our apple trees, and principally, from want of proper attention to the canker. This is 
quite evident from all our new sorts becoming affected by it, as well as the Golden Pippin, and our other fine old cider fruits. To conclude, I am convinced so long as English oak is known to flourish in England, so long by proper management, may our Golden Pippins be known to flourish, as well as they did fifty years back; I will therefore give a list of the esteemed old sorts, with a list of others which are now generally approved of for cider.

Old Golden Pippin

Fox Whelp

Herefordshire Redstreak

Orange Pippin

Red Musk

Hagloe Crab
Wood Cock

Forest Stire

Old Queening

Bennet Apple

Friar

Yellow Elliott.

NEW CIDER APPLES.

Court of Wyck Pippin

Foxley Apple

Downton Pippin

Stead's Kernel

Cockagee
Kirke's Lord Nelson

Kirke's Seedling Golden

Pippin

Franklin's Golden Pippin

Kirke's Golden Rennet

If I were going to plant apples, purposely for 
cider, I should confine myself to a few sorts for if we have those sorts which are good, and good bearers, what can we wish more? I should therefore recommend the following :-

Court of Wyck Pippin . Kirke's Lord Nelson

Foxley Apple

Downton Pippin

Cockagee

Kirke's Seedling Golden

Pippin

Franklin's Golden Pippin

The most favourite cider apple now in cultivation, is the cockagee; I am informed by some of our principal cider merchants it is decidedly the best for bottling, and will bring the greatest price; therefore, as this apple is a good bearer, and a free grower, it would be the most profitable of any to plant for cider.

Kirke's Lord Nelson, is not much known at present as a cider fruit, but this apple, which is a good bearer, produces a large quantity of fine astringent saccharine juice, and makes a most excellent cider to drink from the cask.

List of apples from one to twelve sorts recommended for small gardens. 
Par. 74.-

1 Hawthorne Dean

7 Manks Codlin

2 Ribston Pippin

8 Scarlet Nonpareil

3 Kirke's Lord Nelson

9 Scarlet Pearmain

4 Cristy's Pippin

10 Hick's Fancy

5 Beauty of Kent

6 Sykehouse

11 Woodstock Pippin

12 Court of Wyck Pippin

The above are all described in the explanatory list, where the different seasons of ripening, with the character of the apples, may be found.

THE MODE OF PRODUCING NEW KINDS OF

APPLES.

Par. 75. - It is a well known fact, not only among botanists, but all those who hare paid attention to the culture of the vegetable tribe, that by improper management their sorts will degenerate; and this is caused, by such sorts being planted too near together, by which means they unite with each other.

If you plant cabbages and potatoes, or cucum. bers and turnips near each other, or anything of a different nature, they will not injure; but if 
you plant cabbage and cauliflower, or savoy, or anything of a similar nature, it will cause the most perfect sort to degenerate, if they are allowed to bloom together. The same is the case with apples; for, if various sorts are in the same garden blooming near each other, although you might save your seed from what appeared a very fine apple, you would not judge which was the male parent: in order to elucidate this particular, I will endeavour to state as plainly as possible, the nature of the apple from its first formation, till it becomes perfect, and produces the ripe pip or seed.

In the first place, when the bloom is quite open, the principal attraction is the leaves of the bloom, five in number; that which is called the corolla; below the flower, where the small green apple is formed, which continues to grow larger till it comes to perfection, this is called the flower cup or calyx; in the centre of the cup you see small yellow things, which are called stiles, and below the stiles are to be seen several other very small things with round heads like pins, which are called stamens, and these produce a fine dust 
called the Farina or Pollen, which is collected by the bees and other insects, and which the former so industriously collect and lay up for their young, \&c.

Various have been the opinions on this subject, but it is now become conclusive, that the bloom becomes impregnated with other varieties, through the bees and other insects; indeed, most insects after they become winged, are fond of the sweets they can collect from flowers; and although we have not so just an idea of many insects as we have of bees, yet I have no doubt many of them take part in crossing the fruits and regetables: but the bees may be seen flying to a great number of different flowers and trees, before they have a sufficient load to take home to their hive, and by thus flying from bloom to bloom, and tree to tree, they occasionally drop part of the Pollen into another flower, which causes it to be impregnated with the nature of the fruit or vegetable from which it was collected; it therefore shows the necessity, if we wish to produce a new variety of any peculiar quality, to plant the trees where they will not be within a 
considerable distance of any other ; for instance, suppose you wish to raise a new keeping apple, it will be necessary to choose two good keeping apples, and if one were very sour, and the other sweet, it will have a great chance of combining these two qualities, which are quite necessary to constitute a good apple: or if you have a favourite early apple, and would wish to get one nearly like it that it would keep, then plant by it a good keeping apple, and you will have a chance of getting one nearly like it, and probably much better.

If your seedlings are at all strong, the best method, and most quick to prove them, is, the following spring after they have come up, to graft them on young fruit-bearing trees; it will bring them into bearing early, and by so doing, you likewise have an opportunity of noticing which are likely to become good bearers.

OBSERVATIONS ON THE DIFFERENT MODES OF GRAFTING.

Par. 76.- Various are the opinions respecting the influence the stock will have on the scion, 
or graft : many persons (for want of sufficient practice) to this day, suppose the stock will affect the scion, and consequently the fruit produced from the tree grafted on a stock whose fruit is different; but during my practice I never bave known in any instance, the fruit to become altered through the stock it was grafted on: in order to illustrate this fact as clearly as possible, I will give my general opinion on the subject.

It is necessary sometimes to convey our ideas (particularly in writing, where it is subject to every criticism) as plainly as possible; I shall therefore commence from the seed of the stock.

In the first place, when the seed first spears, (say the Crab,) its spear grows downwards, (the same by a common bean or pea,) perhaps two inches before we see the green seed leaf above ground, this shews that the fund of regetable matter above ground, must be filtered through the root, for without the root the tree cannot grow, but the root might exist for some time, although the head was cut down; I am there- 
fore most dccidedly of opinion, that the stock in some degree partakes of the nature of the scion which is grafted on it; for if we look at the nature and constitution of a tree, and from practice mark its general progress, there cannot be an existing doubt, that the roots, veins, fibres, or whatever they may be called, which strike from the scion into the stock, must take root and run downwards, and that to the very extremity where the sap flows; this I am further convinced of by putting the graft on the centre of the stock instead of the side, for you always find them make a considerably better growth, and the trees are more durable; therefore, if the graft sends its roots down to the very extremities of the roots of the stock, it either becomes impregnated, it must be the stock and not the scion.

The same by budding; if nature had so ordered it, that the stock should have had any influence on grafting, much more must it have had on budding, where there is nothing left but the mere rind; yet this small bud has been in no instance ever known to degenerate on account of the stock, if budded on a stock it was fond of. 
What I mean by a bud being fond of a stock, is such stocks as buds and grafts are usually worked on: this is one very necessary branch of a nurseryman's profession, when he has a new fruit, to endeavour to find out such stock as is best suited to its constitution, \&c.

I remember many years back, when quite a boy, a common white jasmine which was growing against the house, and being fond even from my earliest years of trying experiments among trees, I took a bud from a striped jasmine, and budded a branch of the green; the bud grew, and what shoots put forth below the bud, most of them became blotch leaved; this is a proof the bud or graft must have an effect on the stock.

There are other modes of grafting, but which are little noticed for fruit trees, except when the trees are very large, and as it will not be foreign to the present work I will mention them.

First, rind grafting; this is principally practised on large trees. After cutting off the branch of the tree (if with a saw it should be made smooth with a knife) cut a slit in the rind, about two inches from the top where it was cut 
off, open the bark without bruising it, (the handle of a budding knife is the best instrument,) then cut a slice of your scion the length of the incision on the branch, nearly the same as described in.whip-grafting; run the scion down between the rind and the wood, placing the wood of the scion against the wood of the stock, then bind it tight round with strong matting, and put clay round it the same as directed in whip-grafting; when this method of grafting was more in practice, many would make a shoulder in the scion, to rest it on the shoulder of the stock; but this I think unnecessary, as the two woods would not gender without the bark, and there would be no bark on the crown of the branch or stock: three or four scions may be put on one large crown; but this method of grafting is by no means to be recommended, for the winds are so apt to blow them out, and if the bodies of the trees were sound and worth grafting, and the branches were too strong for whip-grafting, it would be far better to cut them down nearly to the stem of the tree, and the following year they would throw out fine young wood for whip-grafting, and 
rather than lose, you would save time by this practice; I have whip-grafted with success, branches six and eight inches in circumference.

Grafting by approach, commonly called enarching; this method is principally practised among exotics, consequently the fruit grower will not feel interested in its detail, particularly the apple grower, it being by no means necessary; this practice is principally adopted where the scion and stocks will not unite freely by whipgrafting. 


\section{CHAPTER II.}

On Pear's, Plums, Cherries, Peaches, Nectarines, Apricots, Grape Vines, \&.c. \&.c.

ON PEARS.

Par 77.-What has already been said on the culture of apples, will generally apply to pears; the budding, grafting, pruning, and general management being the same, excepting that they are worked on different stocks. The stock which is generally used, (and which is decidedly the best for standard pear trees, ) is raised from the seed of the small wild pear, which like the true $\mathrm{crab}$ is more durable than those grown from other pears, It has many years been the practice in France, and several parts of the Con- 
tinent, to graft pears on quince stocks, and in this country they have been found to answer extremely well as dwarfs, for they come into bearing much earlier than those on the pear stock, and the fruit exceedingly fine, and by keeping them spurred like dwarf apple trees, they may be kept within any compass you wish, as they do not grow near so strong as those on the pear stock.

Many sorts of pears, which are generally grown against walls, have got the name of bad bearers through bad pruning, it being a general method to spur them all indiscriminately; at the same time, some sorts scarcely ever bloom, except at the extremities of the young shoots, therefore, if they are removed it is impossible to have fruit.

This may be easily remedied, when you have discovered which sorts bear at the ends of the shoot, by leaving a sufficient quantity of young wood for that purpose.

The confusion in the names of pears is quite equal to the apples; I shall therefore confine myself in the explanatory list of pears which 
follows, to such sorts as are known to be good; and such as are sufficient for all purposes.

\section{EXPLANATORY LIST OF PEARS.}

Par. 78.-1. Green Chisel; this is a small green pear, very full of juice, and is remarkably sweet; it will ripen in early seasons in July.

2. Present de Malines; this pear is suited either for the wall or standard; in form much like Williams's Bonchretien; smooth skin, and when ripe of a yellow colour; the flesh is melting, and of a rich musky flavour, it is generally a good bearer, and ripens late in the autumn.

3. Jargonelle; this a fine early pear, ripe about August; it is of a green colour with a little russet next the sun,-it gererally bears well.

4. Windsor Pear; this is very fine fruit if eaten in proper season; it is of a green colour, but when quite ripe turns yellow; it should be eaten just as it begins to change colour, or it will soon become mealy and good for nothing; it ripens about the end of August.

5. Hambden Burgamot; this is rather a large 
pear, fine melting flesh and full of juice: it is ripe about the end of September.

6. Autumn Burgamot; this pear, which is of rather a small size, and handsomely formed, is one of the finest flavoured melting pears in cultivation; it is perfection in October.

7. Crasanne; this is a very fine pear for the wall; the flesh is very tender, and full of fine sweet juice; I know not so good a pear in December and the beginning of January.

8. Colmar, is a fine rich sweet pear; it is best adapted for the wall, being a bad bearer as a standard; it is in perfection about January.

9. Virgoleuse; this is a fine melting pear, full of rich juice; it would be more generally cultivated, but in wet seasons they are very apt to crack; it ripens about the end of December.

10. St. Germain; this is a very fine melting pear, full of juice and a general bearer; an east wall will bring the fruit to the greatest perfection; at the same time, they will do well as standards in sheltered situations; they are ready for the dessert in December, and I have eaten them in March. 
11. Spanish Bonchretien; this is a good winter pear, and rather generally admired; it grows large against a wall, and will keep till January.

12. Brown Beurre; this is one of the best late autumn pears we have; they do best against a wall, where they will grow large, of a brown colour, and rather tinged with red; it is a fine juicy melter; and is in perfection through $\mathrm{No}_{0}$ vember.

13. Winter Bonchretien; this is highly esteemed for its long keeping; it is very large, full of rich juice, and will keep till June.

14. Chaumontelle; this is a fine rich juicy pear'; is a great bearer either as a dwarf or standard, and will come into eating in December.

15. Poire D'Auch; this is a handsome green pear of excellent flavour ; is a good bearer, and I may add, there are but few winter pears which equal it; it is fine from December to the end of March:-it is best suited for the wall.

16. Citron $D^{\prime}$ Carlmes; this is rather a small pear of a greenish colour, it is a great bearer, and is ripe in July. 
17. Williams's Bonchretien; this is a very juicy fine pear; is a good bearer, and ripens about September.

18. Swan's Egg; this pear is too generally known to require much comment; it is of an egg shape, and of a brownish green colour; it is a melting pear, full of very fine flavoured juice, and one of the greatest bearers in cultivation; it is ripe in November, and is good at Christmas.

19. Paddington or Tarling; this pear is much esteemed for its long keeping; it is a handsome fruit of a yellowish colour when ripe; it is good from March till the end of May-best suited for the wall.

20. Golden Buerre; this is a fine fruit, full of very fine juice, with melting flesh; it is in perfection about November, and is a general bearer against a wall.

2I. Bishop's Thumb; this pear will do well for wall or standards; it is a long brown fruit, large towards the eye, and tapering towards the stalk; it is a great bearer, and is good in Decem. ber. 
22. Gansell's Burgamot; this pear for its rich melting flesh, and abundance of fine flavoured juice, is decidedly the finest pear of its season; it is rather a shy bearer, but will do best against a wall; I have often seen fine crops on standards; it is in high perfection in Novem. ber.

23. Cardiliac; this is a large pear generally used for baking, and if they can be gathered sound late in the Autumn, they will be good for that purpose through the winter; it is a good bearer, but being generally cultivated as standards, and the fruit growing so large, the high winds are very apt to shake them off.

24. Seckle; this pear among the new varieties is very much esteemed; it is of a middling size, full of very fine sweet juice, and will bear well as standards, - is in eating about October.

25. Maria Louisa; this is a very fine pear; the flesh is melting and full of fine juice; the wood is weeping and best adapted for the wall : at the present day it is esteemed as highly as any of the new varieties, and will no doubt be generally cultivated. 


\section{ALPHABETICAL LIST OF PEARS.}

Those marked with an Asterisk (*) are described? in the explanatory List.

\section{Par. 79.-}

Ashton Town

*Autumn Burgamot

Awken.

Beurre De Roi

Burre de Aremberg

"Bishop's Thumb

Bloody

Britannia

Brocas Burgamot

* Brown Beurre

Burdelieu

*Cardiliac

Catherine

* Chaumontelle

* Colmar

Colmar D. Pache

*Crasanne

*Citron de Carlmes

Dauphine

*D'Auch or Poire D'Auch

Delicis Lardenpont

Dutch Burgamot
* Gansell's Burgamot

Germain Muscal

${ }^{*}$ Golden Beurre

Gray Beurre

*Green Chisel

*Hambden Burgamot

Holland Burgamot

* Jargonelle

Lammas

La Pastorelle

Little Muscat

* Maria Louisa

Moorfowl Egg

Napoleon

Orange Burgamot

- Paddington or Tarling

* Passe Colmar

* Poire d'Ananas

*Present de Malines

Quos Madam

Red Muscatelle

* Seckle 
PLUMS.

-Spanish Bonchretien

* St. Germain

Summer Burgamot

* Swan's Egg

*Urbaniste

*Uvedel's St. Germain

*Vanmons

Vergoleuse

Vine Pear

Williams' Bonchretien

* Windsor

* Winter Bonchretien

Winter Russelet

PLUMS.

Par. 80.-We have not to complain so much of the coining of names for plums, as for apples and pears: nevertheless, a confused nomenclature has found its way among them; however, I trust that those I shall mention in the explanatory list will be so clearly described, that every person will be satisfied of his competency to decide on each particular sort when he sees the fruit; and more especially as plums cannot be so easily mistaken, because the soils or situation will not have the same effect in changing their character, as they have on some other fruits.

EXPLANATORY LIST OF PLUMS.

Par. 81.-Orleans; this plum is a fine large 
rich fruit, it is a great bearer, and good for all purposes.

2. Poupart's plum; this plum was raised from seed, by Mr. James Poupart, near Fulham; it is a very great bearer, of a red colour, and rather a long form, it is a tolerable good plum, but best suited for culinary purposes.

3. Blue Perdigron; this plum is of a very dark blue colour, is good flavoured, and ripens in August.

4. White Bonum Magnum, or Egg Plum; this is a very great bearer, the fruit is large, in the form of an egg, and very handsome; it is not a bad eating plum, though it is principally used for baking; it ripens in September.

5. Red Bonum Magnum, or Red Imperial; this is a large red plum in the form of an egg, it is a good bearer, but like the white, it is principally used for culinary purposes; it ripens early in October.

6. La Royale; is a very fine flavoured plum of a red colour; this being rather tender in the bloom, it succeeds best against a west wall; it ripens late in September. 
7. Downton Imperatrice; this plum was raised by Mr. Knight of Downton, and said to be a seedling from the white Magnum Bonum, claiming the blue Imperatrice, for its male parent; it is considered a good plum and a tolerable bearer.

8. Drap d'Or ; this plum is very much admired, and is a general bearer, particularly against a wall; it ripens late in September.

9. Green Gage; this plum is too well known to require much being said of it ; it is decidedly the finest plum in cultivation; it ripens late in August. There are several new varieties of this plum, but all are very inferior to the original, or which is generally called, the royal Green Gage.

10. Blue Imperatrice; this is one of the best late plums we have; it is best adapted for the wall, and when perfectly ripe, there is no plum of its season equal to it for sweetness; it ripens in October, and I have eaten fine ones from the trees in the middle of November.

11. La Diliciuse; this a large red American plum, said to have received its name from Charles

$$
\text { E } 5
$$


the Tenth. Some English nurserymen have named it after their own bent, I believe without any legitimate claim to its origin; it is very peculiar in its habit, both of its wood and its foliage, the fruit is of a large size, oval purplish colour, rich and juicy, and makes an excellent preserve, ripens about the end of September or beginning of October.

12. Saint Catharine; this is a good plum and is a good bearer; it is ripe in September, and will hang a long time on the tree.

13. Winesour; this plum is much esteemed for preserving; it is a late plum, and is a good bearer.

14. La Mirabelle; this is a handsome small yellow plum, very full of juice; it is ripe about the middle of September, and is a good bearer.

15. Coe's Golden Drop; this plum is of a fine amber colour, much in the form of the white egg plum, and of about half the size; they bear well as standards or against the wall, and when ripe, the flavour is very fine, and certainly the most beautiful plum for the dessert, of its season; it ripens towards the end of September. 
PLUMS.

16. Kirke's fine Red Plum; this plum, which comes in just after the Orleans, is large, fine flavoured, and is a good bearer; it deserves to be brought into general cultivation.

17. Street's Plum, or St. Lowe; this plum, which is a great bearer, exceeds all I ever saw for size; it is much in the form of the Orleans, but considerably larger and very handsome; it is of a red colour, and generally carries a good bloom on the fruit; they bear well as standards, or against the wall; it ripens about September.

18. Blue Gage : this is a most excellent plum for the wall, the flavour is very fine, and it is generally a good bearer.

19. Early Orleans ; this is rather earlier than the old Orleans plum; it is a good bearer, and the fruit is very much admired.

20. Yellow Orleans; this is a beautiful transparent plum, nearly as large as the old Orleans, good flavoured, and very handsome for the dessert; it will bear well as a standard; it ripens about September. 


\section{ALPHABETICAL LIST OF PLUMS.}

Those marked with an Asterisk (*) are described in the explanatory. List.

Par. 82.-

Admirable

Apricot Plum

Avone

* Blue Perdigron

Brignole

*Blue Gage

*Blue Imperatrice

Elue Matchless

*Catharine

*Coe's Golden Drop

*Downton Imperatrice

*Drap d'Or

Early Amber

Fotheringham

Goliah

* Green Gage

Gross Mirabelle

Jaune Hative

* Kirke's Large Red

*La Mirabelle

*La Royale

* La Diliciuse

*Magnum Bonum White *Magnum Bonum Red
Mirabelle

Morocco

* Orleans Red

*___ Early New Early Yellow

*Poupart's Seedling

Precos de Tours

Pruin

Queen Mother

Reian Claude Violet

Red Diaper

Royal Dauphin

*Street's Large Red

Sharp's Emperor

Stoneless

Violet

White Bullace

White Damson

White Imperatrice

White Pear

White Perdigron

*Wine Sour

Yellow Gage 
CHERRIES.

Par. 83.-The culture of cherries in this country being rather large, and profitable to grow, it is necessary to make a few observations on the constitution of this tree.

There is no fruit tree I know of more subject to gum than the cherry, which is frequently caused by the land, particularly if the bottom is strong clay; the most essential point to be observed in planting orchards of this fruit, is to select those trees which have been budded standard high, for those budded within a few inches of the ground, and trained up for standards, are very liable to sink below the bud, which is which almost sure to cause the tree to decay early.

Likewise, this should always be observed in planting of dwarf trained cherries, to keep the bud or graft a few inches above the surface of the earth; for if cherries once begin to gum, they seldom recover. I have given a description of some of the best sorts, which will be found in the explanatory list. 
There is no stock so durable for budding and grafting cherries on as the small wild black cherry, the seed of which should always be selected for that purpose.

\section{EXPLANATORY IIST OF CHERRIES.}

Par. 84.-1. May-duke; this cherry which ripens early in June against a south wall, is one of the best cherries in cultivation : they are great bearers as standards, and the flarour is very fine.

2. Ronald's Black heart, or Circassian; this is a fine large black cherry and good bearer; it would deserve general cultivation, but the wood in some soils is very apt to decay; it ripens early in July.

3. Black-heart; this is a well known good fruit, handsome, and a good bearer.

4. Arch-duke; this is an exceeding fine cherry, larger than the May-duke, and a good bearer; it is not properly in perfection till July. This is a valuable cherry to grow for the market.

5. Morella ; this cherry is one of the greatest 
bearers, either as standards, or against a wall, we have in cultivation; it is large and handsome, and in the month of October is nearly black,at this season it is a great addition to the dessert; it is also fine for tarts and preserving, and by far the best for putting in brandy.

6. Bleeding Heart ; this is a very fine fruit, is ripe about the middle of July, but it is not a general bearer.

7. Harrison's Heart; this by many persons is considered a very fine cherry ; it comes in late for the dessert, being ripe in August.

'8. Black Coroon; this is a very fine cherry, and generally is a good bearer; it ripens in July and August.

9. Biggereau: this is a very fine cherry, and is a great ornament to the dessert in July; they will do well as standards, but the fruit will come finer against a west wall.

10. Kentish; the wood of this cherry very much resembles the wood of the Morella, and is one of the best to plant for orchards, the constitution of the tree being strong, and the demand for the fruit great, being consumed in 
large quantities for kitchen purposes: it likewise very much resembles the Flemish, for which it is a very good substitute, being a better cherry and a better bearer.

11. Florence; this is a most beautiful cherry for the dessert, and will bear well as standards, but the fruit will grow larger against the wall,the flavour is excellent.

12. Waterloo; this cherry is one of the fine productions of $\mathrm{Mr}$. Knight; it is a very fine sweet flavoured fruit, and tolerably productive.

\section{ALPHABETICAL LIST OF CHERRIES.}

Those marked with an Asterisk (*) are described Par. 85.in the explanatory List.

Adam's Crown

Amber Heart

*Arch-Duke

*Biggereau

*Black Coroon

Black Eagle

*Black Heart

Black Tartarian

*Bleeding Heart
Carnation

Churchill's Heart

Double Blossoin

- Early May

Elton

Flemish

*Florence

Graffion

Harrison's Heart 
Holman's late Duke

*Kentish

Kensington Duke

Knight's new Black

Lady Southampton's Duke

*May-duke

Montmorencie

*Morella
Ox Heart

*Ronald's Black Heart or

Circassian

Waterloo

Weeping

Wentworth Heart

White Heart

White Tartarian

\section{APRICOTS.}

Par. 86.-Various have been the opinions respecting the stocks generally used for budding apricots, as they will grow on the muscle, the Brussels, and the common plum stock; but it is a general opinion (and not without foundation) that those budded on the Brussels stock are more liable to decay.

Having tried the whole of the above stocks for years past, I find none so well suited for Apricots as the common plum stock, usually called commoners, except the Royal Orange, which does best on the muscle; there may be many who will not agree with my recommending the common plum before the muscle, for the Moor Park, but I give it the decided preference. 
Par. 87.-1. Moor Park; this apricot is considered decidedly the best in cultivation; it is a very great bearer, the fruit is very fine, and deserves to be recommended before any other; -it ripens about the middle of August.

I have seen the Moor Park bear well as standards in the open ground.

2. Peach Apricot; this is a fine large apricot, very much like the Moor Park, and ripens about the same time.

3. Turkey; this is a tolerably good apricot, of rather a deep colour, but not very full of juice, -it ripens late in August.

4. Red Masculine; this should always be planted amongst a collection, for it comes in earlier than most other sorts; it is a small fruit, red towards the sun when ripe, and is esteemed for being ready before other sorts,-it ripens in July.

5. Algiers; this is a yellow apricot, of rather 
a flat shape, and good flavour; it ripens in $\mathrm{Au}$ gust.

6. Small Orange Apricot; this is a great bearer, and is grown principally for preserving, and tarts.

7. Royal Orange; this is a fine apricot of a yellow colour, -it is ripe in August.

8. Roman; this is a large yellow apricot of a good flavour, - it is ripe about the middle of August.

9. Breda; this is an excellent apricot, large, of a yellow colour, full of fine flavoured juice, and is a good bearer,-ripe about the end of August: it may be planted as an open standard.

17. Brussels; this is rather a small apricot, but is a very great bearer, and is generally preferred for planting as standards, in the open ground; it is of a red colour towards the sun, and looks very handsome on the trees; it has a tart flavour which is generally admired when grown on the open standards, -it is ripe in September. 


\section{ALPHABETICAL LIST OF APRICOTS.}

Those marked with an Asterisk (*) are described in the explanatory List.

Par. 88.-

Alberge

*Algiers

Black

*Breda

*Brussels

Dutch

Gold Blotched Leaved

Grover's Breda

*Moor Park

*Orange

*Peach
Persian

Portugal

Provence

*Red Masculine

*Roman

*Royal Orange

Temple

Transparent

*Turkey

White Masculine

PEACHES AND NECTARINES.

Par. 89.-Peaches and Nectarines being so much alike in nature and cultivation, what is said of one will equally apply to the other; it appears, from the best authorities, that the almond was the original parent of the above fruits, and they grow freely budded on the almond stock, but they are far more durable 
when budded on the plum. To enter here into a detail of the different peaches and nectarines which grow best on the different sorts of plums, would be wholly unnecessary, as I do not consider myself as writing complete and full instructions to render every one of my readers competent to fill the arduous labours of a nurseryman, and to particularise each would rather tend to confuse than inform; suffice it to say, that neither peach or nectarine will succeed on the Brussels Stock, and the stocks generally used for peaches and nectarines, which they like most, are the Muscle and Pear plums.

It often occurs, that peaches and nectarines swell too large for the stock they are budded on; this plainly denotes the stock is not suited to the constitution of that rariety; and this the nurserymen in the neighbourhood of London have made their study, and have brought it to that perfection, which has given them a decided superiority over most of their country contemporaries, who, generally speaking, hare not sufficient practice in this department; indeed it is no small matter of consideration, for it is not 
only the sum paid for the trees, but the morti. fication (which can only be known to those who have experienced it) after having planted the trees a few years, of seeing them diseased and and gradually dwindling away. Peaches will grow by grafting, but they never do well, being sure to gum, and get diseased where the scion is put on the stock. "In the explanatory list will be found a description of the best sorts, with their seasons for ripening, \&c.

\section{EXPLANATORY LIST OF PEACHES.}

Par. 90.-Noblesse; this peach is large and handsome, of a whitish green colour, and inclined to red where they are exposed to the sun; it is a fine melter, and very full of rich juice; it is a good bearer, and ripens early in September.

2. Montauban; this is a fine melting peach, and full of juice, of a deep red towards the sun; it is a good bearer, and ripens early in September.

3. Vanguard; this peach is in every respect so much like the Noblesse that many persons think it the same, but it is not; the tree is rather of stronger growth, and the fruit something 
larger; there is but little difference in their time for getting ripe.

4. Red Nutmeg; this is a small peach of a deep red colour, and a good bearer ; it ripens early in August, for which it is much esteemed.

5. Early Ann; this peach is admired for being early; it is a good peach, and ripens about the middle of August.

6. Royal George; this is a fine old peach, of a high colour next to the sun; it is full of fine sweet juice, a good bearer, and ripens early.

7. French Mignonne; this is a large beautiful peach of a red colour, a fine melter, and full of sweèt juice; it is a good bearer, and ripens late in August.

8. Royal Kensington; this is a very fine peach, and considered by many persons to be the same as the French Mignonne; some trees being sent from France as a present to her Majesty, Queen Charlotte, it was called the Royal Kensington.

9. Bourdine; this is a fine melting peach, of a red colour next to the sun; it is a great bearer, and ripens about the end of September.

10. Red Magdalen; this is a large beautiful 
peach, of a deep red colour, full of fine rich juice, and ripens early in September. I have seen this peach bear plentifully on standards in the open ground.

11. Chancellor; this is a fine old peach, with melting flesh, full of rich juice, and very handsome; it ripens early in September.

12. Rosanna; this is one of the greatest bearers in cultivation; it is of a deep purple next the sun, and is considered a good peach ; it will bear well as a standard in the open ground;

-it ripens in September.

13. Early Gallande; this peach is highly esteemed, and is certainly one of the best peaches we have; it is a great bearer, very handsome, and ripens early in September.

14. La Teton de Venus; this is a fine rich peach, rather a long form, of a pale red, and ripens late in September.

15. Early Admirable; this is a large fine peach, of a beautiful red colour next the sun; it is full of fine sweet juice, and ripens early in September.

16. Monstrous Pavie of Pompone; this is 
called by our market gardeners a Cling-stone peach, but the French call all Pavies which do not come clean from the stone; it is cultivated more for its size and beauty, than its excellence: it ripens about the middle of October.

17. Grimwood's Royal George; this is a very fine melting peach, a great bearer, and ripens late in August.

18. Catharine; this is a late good peach, but will adhere to the stone; it is of a fine red colour towards the sun, is rich, and full of juice ; it ripens late in October.

19. Late Admirable; this is a very fine melting peach, handsome, full of juice; and ripens late in September.

20. Old Newington; this peach is handsome, and of a deep red towards the sun; it is tolera. bly full of juice, but it will adhere to the stone; -it ripens about the end of September.

21. Double Swalsh; this is a very fine melting peach,-is ripe early in September.

22. Smoth-leaved Royal George; this is a most excellent peach, full of fine rich juice, 
handsome, and one of the greatest bearers we have, - it is ripe early in September.

23. Violet Hative; this is a fine high coloured peach, melting flesh, with an abundance of rich juice; it is a good bearer, and ripens late in August.

24. Millet's Mignion; this is a very fine large melting peach, and excellent for forcing, it not being so subject to mildew as some sorts; it is a good bearer,-is ripe early in September.

\section{ALPHABETICAL LIST OF PEACHES.}

Those marked with an Asterisk. (*) are describ ed in the explanatory List.

Par. 91.-

Acton Scot

Belgarde

Bell Chevreux

*Bourdine

Double Montagne

Braddick's

Downton

* Early Admirable

*__ Ann

Buckinghamshire Mignion

Catharine

*Chancellor

Double Blossom

$*$

- Avant

_- Purple Avant

*___ Gallande

__ Purple

_- Newington

*French Mignion 
*Grimwood's Royal George *Nutmeg Red

Gross Mignion

Incomparable

Java

* Late Admirable

Late Gallande

* La Teton D'Venus

Lowe's Large Melter

*Millet's Mignion

*Monstrous Pavia of Pompone

* Montauban

*Newington

Nivette

*Noblesse

*Red Magdalen
*Rosanna
*Royal Kensington
*Royal George
*Smooth-Leaved Royal
$\quad$ George
Spring Grove, or Persian
$\quad$ Peach
*Vanguard
*Violet Hative
White Magdalen
Yellow Alberge

EXPLANATORY LIST OF NECTARINES.

Par. 92.-1. Elruge; this is one of the finest nectarines we have; it is of a good size, and a great bearer; the colour is a dark red towards the sun, and a yellowish green next the wall; the flesh is fine and melting, and full of sweet juice; it ripens late in August : it is also a fine nectarine for forcing.

2. Newington; this is a very good Nectarine, and a great bearer, of a fine red colour, -it ad- 
heres to the stone, but is full of fine sweet juice: it ripens early in September.

3. Red Roman; this is an old well-known good nectarine, of a deep red or purple next the sun, and rather yellow on the wall side,-it is a good bearer, and ripens early in September.

4. Brugnion; this is a good'nectarine, of a deep red towards the sun, and a pale yellow next to the wall ; it is fine eating when full ripe from the tree, but soon loses its flavour after it is gathered; it ripens late in August.

5. Murrey: this is a very fine nectarine, of a purple colour towards the sun, large, a good bearer, full of fine sweet juice, and may be considered one of the best; it ripens early in September.

6. Golden or Temple Nectarine; this is handsome, of a light red towards the sun, and yellow on the wall side; it has plenty of juice, and is generally admired; it ripens late in September.

7. Violet Hative; this is a most excellent nectarine, of a deep red towards the sun; it is 
a fine rich melting fruit, full of sweet juice, and a good bearer; it ripens late in August.

8. Fairchild's Early; this is a small early nectarine, of a fine red colour, the flesh is melting and full of fine juice; is ripe about the middle of August.

9. Vermash; this is a fine late nectarine, of a green colour, a "little inclined to red towards the sun ; it ripens late in September.

10. Italian; this is a fine large nectarine, of a deep red next the sun, full of rich juice, and is greatly admired; it ripens early in September.

\section{ALPHABETICAL LIST OF NEC. TARINES.}

Those marked with an Asterisk (*) are described in the explanatory List

Par. 93.-

Aromatic

Brugnion

*Elruge
*Fairchild's Early Genoese

*Italian 
*Murrey

Newfoundland

* Newington

New White

old White

Peterborough
*Roman

St. Omers

Temple

*Violet Hative

* Vermash

GRAPE VINES.

Par. 94.-The principal part of this delicious fruit is grown in hot-houses and vineries, as our climate will not admit of their coming to perfection in the open air, excepting a few sorts. Those will be found in the explanatory list which will suit the different situations best.

I know of no grape for the open wall to equal the Royal Muscadine; it seldom fails to ripen, is a great bearer, and a most excellent grape for the dessert; it also makes very fine wine.

EXPLANATORY IIST OF GRAPE VINES.

Those marked with $W$. are for the $W$ all-those $V$. are for the Vinery-and those $H$. are the Hot.house.

Par. 95.-1. Royal Muscadine, by some 
called the Malmsey; this is an excellent grape for the wall or vinery, the berries when ripe are of an amber colour, large, round, and very fine flavoured; it is one of the best white grapes we have for the open wall, for it is a great bearer and seldom fails to ripen. $W . V . H$.

.2 Black Muscadine: this is a great bearer, and will often ripen against the open wall : the berries are handsome, having a very fine purple bloom. $V$.

3. Black Damascus; this is a very fine large black grape, full of rich juice, and highly esteemed. $H$.

4. White Muscat of Alexandria; this grape is in high estimation for the hot-house, the berries are of a fine oval shape, the bunches long and large, and the flavour much admired. $H$.

5. White Muscat; this is a good bearer, with large berries of rather an amber colour. $V$. $H$.

6. White Chasselas, called by some the White Muscadine; this is a very good grape for the wall, the berries rather resemble the Royal Muscadine, but are not so large. $W$. 
7. Elford's Seedling; this grape is remarkable for its bearing, the seed being sown in January 1821 , and fruit produced from the seedling was exhibited at a meeting of the Horticultural Society, on the 1st of October 1822 ; it is a tolerably good grape. $W . V$.

8. The Black Tripoli; this is a very fine black grape, with large berries, full of fine rich juice. $H$.

9. Black Muscadel has rather a peculiar flavour, but is generally considered pleasant, the berries are black, of an oval shape, and large. $H$.

10. Red Muscadel; the bunches of this grape grow very large, and likewise the berries, which are red. $H$.

11. Black Alicant or Spanish; this is a tolerably large sized black grape, and the flavour were generally admired. $V . H$.

12. Black Frontinac; the berries of this grape are not very large, full of fine rich juice, and are greatly admired. $\quad V . H$.

13. White Frontinac; the berries of this grape are small and round, the bunches grow 
long and tolerably large; the juice has a very peculiar flavour, but it is highly esteemed. $W$. V. $H$.

14. Grizzly Frontinac; this grape is rather of a brown red colour, very fine, and generally admired. $V . H$.

15. Red Frontinac; the berries of this grape are rather large, of a dingy red colour; it is considered a very fine grape. $V . H$.

16. Black Hamburgh; this grape, for the hothouse or vinery, cannot be excelled; the berries are large, round, and handsome, and the bunches well formed; it is a great bearer, and of excellent flavour. $V . H$.

16. Red Hamburgh; this is a tolerably good grape, the berries are of a dark red colour. V. $H$.

18. White Sweet Water; the flavour of this grape is most excellent, the berries are of a tolerable size, but the bunches do not grow handsomely. W. $V . H$.

19. New White Sweet Water; this is a most excellent grape, a great bearer, and the bunches not so irregular as the former. $W . V . H$. 
10. Black Sweet Water; this grape has a small sweet berry which is very liable to crack, consequently against the open wall is much destroyed by birds and flies; it is an early grape. $W . V$.

21. Black Cluster; this is a small black grape, a great bearer, and covered when ripe with a fine bloom. $W$.

22. White Raisin; the berries of this grape are very large, with a thick skin, the bunches also grow very large and handsome. $H$.

23. Claret; this grape has small black berries, with red juice; it is not an agreeable fruit to eat, but makes excellent wine. $V . H$.

24. Lombardy; this is a large red grape, the bunches grow very large and are full of rich juice. $V . H$.

25. St. Peter's; this grape is very black when ripe, the berries are large, of an oval shape, and the bunches very large; it is a good grape. $V . H$.

26. West's St. Peter's; this is a fine black grape, now in high estimation, the bunches 
come fine, the berries large, and flavour excel. lent. $V . H$.

27. Sir Abraham Pitcher's; this is a large fine black grape, and greatly admired. $V . H$.

28. Black Prince; this is one of the best black grapes for the natural wall, as it seldom fails to ripen, the bunches grow large, particularly in the vinery, and the berries, which are tolerably large, are full of fine sweet juice; it is now much in request. $W . V . H$.

29. White Tokay; this is a fine grape of very delicate appearance, but rather a bad bearer. $V$. 30. Black Portugal; the berries of this grape are of a middling size, and in favourable seasons will ripen against the natural wall; it is a good grape. W. $V . H$. 


\section{ALPHABETICAL LIST OF GRAPE VINES.}

Those marked with an Asterisk (*) are described in the explanatory List.

Par. 96.-

Aleppo

*Black Alicant

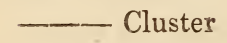

*__ Damascus

Esperion

-_- Frankendall

*

cat Noir

Gibraltar

*___ Hamburgh

__ Lisbon

- Morillon

- Morocco

*__ Muscadel.

-__. Muscadine

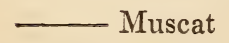

*___ Portugal

*__ Prince

* __ Sir Abm. Pitcher's

* St. Peter's
*Black Sweet Water

*___ Tripoli

*Chasselas

*Claret

*Elford's Seedling

*Grizzly Frontinac

*Golden Galacian

*Lombardy

Malmsey

Miller's Burgundy

Malvoise or Blue Tokay

Muscat of Alexandria

Muscatelle

*New White Sweet Water

*Red Frontinac or Muscat

Rouge

- Constantia

* - Hamburgh

*__ Muscadel

Muscat 
Red Raisin

- Smyrna

- Muscat of Alexandria

- Muscat of Jerusalem

- Syracuse

*Royal Muscadine

Tottenham Park Muscat

*West's St. Peter's

*White Sweet Water

-_- Frontinac

*___ Muscat of Alexandria
White Nice

__ Parsley Leared

__ Raisin Syrian

__ Muscat of Lunel

Cornichon

__- Hamburgh

_- Olcobaca

- Morilion

- Muscat

*__ Teneriffe

*__ Tokay

EXPLANATORY LIST OF FIGS.

Par. 97. Yellow Ischia, is a large fine flavoured fruit, with a yellow skin and deep red flesh; it is ripe about the middle of October.

2. Brown Naples Fig; this fruit is long, of a brown colour, well-flavoured, and is a good bearer; it ripens early in October. In good seasons this fig will ripen well on standards.

3. Green Ischia; this has a thin green skin, with a brown cast; when ripe, the inside is a deep red inclining to purple; it is a good fig, and ripens late in September.

4. Malta; this is a fine flavoured, small brown 
fig ; the wood is rather tender, but if the wood ripens well, it is generally a good bearer; it ripens early in September.

5. Black Ischia; this fig is one of the greatest bearers we have; the fruit when ripe is nearly black, of a small size, but finely flaroured; it is good for forcing, wall or standards, and ripens early.

6. Large White Genoa; this is a large fig, with a thin skin of pale yellow; it is a fine fruit, good bearer, and ripens late in August or beginning of September; it is a good fig for forcing.

7. Black Genoa; this is a long dark fig, quite red inside, is fine flavoured, and ripens early.

- 8. Small White Fig; this is a small, pale yellow fruit, of very good flavour, a great bearer, and will do well as standards; it ripens early.

9. Large Brown Ischia; this fig grows very large,-it is brown outside, and purple within, is fine flavoured, and will often produce two crops in the year: it ripens early. 
10. Black Italian; this is a small fig of a very fine flavour; it is one of the best for growing in pots, being a very great bearer.

\section{ALPHABETICAL LIST OF FIGS.}

Those marked with an Asterisk (*) are described in the explanatory List.

Par. 98.-

*Black Genoa

Madona

* Ischie

* __ Italian

Blue Ischie

Brown Ischie

*___Naples

Common Blue

*Maltese Murrey

*Small Early White

Turkey Large Black

*White Genoa

*Yellow Ischie

*Green Ischie

CHESTNUTS.

Par. 99.-

Golden Striped Silver Striped

Spanish

Virginian 


\section{BARBERRIES.}

Par. 100.-

Black Sweet

Common Red with Stones.

Red without Stones

QUINCES.

Par. 101.-

Apple Quince

Oblong

Portugal

WALNUTS.

Par. 102.-

Black Virginian or French Walnut Hickery Large Walnut

Cob Walnut Small Walnut

Double Walnut

FILBERTS AND HAZLE NUTS.

\section{Par. 103.-}

Barcelona or Spanish Nut Cosford Nut

Cluster Wood Nut Dwarf Prolific Nut

Cob Nut Red Filbert

Common Wood Nut White Filbert 
RASPBERRIES, STRAWBERRIES, \&C. 113

RASPBERRIES.

Par. 104.-

Double-bearing Red

Large Red

White Red Antwerp

Early White

Smooth Cane

STRAWBERRIES.

Par. 105.-

Alphine

Bath Scarlet

Carolina

Chili

Downton

Keen's Imperial

_— New Seedling

Knight's Seedling

Mathevin Castle
Nairn's Scarlet

New Hautboy

Pine Apple

Roseberry

Scarlet

Suranam

Wilmot's Scarlet

Black Imperial

Wood Strawberry

CURRANTS.

Par. 106.-

Black American

Long Bunched Red

Common

Red Common

Large Pale Red Cham-

White Common

paigne

Dutch 
COMMON GOOSEBERRIES IN THIS COUNTRY.

Par. 107.-

Champaigne

Common White

Early Black .

Green Gascoin

Hairy and Smooth Red
Large Rough Yellow

Large Smooth Dutch Yellow Yellow

Small Early Yellow

Smooth Green

RED GOOSEBERRIES.

$\begin{array}{ll}\text { Alcock's King } & \text { Fox's Jolly Smoker } \\ \text { Boardman's Royal Oak } & \text { Hall's Porcupine } \\ \text { Brundret's Atlas } & \text { Lomax Victory } \\ \text { Chapman's Peerless } & \text { Mason's Hercules } \\ \text { Dean's Glory of England } & \text { Taylor's Volunteer } \\ \text { Duke of York } & \text { Warrington } \\ \text { Farlow's Lord Hood } & \text { Worthington's Glory of } \\ \text { Fisher's Conqueror } & \text { Eccles }\end{array}$

GREEN GOOSEBERRIES.

Chadwick's Hero

Royal Green Gage

Dean's Lord Hood

Smith's Mask

Mill's Langley Green

Yeates's Duke of Bedford

Reid's Satisfaction

WHITE GOOSEBERRIES.

Atkinson's White Hall Gibson's Apollo

Chapman's Highland White Kenyon's Noble

Davenport's Lady Woodward's Whitesmith 
COLLECTION OF VERY FINE SORTS OF GOOSEBERRIES.

Ackerley's Double Bearer Nixon's Golden Eagle

Costerdina Goliah

Ridding's Old England

Golden Drop

Royal George

Goliah Champion

Royden's Triumph

Hampson's Bearer

High Sheriff

Rumbulion

Sparkler

Jackson's Golden Orange

Supreme Red

Layford's Seedling

White Walnut

Monk's Charles Fox

Worthington's Lilly. 


\section{GENERAL OBSERVATIONS.}

Par. 108.-THE generality of practical horticulturalists have been inclined to despise the theorist, but since the study has now become not only a fashionable but a profitable source of amusement, it has led many scientific theorists to furnish the practical man with much useful information, which the latter has been able to improve on; and from experiments and practice placed England on a level, and, I may add, in a superior situation to all foreign countries in this respect. The knowledge I possess on this subject, as well as gardening in general, has certainly been greatly assisted by the study of different works which have appeared on these subjects; 
but because their authors may not have understood practically what they treated of, is no reason why I should be the less sensible of the obligations I am under to them. Yet, it may be said, these works are mostly produced from ancient writings, as the substance of most of them was known and treated of by our forefathers: but ought this to be allowed to depreciate the merit of their labours? Would the practical man, I would ask, give himself the trouble to search after these ancient works, did he know of their existence, putting out of the question the expense he would be at, (as most books, after a certain date, become scarce, and are then much enhanced in value, ) and would he, when their attainment was accomplished, find himself competent to suggest the improvements made by most modern authors? I will (speaking collectively) fearlessly answer with regard to the first, he would not be at the trouble; and with the second, he would be fully sensible of the wide difference between imaginary and actual powers of improving. Thus might we proceed in the jog-trot pace of antiquity, were it not for 
the intelligence and encouragement of modern times.

One thing we much cause to lament, which is, the premature decay of some of our most ornamental and useful timber trees, particularly the elm, which is caused by a most destructive insect: the tree is first maltreated by bruises on the bark, or otherwise injured, then follows this destructive insect, which, in one of its stages, eats into the tree, and rapidly consumes it; these serious appearances are to be discerned extensively Kensington Gardens, and many other places. I would here hazard an opinion, from having made it my study for many years; but as the cause may only have been an oversight in those who have the care of them, it might appear officious and misplaced in a work of this nature.

I shall now, previous to drawing to a conclusion, make a few additional remarks on planting of orchards. The first thing to consider, when orchards are about to be planted, is the soil which will best suit the different sorts of fruit; if it is a fine deep, loamy soil, all kinds of fruit trees will succeed on it; but standard 
apples and pears will not do well on any other ; plums (although they like loam) will do well on a sandy or gravelly soil, provided the gravel be not too near the surface; cherries will likewise succeed on various soils, although they do best on a light loam.

When an orchard is about being planted on a fertile piece of land, (particularly when it is intended for family use, ) the various explanatory lists of fruits should be consulted, and a selection made therefrom (according to the size of the orchard) of all the different fruits, consisting of Apples, Pears, Plums, Cherries, Medlars, Walnutś, Chesnuts, Damsons, Mulberries and Quinces, the whole of which are useful in their seasons for the dessert and culinary purposes, although a few only of some of the sorts will be necessary, they ought to be planted, to complete the orchard.

It is an advisable plan to plant a row of Walnut trees on the north or north-east side of the orchard, as they will greatly break the winds from the bloom of the other trees; for although the walnut is much later than many fruits in producing its leaves, it greatly assists in protect- 
ing the neighbouring bloom from the east and north-east blasts, from which it generally suffers more than from any other cause, and the walnut itself from being so late in the season before it is in bloom, it is less likely to suffer than most other fruits:

Indeed, if we could protect the peaches and nectarines while in bloom, we should have them as fine and plentiful in the open ground in this country as they are in America; but the peach and nectarine producing its bloom before they put forth their leaves, the cold east wind, which we are'almost invariably subject to in England, in the early part of the spring, is too sharp for the tender bloom, and consequently they seldom produce a crop, except in sheltered situations. On the contrary, in North America, although they are subject to very severe weather throughout the winter, when the frost breaks up and the spring commences, they generally have a continuance of fine mild weather, therefore the growth of this fruit has a preference; indeed, they are in the habit of planting orchards of peaches and nectarines as common as we do apples. 
Before I leave this subject, it will be necessary to speak of the increasing value land would be brought to by cultivating it with apples.

As one acre contains one hundred and sixty square rods, and each rod measures sixteen feet and a half square, if the trees were planted at a rod apart, it would of course take one hundred and sixty trees; or if they were planted wider, say one hundred to the acre, we have then to consider what would be the arerage profit arising from it. In the first place, while the trees are in a young state, the injury will be so trifling to the under crops, for the first five or six years, as to be scarcely worthy of notice; and by planting good apples and sure bearers, in that time their produce would more than pay every expense of the purchase of the trees and planting, and from that time the profits would every year increase as the trees grew larger ; on the seventh year from planting, suppose you could only ensure one bushel from each tree, making one hundred bushels, (this is putting it at the lowest calculation, and each bushel worth fire shillings, this will amount to twenty-five pounds; and allowing 
every future year the fruit of each tree to increase in value only sixpence, from the increasing growth of the tree for twenty years, which by planting at that distance they would have sufficient room to do, it would make the produce of each tree worth fifteen shillings, and the gross produce of the acre worth seventy-five pounds per year, independent of the meadow.

In this statement, it must be allowed, I have stated the average produce at the lowest, having allowed each tree at the age of twenty-seven years to produce only three bushels, and each bushel at five shillings; and as the demand for apples is, and always will be very great, I know of no crop the land could produce that would tend to a more sure or greater source of profit.

And lastly, it ought to be borne in mind, that the apple provides the dessert at seasons when we can scarcely have have any other of our own produce; and also the pudding and pie, which we cannot conveniently procure at all seasons from other fruit, which is, from the tart, to the dumpling made for the peasant's child, of universal service as well as a luxury. 


\section{PART II.}

\section{CHAPTER I.}

General Description of Hothouses intended for Pines, including situations, aspects, \&.c.; also instructions for Pits and Hot-beds.

Par. 1. The site on which to erect a hothouse, should be selected where, if possible, it will receive the benefit of the sun from the earliest time in the morning until the evening without obstruction from other buildings, trees, or any other causes; likewise it would be equally desirable, if convenient, to select a spot which is naturally dry, and sheltered at the back. 
Many new designs for hothouses have recently been introduced with the usual recommendation consequent on ushering them into notoriety; but although I am in favour of some newly invented glass-houses for other purposes, I am decidedly of opinion, taking all things into consideration, that there is not any formed which is so well. suited for the main, or general pinery, as the first I shall describe.

The structure should extend lengthways, from east to west, the back formed of a sound brick wall on the north, from eight to sixteen feet high, as the size of the house may require, and glass-work on the south, east and west, with upright moveable sashes in the front, in frames placed on a brick foundation, raised about eighteen inches or two feet from the ground: also both ends to be formed of glass-work in fixed sashes placed on brick-work to correspond with the front and back walls, with a door half glazed at one or both ends, according to the size of the house, the roof likewise to be formed of glazed, sloping, moveable sashes, extending from the north wall downwards to the top of the 
sashes in front; and for the information of those not well versed in hothouse building, a more detailed statement may be useful.

Upon the low front walls, a plate or frame of wood is placed, of sufficient strength and substance to contain the uprights, to be also formed of wood, which should be from three feet to three feet and-a-half apart, and formed so as to contain the upright sashes, which may be from three to five feet high, more or less as the size of the house will require, with another brace-plate, or plate of wood along the top of the uprights, to fix and secure them in; and from the top of this front upright frame-work, rafters are extended to the top of the back wall, three feet to three feet and a half apart for the support of the sloping top sashes; of the same width as the upright, and the top sashes, ranged in two or three tiers, one above another, according to the width of the house, so constructed that they may slide up and down as occasion requires, and if made to slide upon rollers, it will be by far more convenient to let up and down, with pullies, particularly when expedition is required in stormy weather, \&c.; the front upright sashes may be formed nearly 
the same as window sashes, made either to slide or swing open, or shut with ease, and the top sashes made of sufficiently strong outside framework, with narrow bars of wood grooved out, in -which to lay the glass, ranged lengthways, six, eight, or nine inches apart; the glass to be laid in putty on the ledges or bars, with the ends lapped over one another about half an inch, having the puttying work neatly and closely performed, thoroughly water-tight, and the whole of the wood-work should be properly painted.

The dimensions of the pinery must entirely depend upon circumstances, according to the size of the establishment, the wish of the proprietor, or the general intentions for which the pinery is formed; it may be from ten to fifty feet long or more, from eight, ten, to fifteen feet wide, and when the house is wide and lofty, the top rafters should be supported by uprights in the centre of the house; these should not be larger than really necessary, both as regards their appearance, and also the room they take up, together with obstructing the rays of the 
sun, therefore solid iron uprights, of a round form, are generally to be preferred, and if about three inches in diameter, they will be of sufficient strength to support the largest rafters required; -if well fixed at the bottom and top, and perfectly upright, and being painted will not disfigure the house.

Although I have stated thus much as a general outline about the external formation of the hothouse, I beg to remark, that if not absolutely necessary, it is highly desirable, to employ persons for such works, who have been accustomed to hothouse building, otherwise it ought to be under the superintendence of the experienced gardener, in order to prevent the house from being badly constructed, which afterwards proves injurious to the crops, and frequently causes much inconvenience and disappointment; but the best guarantee is to employ a practical horticultural surveyor, whose judgment and probity can be relied upon.

The internal part of the hothouse arrangements will also require care and judgment. In the first place, the flues, which must range in a 
horizontal form, should be so constructed that the heat may be conveyed to all parts of the house ; and it is of great advantage to have them detached from the walls two or three inches or more, that they may give the heat from both sides. It is highly requisite to carry one flue along the front, and both ends of the house, continued to that behind, being of considerable utility in resisting the severity of the frost, cold damps, \&c.; and the back flues should be arranged in two or three returns, one over the other, the uppermost terminating with a chimney for carrying off the smoke, after having passed through all the flues. Generally the walls of the flues should be made of brick on edge only, that they may impart the heat early and with more effect, six or nine inches in width, by twelve deep in the clear. Good mortar should be used to the brick-work, and made very close at the joints, to prevent any smoke oozing out into the house. The insides may be thinly plastered, and each range, and the returns, covered with paving tiles, also closely cemented.

When the hothouse is of very wide dimensions, 
and long in proportion, say forty feet or more, two or more fire-places will be necessary, each having its separate range of flues, divided into equal proportions, with a chimney attached to each division. Where there are two pits ranged along the house, one before the other, then the flue may be carried along the space between them; but in this case the flue must be detached from the bark pit bed, not less than two or three inches, to prevent the heat drying the bark too much, or it might be in danger of taking fire by accident, through overheating the flues: but for houses of moderate width, with only 'one pit, the flues ranged round the house as described above, will be sufficient.

It will be necessary occasionally to cleanse the flues when they become clogged with soot, for which purpose, places should be contrived in the brickwork, at convenient distances, to make a small opening, or by the removal of tiles; but. be careful that those apertures are made perfectly secure again.

At the furnace, or commencement of the first flue, it is requisite to have a regulator or register, 
with a sliding plate of iron, in a frame of iron fixed in the brickwork near the fire-place, to slide across the flue, occasionally to reduce the heat when it may be too powerful, or to admit it more strong when necessary.

The fire-place or furnace from which the flues proceed, should be constructed outside the hothouse at the back, the heat conveyed through a single funnel, along next the end and front walls, being continued to that behind. The fire-place may be at one end or in the middle, and the grate, formed of iron-work, should be about fifteen or eighteen inches below the lowest flue, which will give'a proper draught for the smoke and heat to ascend without returning; also the. fire-place should be formed about twelve or fourteen inches wide by about eighteen or twenty deep, with an arched top, having an iron door on hinges, placed at the mouth, to shut close, and to be confined with a latch or catch.

It is a desirable plan to have the fire-places inclosed under a shed, for by being defended from the weather both above and on the sides, is very advantageous in preserving the regularity of the 
fires, which is (particularly at times) of considerable importance.

The pit for the bark bed should extend nearly the whole length, and the width in proportion to that of the house, from five to eight feet, leaving a passage or walk all round between the flues and the pit, of eighteen inches or two feet. The walls of the pit should be about three to three-and-a-half feet in height, composed of thin brick-work, sinking the bottom about one foot below the surface, unless the soil is naturally wet underneath; in that case it is better not sunk at all. The bottom of the pit should be pared with bricks or paving tiles, and the top of the brick-work be secured with a plate of wood. In large pineries of considerable width, two pits are sometimes erected, to range parallel, one before the other, separated by a passage between, the largest and highest pit behind for the large fruiting pines, and a lower and smaller one in front for the succession of small plants; and when the house is of great length, a division across the centre of the pits is very convenient, and, where the width of the house will permit, a 
flue can be carried along between the two pits lengthways, as before named. But the plan to be most recommended, both for convenience and appearance, and I may add, success, is to have one pit only in each house, and to have the succession house or houses built at one end, or both in one range, to correspond with the main pinery, divided inside by a partition of glass-work only. This will be very advantageous, both for raising the young plants, and also to forward the whole of the succession, until they arrive at a proper age and strength for placing finally in the main pinery for fruiting; or when a succession house is built detached from the principal pinery, the same form of building as the latter will likewise suit for the former, although generally of less dimensions. Having seen much practice with steam and hot water, I may here observe that I intend under the head of steam and hot water, to give a more comprehensive opinion relative to heating pineries; and before I finish this treatise I intend to spare neither pains nor expense in order to become thoroughly satisfied in every particular relative to the properties of hot water 
and steam for such purposes; which I consider highly necessary, after the various theories which have appeared on the subject, prior to recommending its general adoption, particularly as it is now recommended by some for growing pines to maturity, without tan or any other heat; and I think such caution the more necessary since the management of pines under the above prin. ciple of constructing the hothouse, and the treatment alluded to, has stood the test, and proved so eminently successful for so many years.

Nevertheless, as it must be expected that a work of this nature will include the new plans of the present day, and as I am far from clinging to the old, where improvements are at all visible in the new, I will next give a description (or at least copy a description from the transactions of the Horticultural Society) of a pinery which is stated to have succeeded with steam, without the aid of a bark pit or any other heat; but I may here state that hot water heating is eridently superseding that of steam, being of much less trouble, and also less dangerous, while its pro. perties may be considered quite equal if not 
superior to steam for horticultural purposes. Nay more, I have the satisfaction in stating, that when I have recommended the hot water system, where I have been employed in making improvements, or forming new gardens, it has received great praise, both from my employers and their gardeners, where properly managed; therefore, although I am not at present going the length of some as regards pines, still I intend, in a future stage of the work, to recommend its adoption for those purposes, for which I know it to be superior to any other mode of heating; and the following mode of growing pines I give verbatim, as it appeared in print:-

"On the Culture of the Pine Apple, in a Letter to the Secretary of the Horticultural Society, by Mr. Alexander Stewart, Gardener to Sir Robert Preston, Bart. at Valleyfield, near Culross, Perthshire ; read Dec. 2nd, 1823.

"The nature of the pine apple is by no means so well understood in Scotland as in England; the plants are kept in too dry an atmosphere generally, and not allowed sufficient heat and moisture in the summer season. Early in 1820, 
Mr. Stewart felt very desirous to grow pines without the aid of tan, and with more steam than he had hitherto been able to do. He therefore got a pit, in which he built two flues, and supported over them, on brick props, a flooring of parement, covered with a layer of gravel and sand on which to place the pots; at the sides were openings, to admit the heated air from below, to warm the atmosphere of the plants; the upper level of the platform, on which the plants stand, is nearly on a level with the external surface. The pots of plants are set on the sand, so that when moisture is added either to it or to the plants, it causes a fine gentle steam to arise through the whole of the pit, which can be regulated at pleasure, by adding more or less fire, according to the season or other circumstances." After nearly three year's experience, Mr. Stewart is "fully convinced" that $\tan$ is quite unnecessary, not only as a source of bottom heat, but even for rooting the crowns and suck. ers. "The temperature kept during the spring and summer is from eighty to one hundred degrees through the day, and as low as from sixty. 
five to sixty degrees during the night: in autumn or winter it is as low as fifty-five or fifty degrees." He has no hesitation in stating that, when coals are moderate in price, it is the cheapest plan he has seen adopted; and he sends the particulars to the Horticultural Society, "in hopes that they may assist in establishing Mr. Knight's views on the subject of cultivating the pine apple."

Another plan recommended by some for a pinery, is to have the whole roof formed of glass-work; and instead of extending lengthways east and west, as described in the first plan, it is made to extend lengthways from south to north, with the top, of a ridge-form, sloping equally on both sides, east and west; the walls may be raised of an equal height all round for fixing the glass-work upon, varying from one foot and a half to three feet, and the upright sashes along the sides, from two to three feet or more in height, according to the height of the wall, and to be made to slide or swing open; the sloping top-glasses, reaching from the top of the uprights on both sides, to meet in the centre of the roof, and the sashes made 
to slide upon the rafters and frame-work, the same as in the former south-fronting hot-house; both ends may be also formed of glass-work, which makes the structure look more uniform, or if preferred, the north end may be made of brick-work ; in the latter case, the fireplace may be made there, and covered in, but the forming of fire-places for a house built after this plan, the situation, and circumstances, must guide the judgment: the bark-pit to be extended along the centre of the house, with the flues or pipes along the inside of the walls, or if the house is of sufficient width, two pits can be made, and the flue or pipe run between the pits.

Some approve of this form of pinery in preference to the first-named, contending, that it receives more effectual benefit from the sun; but in this opinion I do not altogether agree, as I never could perceive that it had that effect, neither do I consider that it comprises any other particular advantage to cause it to be preferred to a hothouse facing the south; and in winter I should say, on the contrary, as. the sun at that season has less effect within, than when the sloping 
glass roof is directly facing the south, or as nearly so as circumstances will permit; nevertheless, there are situations where a double glassroofed hothouse may be erected, and not con. venient or desirable to build one facing the south, in such cases it is by no means to be rejected.

Some pineries are built of a circular form, with a wall all round, two or three feet high, with upright sashes and sloping roofs, in the same proportion as described in the last plan, having the flues for fire-heat, or pipes for water, or steam heat, carried round the inside walls, with a circular pit, or two semi-circular pits, if the house be large enough, with a walk round between the pits and the outside walls.

However much persons' taste or their ideas may differ, as to the form of the hothouse to be constructed, I would strongly recommend them them to be raised only of a moderate height for pines; as the internal heat will have much better effects, and the plants will grow much stronger than when the glasses are lofty; the latter often makes the plants weak, with long leaves, leaving 
the bottoms slender, in which case the fruit cannot be expected to arrive to that perfection and size, as when the plants are strong and robust; therefore a house about five or six feet high in front, by ten or twelve behind, generally proves more successful for pines, than when they are built much higher.

When convenient, the building of hothouses should be commenced in the spring, or sufficiently early in the summer, to have them completed early in the autumn, that they may be thoroughly dry, well painted, and in good condition to receive the pines.

Having given the foregoing directions for the formation of hothouses for pines, of a superior class, I will now furnish directions for the construction of pits, in which pines are grown in great perfection.

The pits, if possible, should be erected in a sheltered situation, lengthways from east to west, five or six feet wide or more, the length depending on the quantity of pines intended to be grown, the walls all round the pit to be of solid brick work, raised five or six feet at the 
back, and three or four in front, with both ends corresponding with the back, and front walls; having a frame-work of wood along the top of the walls for the lights to fit closely upon, with rafters fixed from back to front of the pit, the same distance apart as the width of the glass light, for the latter to rest and slide upon, and which are generally from three to four feet wide, the light well glazed and thoroughly watertight; the pit should not be sunk much, and if the bottom is naturally wet, it ought not to be sunk at all, but the walls raised the height before mentioned above the surface; in this method of growing pines, I must strongly recommend hot water or steam heating in preference to fire heat, the first for choice, although I have seen the most brilliant success attend the steam. The pipes may be carried all round the pit, if there be sufficient space between the bark in front, and the glass, if not, have the pipes behind only, always allowing a proper space below, for the bark bed, which should be about three feet or 'three feet and-a-half deep. 
But when it is intended to grow pines to maturity by this practice, the pits may be made much wider and deeper than those above described; and where the spot selected for the pits is of a dry nature, the pits may be sunk more in proportion, to give room for the larger growth of the pines, between the bark bed and the glasses, and when the pits are thus formed for fruiting the pines, there can be no difficulty in carrying the pipes all round the pit.

By this method of growing pines in pits, large quantities may be produced with greater safety and with much less expense and trouble than many may imagine, and indeed where the practice has not been witnessed, it would be scarcely possible to form an idea, or at least to become reconciled, that it is attended with triumphant success; but be it recollected, that this is for the growth of pines alone, and therefore ought not to do away in large establishments with the principal hothouse pinery, as it serves so many other useful purposes, as well as being an appendage of no mean consideration, where forcing is carried on extensively. 
I need only remark further on this subject, that where pits are intended for pines, they may be made of such dimensions that will suit them in their various stages of growth; but I am still of opinion that a moderate bottom heat is highly essential for the growth of pines, indeed the bark bed heat alone, in pits of this description, is sufficient, except in very severe weather for the young plants, or to strike the suckers and crowns in, the proper seasons and management of which will be hereafter described.

Hotbeds made of dung, are sometimes for convenience substituted for bark beds, for striking the suckers and crowns, with common deep garden frames and lights, and may continue therein two or three months, or occasionally through the winter, where there is not a more proper place ready to receive them; the beds should be made in the usual form of dung hot-beds, three or four feet deep with the frames placed thereon, and in about eight or ten days, or when the violent heat has abated, place on the top of the dung within the frame 
some tan, new or old will do, about eight inches thick for plunging the pots in; and when the heat is greatly reduced, if the plants are intended to remain for some time, strong linings of hot dung must be applied, and if to continue through the winter, it must be renewed once in three or four weeks, as occasion requires; but if the heat of the bed should so decline that the linings will not sufficiently revive it, pre. pare a new bed, and when ready, remove the plants thereto as expeditiously as possible, replunge them, and treat this bed as directed for the former, with the addition in winter of defending the outside linings with straw or stable litter, to counteract the severity of the frost, the effects of heavy falls of snow, \&xc. I may also here remark, that lining the outside of the bricked pits with light dry litter during the winter seasons, has a most beneficial effect, by greatly assisting to repel the severity of the weather; indeed, at all seasons it is useful rather than otherwise, and to more effectually preserve the internal heat, covering the glasses of the pits or frames every night in sharp frosty 
weather, will be found beneficial, or continued the whole day when very rigorous, with straw or garden matts, or matts placed over the straw may be necessary, but do not keep the plants from the light longer than compelled by the weather; let it be understood, that the last method of growing pines while young, on dung hotbeds, is only recommended when it may happen that there is not convenience in the main pinery, succession house, or the bark bed pits.

\section{DESCRIPTION OF SOILS.}

Par. 2. The soil which is most favourable for pines should be principally of a light, rich, loamy nature, of one third maiden, or fresh from a common or field, if with the turf on, the better; one-third of rich garden mould, and one-third of rotten dung; this being thoroughly turned over, and rotted, and well mixed, should be placed in a dry shed, and before used ought to be sifted to free it from all lumps, stones, \&c., and is much better for potting than in a wet state; but it should in no case be taken under cover until it 
is thoroughly rotten and fit for use, as the sun, air, rain, \&c., is of great benefit to it while in a state of pulverization and decomposition, and by preparing the compost annually, it will always be ready for use; but in case there may be a want of this previously prepared, some rich mellow garden mould, some dry rotten dung, with some light loam taken from near the surface, being well mixed together, and sifted or screened, may suffice for immediate use ; and if the soil appears too strong, add a small portion of light sandy opening mould, or some sea-sand or drift.

\section{METHOD OF RAISING PINE PLANTS.}

Par. 3.-Pines are propagated principally from suckers growing out of the stems of the fruiting plants, both from the lower part, and also from some which will produce them near the apple, or other parts of the stalk; likewise the crowns from the top of the ripe fruit, when they can be preserved when sent to table, will make fine strong plants, which should be taken from the fruit with a gentle twist. The suckers may be 
allowed to remain on the stems of the old plants until the fruit is ripe and removed, and for two or three weeks after to give them strength, unless any of them are grown very strong, in which case they should be removed, to prevent them from impoverishing the fruit, and prevent it swelling to the size it otherwise would. Although the suckers and crowns from the old fruiting plants are to be preferred, the plants may sometimes be raised, if required, from the succession pines, when they happen to run to fruit prior to their proper growth. It will, therefore, be necessary to procure a sufficient quantity of suckers and crowns during their fruiting season, to keep up a regular succession for fruiting annually, as the old plants that do not decay, are not to be preferred for fruiting generally; and when they are preserved, a strong sucker only, is allowed to remain on the old plant, which will sometimes grow large, and fruit the following year.

After the crowns and suckers have been detached from the fruit and stems, as before described, should they be in a very soft succulent state, 
they may be laid open in the hothouse for six or eight days, or more, to harden them before being planted; and although destitute of roots, they, when planted and plunged in the bark bed, will soon form roots and grow. I may here observe, that the crowns and suckers may be preserved in summer, or in the autumn, or at any season when the fruit is ripe, or the suckers is in a fit state to be removed; and I should recommend to get as many crowns returned as can be obtained, as they generally grow stocky, strong, and produce fine fruit; and also the largest and strongest suckers should be selected; and when the suckers on the lower part of the stem are allowed to remain after the fruit is gathered, as before directed, for the purpose of gaining strength, some of the old leaves may be cut or pulled off the stem, to give the suckers room to swell, but at all times, when the suckers appear about eight or ten inches long or more, particularly when they appear brownish at the bottom, with small tuberances, from which the roots are emitted, they are in a fit and proper state to be removed for planting; being careful 
to remove them from the old stem without breaking or bruising, by placing the hand near the lower part of the sucker, and loosen and slip them off clean. When they appear dry and hard at the bottom, they may be immediately planted, first cutting the ragged part at the bottom smooth, and remove some of the under leaves by cutting or pulling them off, indeed, the future progres of the plants much depends upon the suckers and crowns being properly prepared for planting.

The sizes of pots usually used for planting the crowns and suckers in, are forty-eights and thirty-twos, the forty-eights for the small, and thirty-twos for the larger; the pots being filled with the proper mould, (as described under the bead of soils,) they should be planted shallow in the earth, only sufficient to make them fast in an upright position, then give them a light watering, and plunge them in the bark bed, which should be of a moderate heat; and if no other is ready, they may be placed in the main pinery, the pots plunged close together, and fill up all the cavities between them with 
the bark; by this treatment the plants will strike root in about ten days or a fortnight, they will then require a moderate watering, both to the earth, and over the plants, and when they begin to grow, and are well rooted, they will require water twice a week in hot weather; and if not in the main pinery, air should be admitted at about the same proportion as is directed to be there kept.

It may happen, that there may not be room or convenience at the time of planting the suckers, \&c., in the principal pinery, the succession house, (if any) or a regular bark pit; in that case a dung hot-bed may be made for the purpose, for a one-light frame or more, if required, which should be prepared ten days or a fortnight before it is wanted, in order that the strong rank heat may subside before the pots are introduced, the top of the bed being then levelled, put on about eight or ten inches of bark, and plunge the pots therein two or there days after, when if the bed was made about three feet deep of the dung, that will generally be about the time it may be used; but in all 
cases it will be necessary to examine the heat of the bed, and be cautious not to plunge the pots while it is too violent; and in case the heat should increase to too great a degree, it will be necessary to draw up the pots half-way, or raise them sufficiently to prevent the plants from burning.

If the plants are raised in a bark-bed pit, or the principal pinery, or succession house, they may there remain; but it will be necessary occasionally, when the heat declines, to fork up the tan, or when the heat is greatly reduced, a small quantity of new bark may be added, and mixed with the old, ard then plunge the pots again immediately. If the heat in the dung hot bed should decline before convenient to remove the plants, it can be revived by linings of fresh hot dung along the sides, but in six weeks or two months they will be in a fit state to remore in the same pots to the succession house or bark-bed pits, but where there is not this accommodation, they may be removed to the barkbed of the main pinery. About October or November is the usual time for completing this 
work, that they may remain where placed through the winter; or if not convenient, to place them either in the main pinery, succession house, or bark pits, a new hot bed may be made to receive them if thought necessary; but the heat of the old or new hot beds should always be kept up as long as possible by additional linings, and in cold weather, warm litter should be applied round the sides of the frames, and the glasses covered by night, and in frosty weather they should be covered with litter or matts, and in very severe weather both may be necessary, the mats being placed outside to fasten down the litter; nevertheless, although I have given these instructions relative to the management of the pine plants in the hot beds, it is by far more preferable, both for convenience and safety, to remove them for the winter into the pinery or bark pits.

GENERAI CULTURE OF PINES.

Par. 4.-After giving plain yet sufficiently elaborate directions for raising the plants, it will 
now become necessary to furnish instructions for their future and general cultivation.

If the plants are raised at home, as directed in the last paragraph, I need not add any thing more on the subject of removal, but where pine plants are brought from a distance, it will be highly requisite that great care and attention should be paid to their removal ; and the seasor most proper, for the principal furnishing the pinery, being early in the autumn, (September or October is the most preferable, but not later than November,) will be the most desirable time to remove them; but this will depend on circumstances; for if not convenient in the autumn, they may be removed in the spring, about the end of March, or beginning of April, or almost at any time, but these are the two principal seasous.

When removing pine plants a considerable distance, which are large, the leaves should be gently drawn together and tied, and then placed upright in a cart or waggon (a spring van is best) with plenty of soft straw or litter, which should be made firm as possible between the pots to 
keep them steady and the pots from breaking, and when they are sent by carriers or stage waggons, it will be necessary to pack them in baskets, if large plants, three or four in a large basket, or separately in a small one, and small plants may be packed in large baskets close together, as many as the basket will hold, so that the pots are kept apart by the litter, to prevent their breaking; but in all cases in cold weather the plants should be protected by covering; if in an open cart or waggon without a tilt, a temporary tilt, may be formed over the plants, and covered with mats or a rick-cloth, or any other thing that will protect them from the cold. When sent in baskets, sticks should be placed round the edges, upright, and drawn together at the top, and tied, of sufficient height not to touch the plants, and then covered securely round with garden mats. Having given the foregoing directions for the removal of the plants, their general management in the hothouse, will necessarily follow, and which I intend (fearless of all the new and various crotchets) to confine myself to one safe, tried, and straightforward 
method, in order that the reader may not be confused with various methods under this head. The autumn being the season for preparing the pinery for the plants, or at least the time when the most full and necessary directions are required, I will commence with instructions accordingly.

The pits should now be furnished with new $\tan$, and some of the best of the old may be screened and mixed among the new, raising it several inches above the top of the pit to allow for settling; and when it has become of a proper moderate heat, both in the principal pinery and the succession house, the pots should be plunged in the bark, placing the largest behind, and the smallest in front; and when there is no succession house, or other convenience, the small plants may be placed in front of the large fruiting plants in the main or fruiting pinery, or at one end, placing the succession plants next the fruiting, and the smaller or next in succession near the end, or in large pineries where there are two pits, the largest behind should be for the fruiting plants, and the 
smaller in front may be allotted for the succession and small plants.

At the same time, where there are separate houses, it is more convenient, and generally more successful, for by having the succession and small plants in a separate house or in other bark pits, a more general moderate heat may be kept therein, than sometimes is required for the truiting pines in winter, and more particularly towards spring, when it is necessary to forward the fruiting; moreover, the main stove will not require to be so much crowded, and the strong heat which is requisite for the fruiting plants, will sometimes cause the succession plants to fruit in that early state, before they have size or strength sufficient to be of any valuable size; and also the small plants will occasionally run to fruit through the same cause, without being of any use, and those which do not, are frequently also injured; and when the regular succession is thus injured, it will cause great disappointment for the following two years: although I have given these hints, to prevent the chance of disappointment where it 
can be avoided, yet it often happens that the whole will succeed together in the same house.

By the foregoing practice, the plants will always be at three different stages of growth; first, the two years old or fruiting pines; next in succession, the one year old plants; and thirdly, the young plants just raised, by which method a regular annual supply will be continually kept.

When it is convenient, it is a desirable plan, before removing the plants to where they are to remain, to let the bark beds settle a little and ferment, and the glasses kept close to draw up the heat; and when at a proper temperature, with the assistance of a short, narrow, onehanded fork, open the bark, and plunge the pots as before directed; but be careful should the heat become too powerful, to raise the pots up one-third or half way, to prevent the roots from burning, and replace them again up to the rim when the excessive heat has subsided; and if it be necessary to plunge the plants while the heat is too strong, they may at first be: 
plunged only one-third or half-way up the pots, and lower them after as before stated. When the bark beds are thus furnished with the plants, the house should be shut close, and in cold weather add a moderate fire heat in the evening, to more effectually warm the interior.

AT FULL GRotwth, ORDER OF FRUITING, \&C.

Par. 5.-The two years old pines generally attain their full growth, and the fruit corne to perfection from June till October. The fruit cannot easily ripen without being detected by the powerful scent it produces in the house, and may be then observed, by its changing colour, most sorts turning yellow, and they should be cut as soon as they appear ripe, otherwise they will be become too mellow, and lose much of that rich flavour so peculiar to this fruit. I have above stated, that they generally ripen from June till October, but the principal part ripen in July and August, and some will occasionally ripen in the winter and spring. 
POTS THE PROPER SIZES.

PAR. 6.-Pines being both raised, and grown to maturity in pots, it will be proper to give directions relative to them, and the names of sizes as they may be obtained in casts from the potteries. The smallest size generally used for planting the suckers and crowns in, are called forty-eights, meaning forty-eight to the cast. The next size for the first shifting is thirty-twos, being thirty-two to the cast; the plants being fit to shift out of the first into this size in a few months; the early or strong grown ones may be shifted the same season, or the whole in the following spring. The next size are called twentyfours, or twenty-four to the cast; this is the proper size to shift them into until the next shifting season; but sometimes, when the plants are not over large, they are allowed to remain in this size for fruiting. The next and largest size, generally used for finally shifting the pines, is called sixteens, being sixteen to the cast. The seasons and ways of shifting I intend to give more fully in another paragraph. It is highly 
necessary that the pots should be sound and well burnt, otherwise they are very apt to rot and tumble to pieces; indeed, there is a very great difference in the quality of pots, but in the neighbourhood of London, very excellent red pots may be obtained at half-a-crown or three shillings per cast, the price per cast being the same for all sizes.

DIFFERENT VARIETIES OF PINES, WITH OBSERVATIONS RELATIVE TO THEIR NATURE AND CULTURE.

Par. 7.-It would seem, that the different varieties of pines have greatly increased in number within the last few years, but it is doubtful whether many of those are not renamed, with a view which some have of gleaning a little extra notoriety in the horticultural kingdom, by becoming the supposed original propagator or introducer of a new fruit; indeed, the system has become so prevalent, that it has caused considerable confusion in the naming of many kinds of fruits. I shall therefore proceed to furnish a plain original list of names, with their 
forms, colours, and nature of growth, and also botanically, a list as now described by modern horticulturalists.

Oval, or Queen Pine Apple

Conical Pine

Black Antigua Pine

Brown leared Sugar-loaf Pine, or Pyramidal

Green-leaved, purple-striped, smooth-edged ditto.

Late Mountserrat Pine

King-Pine, smooth green leaves, large fruit

Silver-striped leaved pine, the fruit also variegated.

Gold-striped leaved Pine, (scarce)

Providence Pine

Havannah Pine

Domingo Pine

Barbadoes Pine

Bogwarp Pine

Shining smooth leaved Pine

Green-leaved, purple-striped, smooth-edged

In addition to the above may be added, although not common, the white flesh pine, the red flesh pine, and the green flesh pine, the other varieties being, when ripe, of a pale yellow, green yellow, golden yellow, and olive-coloured.

I will now give a list as known in the botanical 
world, their time of introduction, and from what countries they came.

BROMELIA. PINE APPLE. HEXANDRIA, MONOGYNIA.

Introduced.

1 Ananas Common $\quad$ S. America 1690

2 Semiserrata Semiserate

3 Lucida Shining-leaved

4 Lingulata Tongue-leaved 1759

5 Bracteata Red-bracted Jamaica 1785

6 Fastuosa Noble $\quad$ S. America 1815

7 Melanantha Black-floured Trinidad 1823

8 Nudicaulis Naked-stalked

Pyramidalis S. America

9 Hookeri Hooker's

$\begin{array}{ll}\text { Nudicaulis } & \text { Trinidad } \\ & \end{array}$

10 Sessiliflora Sessile-flowered S. America 1824

11 Acanga Recurved

12 Sylvestris Wild 1820

13 Karatas Upright-leaved W. Indies 1739

14 Humilis Dwarf 1789

15 Pallida Pale S. America 1810

16 Pinguin Broad-leaved W. Indies 1699

17 Chrysantha Yellow-flowered S. America 1820

18 Exudans Clammy 1816

19 Paniculigera Panicled W. Indies 1822 
METHOD OF MAKING THE BARK BED; ITS GENERAL MANAGEMENT AND UTILITY.

Par. 8. - Tan or bark may be obtained at any season of the year from the tanners, it being the bark of the oak cut or ground small for the purpose of tanning hides, and after its properties for that purpose are exhausted, it is thrown from the tan vats, and then becomes a most useful article for the hothouse; but always select that which is the most fresh, or at least such as has not been too long out of the rats to have lost its strength and fermenting qualities, and make choice of the moderately-large cut or middling, in preference to the very small bark, which decays sooner than the larger cut tan, and likewise sooner becomes earthy, or in a dungy state.

In the neighbourhood of London, particularly in the borough of Southwark, any quantity may be obtained, there being many large tanneries. The price generally charged for the bark, is about five shillings for forty bushels, and so on in proportion, according to the size of your cart or waggon, or quantity required; and when ob- 
tained, if it is very fresh and of a raw nature, place it in a heap for a week or more, to cause it to ferment and heat; and if very wet, then spread it out for a few days in fine weather to dry; but when obtained in a proper state, being unly moderately moist, it may be conveyed direct to the hothouse, and placed into the pit, as soon as it may be wanted for making the bark bed. A tanner's fork is the most proper tool for the purpose of shifting the bark from place to place, with four or five times or more; but a common dung fork, with the tines near together, will be a good substitute, when the former is not at hand.

The $\tan$ when carried to the forked up well and regular, to form the bed, which should be raised a few inches above the top of the pit, to allow for settling. It will then ferment, and will be at a proper heat generally in about a week or ten days to receive the pine plants; but sometimes the heat will then be too powerful, which must be carefully attended to. This may be ascertained by running sticks some distance down into the bed, and draw them up daily, and feel the ends; and when the heat has 
164 SORTS OF FUEI, FOR FIRE HEAT.

become moderate, the pots should be plunged therein; or should occasion require the introduction of the plants before the violent heat has sufficiently subsided, they may be plunged only a little or half way, according to the temperature of the bed, and plunged after to the rims, when the heat is proper.

SORTS OF FUEL FOR FIRE HEAT.

Par. 9.-The different sorts of fuel will greatly depend on the situation, but when convenient, coals and coal cinders, or coke, are to be preferred, making the most regular and durable fires, requiring less trouble in the management, and the house kept in a steady and proper degree of heat, with less attention than most other sorts of fuel require; but in those places where the abore are scarce, wood, peat, \&c. may be substituted. Also at the large tanners they make bark peat from the waste of old tan, which may be used with tolerable good effect.

REgUlatiox of heAT, THERMOMETER, \&C.

Par. 10.-As the regulation of heat is one of 
'the most essential points in forcing, a good thermometer is necessary in the pinery and all other forcing houses, that the heat may be properly ascertained, and without which a proper standard degree, cannot be so conveniently maintained. This should be hung up in the centre of the place, with the back towards the sun, in an upright position, that the spirit in the tube may be regulated only by the internal heat in the place, and the heat kept as regular as possible during the rarious forcing months, in such adrances as will be directed.

In the month of January, the thermometer requires the greatest nicety in its arrangement in every description of glass house; indeed, if properly understood, it will greatly serre as a guide to all seasons of the year. As the days lengthen, the pinery will require a higher temperature, from 50 to 55 degrees, and before the end of the month to 60 , advancing the temperature in proportion as the spring advances, until it reaches 80 , about May; and for the main fruiting pinery, s5 degrees, or rather higher, 
may be then kept as a standard heat, during the time of ripening.

In January, if not done before, the vinery should be put in motion for early grapes in June, with a gentle heat at first, from about 45 to 50 degrees, (which is better than being too warm at first,) increasing it in about a week 5 degrees, and in about another week to 55 or 60 , and before the end of the month to 65 , and the temperature may then be kept up as high as is requisite for the pine stove. Also, other fruit houses should be now made active, beginning with a low temgerature, about 40 , and not more thau 47 or 50 during the month of January, nor yet much higher until the fruit is set, 60 being the standard heat allowed, and ought not at any time to exceed 65 ; this may be taken as a guide to most other fruit tree forcing.

Although rather foreign to this work, I may be permitted to remark, that the greenhouse will at this season require the greatest attention, and the nicest management, particularly as regards the heating thereof, much mischief being frequently done to the plants by making 
the house too hot. The temperature during the month of January should be kept as low as about 33 or 35 degrees; generally, the aid of artificial heat is required, only to be sufficient to keep out the frost at any time.

The management of conservatories is widely different to that of the greenhouse; indeed, it would be almost presumption to attempt to lay down any fixed rule for heating them; their situations and aspects, the time of furnishing, and nature of the plants with which they are furnished, being so diversified, that it must be left to the judgment of those who have the care of them.

OF BARK-BED AND FIRE-HEAT.

Par. 11. From October till May the pinery - will require the assistance of fire-heat, as well as the constant heat from the bark bed. When the weather becomes cold, frosty, or foggy, in the autumn, fires should be made every evening about sunset, and also of cold mornings; the evening fires should be continued a sufficient time to heat the flues to such an eligible degree 
of warmth, that will keep the house in a proper temperature until morning: this will be more especially necessary in the fruiting-house, to forward the plants for fruiting; but fire-heat is also necessary, as the weather may require, in the succession departments: also in hard, frosty, and severe cutting weather, the house will require the assistance of fire-heat all day; but be sure not to heat the house immoderately, to force pines to an improper growth, but keep the heat as regular as possible.

About January and February the heat may be triflingly increased in the fruiting-house, to forward plants for fruiting, as at this season the pines generally begin to show and set their fruit, at which time they require a lively bottom heat, and a more general (but mark) yet moderate degree of fire-heat.

The fires may be kept supported till eight, nine, or ten o'clock at night, during the winter, and in severe weather cover the last fire over with ashes, that it may continue to cause a moderate heat the greater part of the night, and also in severe weather the fires should be at- 
tended to early in the morning; but in mild weather, and when the interior of the house is sufficiently warm, the morning fires may be dispensed with.

GIVING AIR AND WATER AT DIFFERENT SEAsoNs.

Par. 12.-During the winter season very moderate admissions of air will only be necessary, to be increased as the spring and warm weather advances, and so on in proportion throughout the year; but this must be regulated according to the fineness of the weather at all seasons; in the winter it should be admitted on warm sunny days, in the warmest part thereof, by opening the glasses an inch or two or more, for an hour or two, more or less as the weather suits; or occasionally as the heat of the house may require.

The pines likewise require very moderate watering in winter, particularly in damp weather; in the depth of winter, only once in a fortnight or three weeks, when the earth appears dry, and then only enough to keep it in a very 
moderately moist state, and at this season the water should be given to the earth only; but as the spring advances, and warm weather succeeds, the waterings should succeed in proportion; at all times keep the plants free from decayed leaves.

It is also very desirable to keep the water in the hothouse, or to have it about the same warmth as the temperature of the pinery.

HOT WATER AND STEAM, THE GENERAL USES THEREOF IN FORCING, WITH EXPLANATORY REMARKS.

Par. 13.- The vast scientific improvements which of late years have so wonderfully developed themselves, none stands forth more prominent than those produced by fire and water.

When we look at the power of steam, which is produced from water and caused by the heat of fire, and view the stupendous undertakings now in progress, through the skill and apparently ardent desire of scientific men to vie with each other, must hand the nineteenth century down to posterity as a gem of science unparal- 
leled in the history of the world; neither is the spirit of competition greater among men of science, than the will of the public is ready, not only to afford their meed of praise, but in almost all apparently practicable undertakings, for the convenience and comfort of the public, generously have they responded with the means of carrying those improvements into effect.

Steam as regards hothouse forcing, has for some years been attended with the most brilliant results, especially as regards pine growing, but this is doomed to give way to that which produced it, namely, hot water, which is now admitted by all whose opinion is worth receiving, to be superior to all other modes of heating.

At first I entertained doubts about the hot water having the proper effect in assisting to ripen fruit equal to the fire-heat of a flue, until from study on the evaporations of artificial as well as natural atmospheres, has led me to the conclusion that hot water heating for every department of hothouse forcing, must be, with proper management, attended with unqualified success. 
The constitution of the atmosphere has a considerable influence on the growth of plants, and more particularly its relation to moisture. The variable state of the rnoisture in the air, was not registered with any degree of accuracy, until within these few years, which improvement may be attributed chiefly to instruments which have been invented for the purpose; but even now, none of them are so perfect as it would be desirable to render them.

When air is cooled below a certain degree, it deposits a portion of the moisture it contains, in the form of dew, and when air deposits dew, it is saturated with moisture, therefore, air always contains that quantity of moisture which would saturate the same quantity of air when its temperature is reduced down to the point at which it deposits dew.

The ordinary state of the atmosphere, as respects moisture in this country, is extremely variable; but the mean result of many observations of the thermometer, and also the dew point, shows that the temperature of deposition and the actual temperature follow each other in 
a regular manner. The difference between the actual temperature and that of the dew point, is least in January, and increases gradually till June, when it again declines to its winter state.

Having studied with considerable care and attention the effects of the atmospheric air in all its relations to vegetation, it has brought me to the conclusion, that the internal air of a forcing house is less liable to suffer by hot wateı heat; being almost free from any noxious effluvia which may arise from other heating; moreover it is a dry heat, which is essential to the ripening of fruit, and yet when necessary, a fine dew may at any time be raised in the house by watering over the pipes when heated.

Altbough I have spoken thus much in praise of hot water heating, let me not be understood by so doing, to underrate the heating by flues, which has stood the test, and proved so eminently successful for generations past; but decidedly I am of opinion, that for general forcing, hot water is the most convenient, safe, and economical mode of heating extant; added to which, it is with very little trouble, and in a very short 
time, made either powerful or weak as the temperature of the house may require.

The manner the flues have been directed to be erected in the different hothouses, may serve greatly as a guide for placing the pipes for hot water heating, they should be placed along such parts of the house, (particularly along next the front classes, ) where the greatest heat is required to resist vigorous frost and severe cold weather; and if a sufficient quantity of pipe be allowed, the temperature may be raised to any necessary height required at any season of the year. I scarcely need remark, that water will always find its level, therefore, when a pipe with returns is placed in the house, the return or returns can be carried, either one over the other from the same, or run parallel, side by side horizontally, and be thus conveyed round the house.

The fire-place for the boiler may be constructed at one end, with one pipe fixed in the boiler, which will act as a funnel to the whole of the pipe, with its returns, and cause the pipes to be continually charged, by having the boiler 
raised a sufficient height above the pipes, to keep them constantly supplied; which, by the heat of the fire, causing the water to keep on the move, will gradually force through all the pipes, and cause the last pipe, or further end of the return, which is also fixed into the boiler, as a funnel to convey the water back into the boiler.

This simple (and I may add elegant) mode of heating with hot water, when compared to to flues, is so easy to manage, the trouble so light, and the expense attending it being infinitely less than any other method, will, no doubt, eventually supersede every other mode of heating.

When the hothouse is very long, with divisions, (the same as directed for heating by flues,) it may be requisite to have more fire-places and boilers, which may be done at convenient distances at the back.

When the boiler is once filled, and likewise, all the pipes thereto attached, (they, being below the top of the boiler,) the principal trouble will be to attend to the fire, and occasionally fill up the boiler. Should the tempe- 
rature of the house be too high, the damper or plate of iron, which is formed in the construction of the fire-place, can be put on to reduce the heat, and he removed again when required.

The size of the pipes may vary according to taste, but to be uniform, the size of the house ought in some measure to be taken into consideration; still, in all cases where the pipes are large, the returns will not require to be so many, as two may do instead of three or four, but those of a moderate size, according to the extent of the house, will, while they answer erery purpose, appear most in unison. But this part will require the judgment to be exercised, of those who have the superintendance.

There are, as a matter of cuurse, some splashes of science sent forth by the competitors of hot water heating, each recommending his apparatus, mode of contrivance, fixing, \&c., as the best; and while such emulation is afloat, and hot water heating for these purposes may be considered almost in its infancy; I think it would be wrong to speak discouraging of either, as sometimes the most simple thing to appearance turns out the best; and what is 
still more to be desired, frequently leads to further improvements; at the same time, although it can be fixed by any one, who has a knowledge of such business, yet there is a great difference in the abilities of tradesmen, this must be admitted, even in setting a copper, or forming any other fire-place out of the common way; therefore, those persons who may wish to excel in this particular branch, connected with gardening architecture, must make it their study before they will become celebrated.

A thing may appear easy when accomplished, or to see another performing it, yet none but ignorant men will attempt to underrate another's science; those who do, are generally weak, and finding they cannot excel, endeavour to gloss over their own stupidity, by striving to deteriorate the science of others; and this is frequently done by (what I consider, the most damning of all human recommendations) faint praise.

Therefore, entertaining these ideas, I have confined myself to recommending such methods, which I know can be depended on, and which 
will, with proper management, prove successful, leaving all others, without prejudice, in the hands of the public, and to future improvements.

\section{RAISING PINES IN HOTBEDS.}

Par. 14.-Pine plants may be raised, and forwarded to a fruiting state in hotbeds made of dung; the frames should be deep, and the top lights well glazed, the beds should be made substantial, from three to four feet deep, and in a sheltered situation, (but where they will have the full command of the sun,) from one, two or more light frames; having from eight to twelve inches of $\tan$ on the top of dung, to plunge the pots in; the depth must be regulated according to the size of the pots ; when the heat declines, strong linings of hot dung should be applied, and in winter the frames defended with straw litter, and mats, as described elsewhere; but as this practice is more generally resorted to for the convenience only of raising the young plants, it does not at all follow that they may be required to be kept in the hot beds during the winter. It will be necessary to be careful 
that the strong heat has subsided, before plunging the pots; this will generally be avoided by making the bed ten or twelve days prior to plunging the plants, and testing the heat of the bed by sticks run therein, in the usual way, the bed should be levelled, and the bark put upon the dung two or three days before the plants are plunged to get warm, and when the plants are plunged, put on the glasses, and treat them as directed in other bark beds.

MANAGEMENT OF THE BARK BED IN THE PINERY.

Par. 15.-The importance of bark bed heat in the pinery has led me to give an exclusive paragraph on its general management; and although part of what is here stated may be found in the directions in the foregoing paragraphs, I trust the present may not be considered tautologous, having avoided as much as possible repetition.

The new bark beds having been made in the autumn and managed as before directed, will generally continue sufficient heat till about Christmas, when it will require to have the 
heat renewed, by taking up the pots, and forking up the tan to the bottom of the pit, and if the bed is much reduced by sinking, \&c., about one-third or fourth of fresh bark should be added, and forked up with the old.

This work should be performed by opening a trench in the bed at one end, and carry the bark from the first trench to the other end, ready to fill up with, then fork the bed thoroughly over, mixing the new tan with old, and directly replunge the pots therein; this will revive the declining heat, and cause it to continue lively for two or three months longer; likewise, this attention to the bark bed in mid winter, will greatly assist the plants in their advancing spring growth, and more particularly the fruiting plants, which generally begin to show their fruit buds about January. and February, which may be discovered by the advancing small crown of leaves; indeed, at this season, it is very essential to have a lively bottom heat about the roots, as it will greatly promote the regular production of the fruit.

In March, or beginning of A pril, the bark beds 
will require another revival after the foregoing instructions, in order to forward the fruit and cause it to swell as it arrives to maturity; the size of the fruit being one of its chief recommendatory properties, and much depends on the care, attention, and skill, which the fruiting department receives during the time the pines are sweiling.

The bark beds for the succession plants will also require similar treatment to keep them always in a kindly growing state; the bottom heat never should be allowed to become too much reduced for any continuance, as that would cause the plants to become stunted, therefore a regular lively hottom heat is highly necessary at those seasons; and as the young plants will require shifting in the spring, the revival of the bark bed may be attended to at the same time. The beds, after the foregoing management, will not require further attention in this way until July or August, unless the heat should sooner decline, which, through inferior bark and other causes, it will sometimes do; then fork up the bark, and about the 
beginning of August, the first succcssion plants should be finally shifted into the large pots for fruiting; then the bark bed should have the last renewal, with a little fresh tan added and forked up together about half way down, at this hot season, will be sufficient, for fear of causing too great heat to scorch the roots.

But in all renewals of the bark beds, when any considerable quantity of new tan has been supplied, or in new made beds, great attention is requisite to discover any tendency to violent heat; and when that appears, immediately draw up the pots, sufficiently to prevent the roots of the plants from burning, as the scorching of the roots frequently proves very injurious, and sometimes entirely ruins the plants.

It may happen sometimes in winter not to be convenient when required to renew the beds with fresh bark; in that case it is an advisable plan to plunge the pots two or three inches over the rims, that in the absence of such renewal of the beds, the roots of the plants may receive every possible advantage from the old tan.

It is likewise necessary both at the time of 
making the new beds in autumn, or of either of the renewals in winter or spring, to keep up a tolerable good fire heat until that of the bed sufficiently rises; also in the spring shifting, and the bark bed being renewed, a moderately good fire heat will greatly assist the plants in taking fresh root, and which should be kept up until the heat of the bed rises to the top.

\section{OCCASIONAL REVIVAL OF THE BARK-BED.}

If the heat of the bark-bed should have greatly declined (particularly in the depth of winter) before it is the usual time, or convenient for the regular renewal, a quantity of fresh bark may be added at top, and forked up with the old, then plunge the pots again directly; this system may, if necessary, be repeated again towards spring, but in the fruiting department, should the heat decline later in the season, or during the general fruiting, it may be renewed without disturbing the fruiting pines; for when they are far advanced, the removal of the pots is apt to check the swelling of the fruit, therefore take out some of the old tan from between the 
184 WiNter MANAgEMENT OF PINES.

pots and add new in its place, this will revive the heat and prove very beneficial.

WINTER MANAGEMENT OF PINES.

Par. 17.-During the winter season, very moderate admissions of air should be allowed, and very little water will be required, particularly through the months of November, December, and January, the plants being during that period not in a state to require it, as they make little or no progress in their growth; therefore merely apply a little water to the earth in the pots, when it appears dry, probably not more than once in two or three weeks, as the dry or moist state of the weather will dictate; but when the plants begin to move, towards the end of January, and in February, or they begin to shew fruit, the watering will require to be more frequent. The air should be admitted only on mild days, while the sun is out, and that in the middle of the day, from half an hour to an hour or two or more, as the state of the weather will permit; but shut the house close when a cold unkind air prevails, and so be guided on till the spring. Observe 
also in winter to keep good fires every evening and cold mornings, and in hard frosty weather they should be continued moderately throughout the day; and when the weather is very severe, both the front and top glasses should be covered with mats or shutters every night. Also when the frost is extremely severe, and not any sun, the covering should be continued night and day; or where the house is furnished (which is the must convenient method) with a painted canvass fixed on rollers at the top, this should be let down, which saves much trouble in covering the top glasses.

SPRING MANAGEMENT OF PINES.

Par. 18.-As the spring advances, and the warm weather ensues, give air more freely, and waterings more frequent, the latter about once a week or more, if the weather is very warm. This will promote a strong growth in the plants, and increase the size of the fruit; but during the cutting easterly winds in March and April, which this climate is so subject to, be careful not to admit too much air to chill the house, as at this 
season, when the plants and fruit are advancing in growth, it is very requisite to keep the house in as regular a temperature as possible.

About March or April, it is of great advantage to the fruiting plants to draw out some of the old mould from the top of the pots, and fill them up with fresh earth or compost. It will promote a free growth in the plants, and prove very beneficial to the fruit.

SUMMER MANAGEMENT OF PINES.

Par. 19.-The latter part of the spring treatment must necessarily run into the summer management of the pines; generally, therefore, about May, the extra heat, whether by fire, hot water, or steam, with which the pinery is heated, may be discontinued until October; yet the bark bed must be supported with a lively bottom heat, as before directed, which, after being made up properly in the spring, the bark bed will generally produce a tolerable heat till August; but should the heat have greatly declined, about June the beds may be forked up, and a small quantity of fresh bark added, forking it up only about half 
the depth of the bed in this hot season; if new $\tan$ is added, it will cause a sufficient heat to promote the regular swelling of the fruit till they arrive at maturity.

The succession plants, by the same rule, will require the same attention to assist them in their growth, observing in hot weather to give plenty of air daily, with waterings two or three times a-week; and about August the first succession plants for fruiting the following year should be shifted into the large size pots, to finally remain therein. Also observe in the shifting that the balls remain entire. Then fork up the bed, only about half-way, with about one-fourth of new bark added; for it often occurs at this hot season, when the bed is forked to the bottom, that the heat becomes too violent. The pots should then be again plunged, and carefully watered, and then treated as before directed, which will cause them to grow freely till October.

Likewise about August, or early in September, if the small succession plants, such as the early planted suckers and crowns of the same year, have made considerable growth, they should be 
shifted into the next size pots, and plunged again without delay into the renewed bark bed.

It should be borne in mind, that at all times during the continuance of hot weather, that plenty of air should be admitted into the house till six or seven in the evening, or longer if the weather is very hot. This is very important, both for strengthening the plants and the swelling of the fruit; and when the sun is very scorching, it is of advantage to shade the pines for two or three hours in the middle of the day. This may be done, in the absence of fixed blinds or rollers, by spreading mats over the top glasses. The waterings also, during the very hot weather, should be repeated two or three times a week. This should be given towards evening or early in the morning, and if possible use river or rain water (the latter is to be preferred) in preference to spring water; but where the latter only can be obtained, let it be exposed to the open air some time before using. The plants require while in a free growing state, that the earth in the pots should be kept moderately muist; but (mark) when the fruit is beginning to ripen, then 
begin to water more sparingly, as too much tnoisture at that time will deteriorate the flavour ; and also as the heat of the summer declines, so must the air and waterings decline in proportion.

When the fruit has advanced to a large size, it is frequently necessary, in order to keep them upright, to place sticks to support them; and sometimes, to encourage the growth of the fruit, the suckers at the bottom, where they have advanced to a tolerable size for planting, say eight inches or more, may be removed, (prepared and planted as before directed,) as these large suckers take away much of the strength of the plants, and thereby deprive the fruit of that support which, when removed, it will receive; but the small suckers may remain till the fruit is ripe, and be treated according to the instructions in the third paragraph.

As the fruit advances to maturity, and which for the most part is from June till October, care should be taken to watch their ripening, which may be discovered by their changing colour, most sorts turning yellow. Then they should be cut, otherwise, by remaining after they have 
190 observations on Shifting pines, \&C.

arrived at full maturity, they become too mellow, and lose much of their peculiar delicious flavour.

The autumn or October management being so clearly laid down in former paragraphs, it will be unnecessary to introduce (separately) any further observations on that head, although in the next paragraph some useful directions will be given.

OBSERVATIONS ON SHIFTING PINES, INCLUDING DIRECTIONS FOR AUTUMN MANAGEMENT.

Par. 20.-Before leaving the subject, I may be excused for offering a few additional remarks on shifting pines generally.

The succession plants will generally require shifting twice a year, but the fruiting plants must not be again disturbed in the pots, after the late summer, or what is generally termed the autumn shifting, prior to their fruiting the following season; unless they become infected with any disease in their early fruiting state, which is sometimes the case; and if such disease should baffle the remedies applied for its cure, it may then be necessary, as a last resource, to endeavor 
ObSERYATIONS ON SHIFTING PINES, \&C. 191

to recover them from the disorder, by shifting them into some fresh mould or compost; but this should not be resorted to, but as the last expedient.

When you intend to commence the general shifting, always have your pots in sufficient quantity, of the different sizes, ready to complete the work; also your compost as handy as possible, that the shifting may be finished, and the pots replunged with all convenient expedition. If the plants are healthy, when turned out of the pots, they only require a little of the old mould rubbed off the eages of the top of the ball, or occasionally a long or matted cluster of outside fibres may be pruned off, and then immediately replanted in the next size pot, placing first a piece of tile (some prefer putting several pieces) over the hole in the pot, then some fresh compost in the bottom, and after placing the plant in the centre, fill up the sides with the same, gently shaking and pressing it down all round, covering over the top of the old ball, about an inch thick, the pots being 
192 OBSERVATIONS ON SHIFTING PINEs, \&C.

filled very near to the top when finished, and then give them a moderate watering.

In the spring shifting, it is thought by some a good plan to shake all the mould from the roots, and trim the fibres short; and when the plants appear unhealthy, the system may not be disregarded, for by cutting away all black roots of a decayed nature; and placing the plants in entire fresh earth, it will frequently restore them, and cause them with proper treatment to become healthy and flourishing; in all cases as soon as the shifting is completed, directly replunge the pots, and shut the pinery close to draw up the heat of the bark bed.

A bout the middle of August, the large plants, either of one or two years growth, having advanced to a large size, and of sufficient strength for immediate succession, or capable of producing fruit in perfection the following year, should now be shifted into larger pots, wherein they are finally to remain for fruiting, and also any others that appear to require larger pots.

This being the season for the last potting of the first succession plants, for fruiting the next 
OBSERVATION ON SHIFTING PINES, \&C. 193

year, they will require the largest sized pots allotted for that purpose; those called twentyfours for the middling size plants, and sixteens for the strong grown plants, and sometimes for very vigorous grown plants the next size pot called twelves, may be selected for shifting them into.

Likewise at this shifting it will be necessary to provide new tan, to add about one-third or fourth of what the pit contains, upon the old, as soon as the plants are taken up for shifting, and fork it well up together about half way the depth of the bed, or where the top of the bed has become very much decayed and earthy, take away a portion of the worst before the new bark is added; this should be done without delay, to be ready to receive the plants as soon as re-potted.

At this season, if more convenient, and the weather is warm and fine, the shifting may take place in the open air, near the pinery, having the pots and compost ready for the purpose; but in the house, should the state of the weather require it; turn the plants out one at a time, and immediately transplant it into the new pot, 
194 observation on SHIFTING PINES, \&C.

first removing a little of the outside mould from the top edges and sides of the balls, and prune away any dry or decayed outside fibres; but if any of the plants at this shifting appear in an unhealthy state, they may be shaken wholly out of the mould, the roots properly pruned, and then potted in entire new compost; if the sun is powerful after they are replunged in the bark bed, afford the plants a slight shade for about a week in the heat of the day, by throwing mats singly orer the top glasses; by that time the plants will take fresh root; after that, air should be given every warm day by opening some of the front or top glasses, or both if the weather is hot.

The revival of the bark bed, as before directed, at this shifting, will be sufficient to carry the plants rell on through this their principal growing season till October, at which time their proper management has been clearly laid down in a former paragraph, (see Par. 4). 
INSECTS, REMARKS THEREON, WITH INSTRUCTIONS HOW TO PREVENT THEM FRON BEING INJURIOUS.

Par. 21.-Pines, like other plants, are liable to be infested with small insects of several kinds, and are frequently, if not attended to in due time, very injurious, causing them to become sickly, and in such a stunted state that neither the plants or fruit make scarcely any progress; some only attack the leaves, but others will infest the plants all orer, even down to the roots; the insects are generally very diminutive, some appearing like dust, and barely visible, and some resembling small scales, while others appear like small bugs; if these are not attended ta when they first make their appearance, they will increase very fast, and soon spread over the whole of the plants; it will therefore be necessary to use every means possible to destroy them on their first appearance in the pinery.

Various causes have been assigned for the pinery becoming foul; some will say the plants were diseased when brought from another house, thereby laying the blame on the former grower; 
others maintain different opinions; but if I may venture an opinion, and considering the rast attention I have paid to the subject, particularly the nature, habits, and effects insects have upon the vegetable kingdom, I think I may be allowed so to do. It is chiefly through bad culture and uncleanliness.

Having made bold to hazard this opinion, I will gire my reasons for so doing, taking as the first example the animal creation. It will be found that bad food, bad drink, and continued filth, (indeed, it is allowed by all who have any knowledge of the subject,) will cause disease and stunted growth, the human frame not exempt, which, through debility of constitution and filth, will frequently cause insects to breed; and if the animal frame is thus liable to breed vermin, can it be surprising that the regetable tribe should do the same, through being first diseased, or that pines should become, what is familiarly termed, lousy, any more than the human frame should be subject to the leprosy of that name, and what is still more convincing, that almost erery tree or vegetable, like different animals, are subject to different species of in- 
sects, some produced by nature when the plant becomes diseased, and some by the winged insects laying their eggs on such trees or plants, which by nature it knows its young will thrive best on.

Therefore, if the pines are made unhealthy by bad treatment, or through neglect, such as planting them in improper soil, chilling them frequently with harsh cold spring water, scorching the roots with violent bark-bed heat, or allowing it to become too cold for the genial nature of the plants, it cannot be surprising that they should become sickly; and when in that sickly stunted state, the vermin is almost sure to follow very rapidly, if not speedily remedied; therefore, pine-growing is by no means to be recommended on a very limited scale, neither ought any one to feel disappointment by failures, where sufficient assistance is not allowed, to be able to pay that attention to them which their nature requires, but where such is allowed, (except by accident,) the fault lays with those who have the management.

Notwithstanding the above cautions, which 
are intended to avoid an internal disease in the plants, (if I may use the term,) insects will at all times make their appearance, which should be attended to without delay: in the first place, be careful to keep the pinery at all times very clean, and when insects appear on the plants, take a brush, a common painter's brush will do, and brush as many of the insects as you conveniently can off the leaves, even down to the heart of the plants, but do not injure them, and also quite down to the bottom where they appear.

- Various methods are also used to destroy the insects; fumigating with tobacco smoke, although an old method is by no means to be despised; indeed, if properly managed, I do not know of a better, although many, from some trifling occurrence, may differ from me. This is done by means of fumigating bellows, or with a smoking pot, letting it burn till the house is filled with a dense smoke, and when the smoke is let off, such of the insects which have not been killed by it, will be in a sickly moving state, and by watering the plants all over through the rose of a large watering-pot, it will dislodge the remainder, 
which will become drown in the water below, or they may be immersed all over in a tub in water, with the chill taken off; some apply tobacco dust, or Scotch snuff, over the plant, and a lotion is also made use of, composed of sulphur, snuff, tobacco, \&c., to wash the leaves with, which is applied with a sponge or small brush, or by dipping the plants all over therein.

When the plants are in a very bad state through insects, mercury is also used; this is done by putting the quicksilver into an open vessel, pour boiling water over it, pouring it off when cold, then adding more boiling water until a sufficient quantity has been impregnated for the use you require, and being placed in a large tub, when only a little warm, take the plants out of the pots, and immerse them therein for a few minutes; when taken out, place them upright to dry, and sponge the leares clean, and take care to remove everything of a scaly nature, as that is no doubt a nest of insects; if the plants are very bad, they may be dipped a second time before they are re-potted; this system in extreme cases is, I think, the most effica- 
cious remedy, as the quicksilver will have no effect upon the plants, although so powerful in its effect upon everything breathing or possessing animation. I should not speak so confidently on this point, had I not have become convinced from experiments of my own on the vegetable tribe.

EARLY GRAPES IN THE PINERY.

Par. 22.-Grapes may be cultivated and brought to maturity in the pinery, in a very superior manner, particularly some of the most esteemed sorts, which will not ripen in this climate without continual artificial heat; moreover, it is generally admitted, and indeed recommended by our best practical gardeners, that the shade produced from the leares of the vine, are of essential service to the pines in summer, through their producing a salutary shade from the extreme heat of the sun; and although the pinery, from the heat which it is necessary to maintain for the general culture of the pine, is of that nature to be repugnant to the growth of most tree fruits, yet it will bring to maturity in 
great perfection those sorts of grapes which other forcing houses cannot be expected to do, the vinery excepted.

The plants should be planted in a border prepared for them, outside the south front, east end, or west end of the house, as circumstances must dictate; when planted in the front, and for quick produce, one plant is generally planted against each style or upright quartering of the front of the hothouse, and after being trained with a single stem of one or two summer's growth, it is introduced into the house early in winter, through a small hole in the wall or other aperture formed for the purpose, and trained up (one stem) along each rafter, having fixed wires or thin slips of wood nailed across to train the young shoots to.

I need not expatiate further on the subject, here, as hereafter the management of the vine will be more elaborately treated on; but before leaving the pinery altogether, I shall make a few remarks on its further uses. 
CHOICE VARIETIES OF FRUITS, FLOWERS, ETC., IN THE PINERY.

Par. 23.-Both in the main pinery, and the succession house, various sorts of exotics may be preserved and forwarded on shelves erected for the purpose, or elsewhere where there is room, particularly such (whether succulent, herbaceous, or woody kinds) which are from similar hot climates to those of the pine, as the heat and management suited to the pine will generally suit the other, the greatest difference in the culture being in potting, and the different soils, which are best suited for the varieties that may be introduced, which must be left to the judg . ment of the cultivator, but for the most part the soil recommended for pines, or of such a nature, will be suitable for stove plants, except some of the succulents; and those particularly which are very full of moisture, should be planted in a light rubbishy or sandy compost, for when the stalks and leares are by nature full of humidity, if planted in rich moist earth they are liable to rot. 
Likewise the pinery is very convenient to bring forward many sorts of hardy plants and flowering shrubs for early blooming, such as roses, honeysuckles, azalias, kalmias, rhododendrons, and various other varieties of American plants, also Persian and Siberian lilacs, pinks, dwarf tulips, hyacinths, narcissus, jonquils, anemones, ranunculuses, \&c.

The pinery is also of considerable use to forward many useful culinary plants, such as kidney beans, cucumbers, small salads, mint, tarragon, \&c.; likewise strawberries in pots. The above useful and ornamental plants may be introduced into the pinery any time in winter, from Decem. ber (or earlier if required) till April, introducing a portion only at a time, in order to keep up a succession, as circumstances may require.

USEFUL REMARKS RELATIVE TO THE CHAPTER ON HOTHOUSE BUILDING, ETC.

Par. 24. - The foregoing paragraphs contained in this chapter will be found to embrace much useful information, which may be considered applicable to many cases connected with hot- 
house building and culture generally, which will preclude the necessity of repetition; at least I intend to avoid it as much as I conveniently can; although in some cases it may be introduced with the view of rendering the substance of each paragraph as intelligible as possible, without the trouble of reference to other parts of the work.

But gardening architecture, like that of landscape gardening, requires not only a natural taste, but a matured judgment is also requisite; and when the two are blended together in the same person, everything that may be wished for may be expected when under such superintendence.

When conservatories are intended to be erected, the taste and judgment are then brought into full play, as situations, aspects, and various other circumstances will preclude the possibility of conreying any thing like an accurate idea or fixed principle for their general construction; for, like landscape gardening, the imagination cannot conveniently be dispensed with (mark, I mean for superior works) in these 
cases. What painters term general effect, is required, breadth of light and shade, connection of parts, grouping, according to the diversity of the scenery. Many think when they have engaged a first-rate gardener he can do anything in laying out or improving, but improvements and alterations are two different things; the knowledge required for a good horticultural gardener to possess, is very different to the taste and judgment requisite for the disposition of woody scenery, and of a fundamental knowledge of arboriculture, which none but those who have a thorough knowledge of the nursery business can possess; for without such knowledge he cannot possibly be a sufficient judge of the nature and constitution of trees generally, to know which will and which will not suit the different soils and situations. This is one principal cause why so many failures take place, and what is still worse, the disappointment which ensues.

It has been said, by some writers on this subject, who profess landscape gardening, that it is a good test of a man's science in erery 
206 REMARKS ON HOTHOUSE BUILDING.

branch of gardening, if he can sketch general scenery, but I have invariably traced such writers to be pen-gardeners only; yet they but too frequently delude, not only the credulous, but many country gentlemen, who ought to be acquainted with such matters, suffer their judgment to be drawn aside by such writers.

Any man who has pretensions to landscape gardening or gardening architecture generally, has a taste for drawing, and without which he cannot excel, for he must be expected to compose a design that can be carried into execution; but I cannot discover what test this can be for the fundamental knowledge of gardening.

The principles of gardening architecture, and particularly as regards conservatories, are synonimous with those of garden scenery, indeed principles of unity and composition are the same in all arts of taste; it would therefore be presumptive to attempt to lay down any fixed principle for the construction of conservatories. 


\section{CHAPTER II.}

On forcing Peaches, Nectarines, and Apricots; Cherries, Grapes, and other choice fruits.

OBSERVATIONS RELATING TO PEACHERIES, VINERIES, AND OTHER FORCING HOUSES; WITH IN'TRODUCTORY REMARKS ON RAISING DIFFERENT SORTS OF FRUITS, VEGETABLES, AND FLOWERS THEREIN.

Par. 25.-By the assistance of forcing houses many sorts of fruits, indeed, most of our best stone fruits, are brought forward, and will ripen in the greatest perfection, several months sooner than they can be obtained in the open air, such as peaches, nectarines, apricots, cherries, plums, \&c. ; also figs, and many other 
desirable fruits; likewise grapes, some of which never ripen in the open air, in any part of England, particularly some of the most choice, large, late sorts, being natives of much warmer climates; and, although some sorts will ripen well in the open air, against south walls, or sometimes when cultivated in the vineyard order in the open ground; yet any of the varieties (particularly the finest) will ripen most effectually in the hothouse; with the flavour highly improved, and the fruit much larger; and by having some of the early sorts, such as will generally ripen against the open wall, introduced into the hothouse, they will ripen early, and cause an early supply in spring, prior to the later sorts coming to perfection; and by proper attention to the culture of the vine, which will be hereafter directed, a very lengthened supply may be obtained.

Raspberries and strawberries can, likewise, be brought to good perfection early in the forcing house; also a few gooseberries and currants for tarts, together with a great many other useful plants for culinary purposes; such as 
rhubarb for tarts, kidney beans, small salading, cucumbers, \&c., may be sowed in pots, or boxes, and may be introduced as may be required, or convenient from November until April: but I would recommend small portions only, for very early forcing; but in January and February, kidney beans, and cucumbers, with many other esculents, may be admitted into the hothouse, for good early crops, without fear of success, and a further supply introduced every three-or four weeks, till April, of such as may be required, which will then be succeeded by crops in the natural way in the open ground.

Pots may also be introduced, containing the roots of tarragon mint, tansey, \&c. ; and occasionally in the borders of the house, may be raised some early dwarf peas, mazagan beans, and lettuce plants, for early use; also kidney beans, mazagan beans, and dwarf, early peas, may be sown thick, in large pots, and placed in the forcing house, late in the winter, or early in spring, and remain there till they have grown an inch or two high, for transplanting 
into hotbeds, warm borders, or protected frames, for a succession, prior to the main summer ground crops.

Flowers likewise, of different varieties, can be brought forward early in the hothouse, and with proper arrangements, a succession kept up during the latter part of the winter, and the early spring months, such as hyacinths narcissus, jonquils, dwarf tulips, irises, anemones, ranuncules, and many other bulbous and tuberous rooted flowers ; also many sorts of fibrous-rocted plants, and ornamented shrubs, including pinks, carnations, roses, honeysuckles, jasmines, double blossom peach, double blossom almond, double blossom cherry, Persian and Siberian lilacs, rhododendrons, andromedas, kalmias, azalias, camellias, \&c. \&c.

DESCRIPTION OF THE DIFFERENT PLANS FOK FORCING HOUSES; METHODS OF HEATING, WITH GENERAL OBSERVATIONS.

Par. 26. - The directions given in the first paragraph for building hothouses, will, in the main, be a sufficient description for forcing houses 
generally, at the same time, a vast difference will present itself in this chapter, relative to the culture generally, of the various fruits, which are brought to perfection in forcing houses, including the modes of heating, \&c.; but my long practice, great application, and consequent experience, compels me to cling for choice, to the hothouse built, facing the south; therefore, for the general building of forcing houses, refer to the first paragraph, second part.

The internal part of the hothouse, for forcing tree fruits, \&c., may either have a pit in the centre for a bark bed, to furnish a constant heat, and for the plunging of various pots with plants in them, or the whole space left open for planting trees; in the latter case, the centre of the bottom of the house may be covered with peaches, nectarines, \&c., as well as along the back walls.

The grape vine is particularly adapted for forcing, in every description of forcing house, as they will stand the high heat of the pinery, where they will come to the greatest perfection; while peaches, nectarines, $\$ c$ c, require a more moderate heat, not ex- 
ceeding sixty, or sixty-five degrees; but in peach houses, also grapes will come to great perfection, but if introduced, they should be confined as much as possible to the rafters, in order that they may not obstruct the rays of the sun, as the sun is most essential, both for the colouring and flavouring the fruit, particularly that of peaches and nectarines.

The vinery, or house intended principally for forcing grapes, may be kept at as high a temperature as that of the pinery, by which means very early crops will be obtained in the greatest perfection; and as the vinery may be of any length required, from ten to one hundred feet, or more, it may be divided by merely a glass partition, in suitable proportions, for very early and later supplies; but in the vinery, or that part where very early crops are intended to be raised, a bark bed along the centre of the house is highly beneficial in assisting the heat produced by fire or hot water; but when not required so early, they can be forced by heat solely of fire or hot water : therefore different forcing houses, are generally in large forcing establishments, allotted 
to the different sorts of fruits separately, although the erections may be in nearly the same form; consisting of pineries, vineries, peacheries, (principally for peaches, nectarines, apricots, plums, figs, \&c.,) and cherry houses, chiefly for cherries; in the whole of which, vines are frequently introduced, to train up under the top glasses, and all the forcing houses are likewise of great utility for producing early flowers, vegetables, \&c.

The various forcing houses are sometimes constructed on different plans, some from taste, others through the situation, not allowing the house to be built lengthways, from east to west; but, they should always be erected to receive as much sun as the situation will admit of. Some forcing houses for tree fruits are formed, for being heated by fire heat, through flues; others by steam or hot water through pipes, without any bark bed. Others are worked by bark bed heat alone, which produces a regular, kind heat throughout the house, but this alone will not bring the trees so forward as when assisted with fire or hot water, or with the latter alone; but where there is a bark bed, less fire or hot water will be re- 


\section{4}

quired, and that only of nights principally, or occasionally of cold mornings, or sometimes throughout the day in very severe weather; but in a mild season, this will only be necessary of evenings, till nine or ten o'clock. Where heated with fire or hot water alone, it will be required to be continued every evening and morning, and moderately all day in cold weather, to support a regular heat.

DESCRIPTION OF A GENERAL FORCING HOUSE.

Par. 27.-A hothouse intended for a general forcing house should certainly, if possible, be built facing the south, or as nearly so as the situation will permit, constructed in the same form as described for pines, in the first paragraph. The dimensions must entirely depend upon circumstances : the back wall may be eight, ten, or twelve feet high, the upright glasses in front four, five, or six feet high, to be in proportion to the back wall; the width from ten, twelve, fifteen to twenty feet, and the length to any extent that may be required, from ten to one hundred feet or more. This must entirely depend on circum- 
stances, and the dimensions arranged and guided by the judgment of those who have the management. Some prefer building the house without upright glasses in front, the top glasses reaching from the top of the back wall down to a low wall in front, with a plate of wood fixed thereon; but the front being formed of upright moveable sashes on a wall one or two feet high, is certainly the most eligible plan, both for appearance and the convenience of head room and other purposes within. If intended to be heated by fire with flues, refer to paragraph the first, where full directions will be found, suitable for heating a house of this description, but if by hot water or steam, refer to paragraph the thirteenth.

When the house is built of considerable length, it may be divided by glass partitions, in which some part or parts may, if preferred, have a bark pit erected, embracing the advantage both of the bark bed heat (and its uses for plunging in, \&c.) and that of fire or hot water. Other portions of the house may be forced by fire or hot water heat alone, without bark, which gives a a much greater space for fruit trees and other 
purposes, the whole of the bottom of the house being free.

When a bark bed is erected in a fruit forcing house, an internal border is prepared along the back, and another of sufficient width along the front for planting the trees in. This is a very desirable plan for vines, but where a bark pit is introduced into a general fruit forcing house, it is necessary the house should be of considerable width, to admit of the borders, pit and paths. The bark bed pit may also be built after the directions in paragraph the first, and it must not be forgotten that where the house is wide, say, from fifteen to twenty feet, it will be necessary to have upright supporters along the middle of the house under each rafter.

PREPARING BORDERS FOR THE TREES, AND THE DIFFERENT SORTS PROPER FOR FORCING; INCLUDING GRAPE VINES.

Par. 28.- The borders in the forcing house must be made according as the width of the house will admit, and also must be guided by the internal arrangements generally, but much de- 
pends upon the judgment of having a thorough practical knowledge of soils, which will suit the different kinds of fruit trees intended to be planted. Generally, where the natural soil, on which the forcing house is built, is of a rich loamy quality, much less judgment will be required in preparing the borders, as all fruit trees will succeed in a light deep loamy soil; and when this is the case, no further trouble is necessary, beyond trenching the ground two spades deep, throwing up the two crumbs, and loosen the soil at the bottom of the trench, before throwing in the next top spit. If the soil is tolerably rich, no manure will be necessary; if poor, add some thoroughly-rotted dung, in proportion to the poorness of the soil; at the bottom of the trench, after it is loosened, and again on the top spit after it is turned over, and more on the second spit after it is turned over, and then throw the second crumb over it, and before planting, the border may be again turned over slightly, to cause it to be well mixed. This will be quite sufficient for all kinds of stone fruits, particularly peaches and nectarines, or 
any trees worked on plums, for those trees are very apt to become diseased through over rich soil, and from which they seldom or ever recover.

Where the soil is naturally of an unkind quality, it will then be necessary to remove a portion thereof, two, three, four, five, or six feet deep, according to the nature of the soil below, and the vacuum filled up with good fresh loamy soil; and if tolerably rich, it will not require any manure to be added, otherwise a small quantity of rotten dung may be mixed with it; but be very sparing of manure for peaches and nectarines, for be it recollected that fruit is required as well as barren wood, and you may at all times assist the tree by removing the fruit when necessary; while, on the other hand, it requires more than ordinary skill to check the trees when they get into too luxurious a state of growth, which generally causes swellings and gumming, and finally terminates with canker and decay. Mark, I am speciking from extensive practice.

When preparing the borders for grape vines, either in the house or along the front, outside, the nature of the soil requires the first consider- 
ation, both for the growth of the vines and the ripening and flavour of the fruit. If the natural soil is of a deep, light, mellow, loamy nature, little is required beyond trenching the border two or three feet deep, mixing with it a tolerable good dressing of compost, such as rotten dung, brick rubbish, scrapings of turnpike roads, \&c. By this practice vines will generally succeed better than by removing the natural soil two or three feet deep, which is often the practice, and bringing in a different soil, which the vine is fond of ; for although the plants may grow very freely for the first few years, yet when the roots get down to the soil of quite a different nature and which they may not be so fond of, they are very apt, just as they are coming into bearing, to lose part of their vigour, which will render them not so well able to stand a crop of fruit, or at least, produce such fine bunches and large berries, as if they had not been too nicely fed at first.

Where it should so happen that the land is of that nature, either a bed of gravel, strata of clay, or otherwise so unkind that it may be deemed necessary to remove the natural soil, and bring 
in that of a different quality, I would recommend it to be taken out both wide and deep, not less than eight or ten feet at least, in order that the vines may have room to extend their roots for years, and three or four feet of the bottom filled up of light loam, with a considerable portion of rough dry brick rubbish, ruad scrapings, \&c.; and where the soil is of such a nature at the bottom as to be repugnant to the nature of the vine, such as a rank clay, \&.c., I would recommend the paving the bottom, prior to putting in the new compost, to prevent the roots getting into a so:l which, if it should not prove altogether so injurious to their growth, may greatly deteriorate the flavour of the fruit, and is frequently the cause of the bunches ripening in a disorderly sort of manner, some of the berries becoming quite ripe, while others are quite sour. But the soil is not always the cause of grapes ripening thus, as bad pruning will often produce the same effects, as well as meagre ragged bunches. Indeed, a celebrated vine-grower, and who in his day was denominated the prince of gardeners, said that (speaking of France) if a vineyard was pruned badly one 
season, it would take seven years to bring it into a proper state of bearing again; and although I may not go the whole length of that assertion, this much I can add, that the knife is the life and spirit of fruit trees, when well handled, but their greatest enemy, in the hands of one not capable of using it properly.

Whether in a general forcing house or in different forcing houses, either constructed on the same plan or otherwise, the sorts of fruit trees chiefly selected for forcing, consists of peaches, nectarines, apricots, cherries, plums, figs, and grapes.

Although I would wish to refer generally to the explanatory lists in the Fruit Grower's Instructor for more full particulars, yet I think it will not be out of place here to name some of the best sorts for forcing, such as I would choose myself. I should therefore select them thus, according to the number required: take the sorts as they stand on the lists. At the same time I am not intending by this to prejudice any other valuable and esteemed kinds, but only recom- 
mending such as I know to be excellent in quality, and suitable for the purposes of forcing.

PEACHES.

1 Noblesse

6 Violet Hative

2 Royal George, smooth-

7 Millet's Mignion leaved

8 Red Magdalen, or old

3. French Mignion Royal George

4 Vanguard

5 Early Gallande

9 Early Admirable

10 Early Ann

NECTARINES.

1 Elruge

2 Red Roman

3 Violet Hative

4 Brugnion

5 Murrey

6 Italian

APRICOTS.

1 Moor Park

3 Royal Orange

2 Breda

4 Roman

CHERRIES.

1 May Duke

4 Archduke

2 Biggereau

5 Florence

3 Circassian

6 Waterloo

PIUMS。

1 Royal Green Grage

4 Coe's Golden Drop

2 Early Orleans

5 St. Looe

3 Late Orleans

6 Blue Gage 
SORTS PROPER FOR FORCING.

F1GS.
1 Large White Genoa
4 Black Ischia
2 Black Italian
5 Malta
3 Large Brown Ischia
6 Green Ischia

GRAPES.

I Black Hamburgh

2 Royal Muscadine, white

3 West's St. Peter's, black

4 White Muscat of Alexandria

5 Black Prince

6 Lombardy, red
7 New White Sweet Water

8 Biack Damascus

9 Black Muscadine

10 White Frontinac

11 St. Peter's, very black

12 White Syrian

PROPER SEASONS AND METHODS OF PLANTING TREES FOR FORCING.

Par. 29. - The month of November is decidedly the best in the year for planting fruit trees, and when the wood becomes tolerably firm, and the leaf falls freely, the earlier in the month the better, as they will in that early season produce fresh roots almost immediately after planting, which is of considerable importance, particularly when they are intended for immediate forcing, although in open weather they may be removed in December, January, 
or February; the trees should be carefully taken up, with good full roots, and if convenient, to remove them with balls of earth, it will be of grat advantage, when intended to be forced the same season.

The trees (except those that may be brought in with round heads in pots or otherwise, for forcing in the centre of the house) ought to be at least two years trained in the wall-tree order; and for peaches, nectarines, and apricots, where the house is chiefly to be devoted to their forcing, I would recommend one row at the back of the house, planted against a neat trellis of thin wood or wire work, fixed near to the wall, about eight or ten feet apart. These should be dwarfs, and be careful not to plant them too deep, only. thoroughly cover the roots, leaving the stem of the stock as much above ground as you conveniently can, to prevent the tree sinking below: where it was budded; and if required to have the back wall covered early, some standards or half standards, with stems three or four feet high, according to the height of the house, may be planted between the dwarfs, but these should be 
removed when the dwarfs require their room, as it would prove a loss rather than a gain to have them too much crowded.

The next and only other row of trees that I would recommend to be planted in the peachhouse, is along near the front path, these also previously trained as before described. The plan I am about to describe is one of the best methods I ever witnessed; have a thin iron frame-work constructed in a semicircular form, about the substance of iron hurdles generally used to protect pleasure grounds, \&c. from sheep; this should be fixed along the front within ten or twwelve inches of the pathway, and made to bow over the centre of the bottom of the house, supported by uprights, fixed at necessary distances along the back, near to the footpath, with strong iron wires run through the frame-work, about five or six inches apart to train the trees to; by this plan the whole of the centre of the house will be covered with fruit trees, as well as the back, and the frame-work being bowed over, it will very little obstruct the sun from the trees at the back, as the frame should be made to 
rise more upright at the front and towards the middle more gradual, and along the top nearly flat, the height at the back not being more than from three and a half or four feet, unless the house is very lofty; in this way the trees will bear exceedingly well, and the fruit become very fine, and also during the time of ripening, the fruit is easily prevented from falling to the ground by placing a net underneath. The house thus planted may be forced by fire heat in the usual way, with flues if preferred; but in this case I should decidedly prefer hot water, both for convenience and appearance, as the pipe with returns may be ranged along the centre under the frame-work, and will scarcely be perceptible to the casual observer, and also along near the front glasses, where if a frame is made between the foot-path and the sashes for the forwarding of flowers, French beans, strawberries, or what might be required, the pipes would be also nearly concealed underneath. If vines are introduced, they may be planted either inside the house or on the outside, and admitted through an aperture made for the purpose; also many 
useful things may be raised under the centre frame, such as small salads, early rhubarb for tarts, tarragon, mint, \&c.

When the centre of the house is left open for forcing generally, many sorts of fruits may be forced therein, either in pots plunged in the earth, or established trees in a bearing state turned out of the pots and planted immediately without disturbing the balls; to effect this the more easily, let the earth in the pots become rather dry, and they will come out of the pots with little trouble, and without injury to the balls.

Let me here remark, that it is by no means a good method to force trees the first year after planting, particularly when remored from nurseries without balls, therefore in all new-planted houses it is desirable for the future welfare of the trees to let them remain open and fully exposed till the following season, and then on]y a small quantity of fruit should be allowed to remain on each tree, particulary if the trees had not received more than two years training when planted. 
NARROW GLASS-HOTSES FOR FORCING, PRINCT-

PALIY BY FIRE-HEAT OR HOT WATER.

Par. 30.-Glass houses of narrow dimensions for forcing fruit trees principally, are sometimes erected (for forcing with hot water or fire heat) against a south wall eight or ten feet high or more, width about five or six feet, and length of any extent that may be required, the whole enclosed with glass moveable sashes (in proper sloping frames) made to slide up and down as occasion may require, from a low front wall about eighteen, inches high, to the top of the back wall; the pipes for hot water or flues for fire-heat, may be rangea along near the front, or down the middle, or along the back part near the wall, the pipes should be raised a little from the ground, and if heated by flues, they should also be raised on low arches, that by being detached from the ground, the house will receive the benefit of the whole of the heat: the trees may be trained to the wall; but if the fiues or pipes are carried along the back close to the wall, it will be necessary to have a trellis 
ten or twelve inches from the flues; or the trees may be planted next the front, and trained up parallel with the glass to wire work, properly arranged for the occasion, about eight or ten inches from the glass, by this latter method the sun has great influence in forwarding the fruit and bringing it to early perfection.

These kinds of glass slips for fruit forcing, may be of long dimensions, and so contrived that part of the trees may be forced one year, and part another, by having the frames and sashes of equal size, so that they may be removed from one division to another, and by giving the trees one or two years' respite, occasionally, exposing them fully to the open air, will greatly renovate their constitution, and strengthen them for future forcing.

FORCING FRAMES FOR FORCING FRUIT-TREES

BY BARK-BED HEAT ALONE.

Par. 31.-In large forcing establishments, besides the foregoing plans for forcing peaches, nectarines, \&c., a kind of forcing frames are constructed, wholly of woodwork at the back, front, 
and ends, made of strong deal boards five or six feet high in the back by two feet in the front, both ends corresponding; in width about eight feet, and the length for one tree ten feet, and so on for two or more trees, at ten feet apart, each frame to have three lights, or sloping glass sashes, with rafters across the frame for them to slide on, and in the back a pannel made to slide, for entrance.

The tan-pit below may be formed either of brick-work or post and planking about three feet deep, the trees are planted in the font, outside, on a raised border, the stem of the tree inclining to the frame, and a piece cut out of the frame to let in the stem, the head admitted within, and trained up about eight or ten inches under the glasses; the bark bed to be renewed at the commencement of each forcing season; and by this plan also, peaches and nectarines will come to good perfection early, but I may observe, it is not very convenient, neither is it very generally adopted. 
VINERY, OR HOUSE PRINCIPALLY FOR FORCING GRAPES, METHODS OF OBTAINING THE PLANTS, WITH USEFUL OBSERVATIONS.

Par. 32.-Where a house is designed chiefly for forcing grapes, the fruit may be brought to the finest possible perfection, much earlier than in forcing houses intended for other fruit trees, as the vine will stand quite as much heat or more, as is usually allowed in the pinery; and by forcing some of the early sorts among the fine large late varieties, this delicious fruit can be produced in May, and by divisions in the vinery, a supply may be continued throughout the summer and autumn.

The vines are generally planted inside the house, some near the back wall, about three feet and a half apart, and trained to trellis work; and others in a border along the front near the pipes or flues, and the stems trained up to the rafters, and as they branch out, the young shoots are trained to wires or thin crossbars of wood, about six inches from the top glass; sometimes the vines are planted on a border 


\section{VINERY FOR FORCING GRAPES, \&C.}

outside the house, and admitted through holes, and conducted to the rafters; but I am of opinion, with must other practical men, that for early and strong forcing, it is better to have the stem inside; but this is not of so much consequence where they are introduced into peach houses, or other glass houses only requiring moderate heat.

Like other fruit trees, the best time for planting is in November, and if then omitted, about the middle of February is the next best season; the plants should be two, three, or four years old for planting in the vinery, particularly if raised from eyes, and if established in pots, they are far preferable; should the roots be through at the bottom of the pots, by breaking the pots to pieces, the balls can be preserved entire. The different sorts may be obtained at most of the respectable nurseries, raised either by layers or from eyes. There appears to be a diversity of opinion among practical men as to which is the most preferable for planting, the layers, or those raised from eyes; some contending, that the layers come into bearing earlier than the eyes, 
OBTAINING TREES FOR FORCING, \&c. 233

while the eyes receive the preference for making a more rapid growth when first planted; however, I have seen both succeed well, when'properly managed, in growth, and likewise produce. Although in Par. $28 \mathrm{I}$ have recommended a limited number of sorts which are known to be good, still there are several other fine varieties of grapes which should not be omitted where the vinery is extensive; also, when the vines have grown large, they ought to be thinned, for there will not be anything gained by having the house too much crowded.

HOW TO OBTAIN FRUIT TREES INTENDED FOR FORCING, WITH A NECESSARY CAUTION.

Par. 33. - When selecting fruit trees for forcing, in order to have such sorts as are recommended in this work, or other favourite sorts, established nurseries of known respectability, and the proprietors thereof of known judgment, should be applied to for the same, as the best security against being supplied with a spurious kind, or the tree worked on a stock which is not suited to the variety, the latter being of con- 
234 obtaining trees for Forcing, \&C.

siderable importance; for although the bud may take, and the tree grow freely for a time if worked on an improper stock, they will frequently, when coming into bearing, dwindle away; and although some may exist for years, they are merely an incumbrance to the house. Here I am speaking more particularly of peaches, nectarines, and apricots, as it cannot be expected from the general practice of gardeners that they should be acquainted sufficiently with the wood of the different kinds, to know them by, while in a young state in the nursery, or the nature of the stocks on which the different sorts ought to be budded; and it is very mortifying when the trees come into bearing to find, instead of a favourite peach, perhaps a nectarine substituted, or some other peach of inferior quality.

\section{MANAGEMENT OF VINES, AND SEANONS FOR FORCING.}

Par. 34.-Prior to the vines being forced, it will be necessary for them to be properly pruned, upon which subject I almost fear to hazard an opinion, there being so many different methods 
adopted, together with the almost impossibility of conveying anything like straightforward directions for the different varieties, and the various prunings they have to go through. At the winter pruning, it has now become almost an invariable rule to spur indiscriminately to one or two eyes, and for a general rule perhaps it may be the best. This practice has however been adopted, chiefly in consequence of its having been discovered that one of the finest forcing grapes, the "Black Hamburgh," succeeds decidedly best by this practice; but this is not the case with every sort; for some, although they mày produce a good supply of bunches, they are very apt not to grow regular and handsome, neither do some sorts ripen so regularly as when produced from the young wood, lett three, four, or five buds long according to their strength; but much depends upon the summer, or rather the spring pruning, (for the first pruning is the principal to insure a crop for the ensuing season;) at this season it is too common a practice to remove the greater part of the small shoots which have no fruit on them, while I should wish it to 
be borne in mind that these small shoots, (I do not mean little dwindling stuff,) if allowed to remain, and cut back to the second or third bud according to their strength, will generally produce fine bunches, while I have remarked that the young wood which had borne the fruit, when cut back, did not produce them so regular and fine, this I have observed to be the case with such sorts as the sweet water, royal muscadine, \&c.; but I feel myself getting into a labyrinth, and must conclude these observations by the excuse set forth at the commencement of the paragraph, with this only addition, that nothing but great practice among vines can conrey anything like the directions for pruning, which the vine requires, leaving out of the question the different varieties, but hope these hints will not be taken amiss by the experienced man and extensive grower, and that it may lead them to watch the nature of the different kinds.

The winter pruning may be done any time in December or later, when the forcing does not commence early, always cutting back to three 
or four buds some of the strongest young shoots of the last summer's growth, to produce a regular supply of bearing wood from the bottom of the vines, some of which should be allowed to run nearly their full length during the summer, but should be cleared of their lateral shoots, which will prevent too great a cluster of twigs, and give light to the house and strength to the main buds of the principal shoot, from which, when allowed to remain of tolerable length at the following winter's pruning, will generally produce the largest and often the finest bunches, probably two, three, or more on each.

In the early part, or about the middle of January, is the general season for setting the vinery in motion; if there is a pit within, which is intended for tan, let the bed be made, the warmth from which will bring the vines into activity; or if the bark bed is not required, the forcing may commence by fire, steam, or hotwater heat alone, whichever bas been allotted for the purpose; but with or without a bark bed, the assistance of fires for warming the 
house by flues or pipes will be very essential after the first week or ten days of the house having been heated by the bark bed; the fires should be made every evening, and kept up till nine or ten o'clock to warm the air of the house till morning, when it will be necessary (particularly if there be no bark bed) to revive the fires, and in cold weather continue them the whole day moderately; but when the season is more advanced, and the sun becomes powerful, the fires may be discontinued after the morning, until the evening, and thus the heat may be managed till May, or later, if the weather proves cold, or be guided more especially as the fruit appears to ripen, generally keeping up the temperature equal to the pine stove; when the vines begin to break, or rather the shoots begin to put forth, give air moderately in the middle of warm sunny days, either in the front, or by drawing open some of the top-glasses next the back, and more freely as the warm weather advances.

As the summer growth of the vines advances, the young shoots require great attention; all 
those which have fruit on them, and also such as may be considered eligible for reserving for bearing the next season, should be trained in regular order, and should be kept clear of all laterals and twigs of a useless nature; and after the bloom is over, and the fruit well set, the shoots on which the fruit appears should be shortened to about two joints above the fruit; or where there are two bunches, and the shoot weak, one bud only may be left above the top bunch, this will greatly encourage the swelling of the fruit.

While the berries are small, and the bunches appear likely to become crowded, some of the most irregular berries may be thinned out with a pair of pointed scissors, which will give the others room to swell, and cause the berries to grow regular, and the bunches to become handsome.

Vines which are grown in the pinery, or pine hothouse, generally produce ripe fruit in the same order, and in the same seasons as those above stated in the first forcing of the vinery, which is generally about May a few, plentiful in 
June and July, and so on until the succession is ready.

GREEN HOUSE, OR COLD GLASS HOUSE FOR VINES.

Par. 35.-Vines are frequently introduced into greenhouses when constructed with a glass roof, similar to that of the hothouse, the vines planted in a border outside of the front, and carried through to the rafters inside as before directed, and treated in the same manner as the hothouse, selecting such sorts as are tolerably early in their ripening, such as the royal muscadine, black Hamburgh, \&c. ; and if the house is furnished with fire flues, or hot water pipes, they may be moderately heated occasionally in March, April, and May, as the weather may dictate, this will forward their fruiting; and in such houses, very abundant crops of fruit are brought to good perfection, six weeks or more, before those grown in the open air ; and even if there is not any artificial heat internally, the benefit of the sun through the glass, tugether with the protection it affords in cold weather, 
will generally produce good crops, and con. siderably forward the ripening of the fruit, and in most seasons, superior to those against the walls in the open air.

PEACH HOUSE, ITS CULTURE, AND GENERAI UTILITY FOR FORCING.

Par. 36. - The peachery is principally appropriated for forcing peaches, nectarines, and apricots, and if required, many other sorts of fruits; such as plums, cherries, figs, vines, \&c.

Previous to the forcing being commenced, the peaches, nectarines, \&c., should be properly pruned, according to their orders of bearing, nearly in the same way as is usually practised for fruit bearing trees in the open air. The peach house is also of great utility for forwarding many useful and ornamental plants, as directed in other hothouse culture.

The forcing is generally begun about the middle, or towards the end of January, or sometimes early in February; if there is a bark pit, the bed should be made a week or ten days prior to commencing the fires; 
when the fires are began, either for flues or pipes, they must be continued every evening moderately till nine or ten o'clock, and so left to cause proper warmth in the house during the night, and be revived in the morning, if cold weather; and if there be no bark bed, continue the fire throughout the day, but when there is a bark bed, the day fires will only be necessary in sharp, cutting weather, or during severe frosts; always, however, endeavour to keep as regular a heat as possible, which ought not to exceed sixty degrees, or thereabouts, as a greater heat is very apt to prove unsuccessful, not only to peaches and nectarines, but also to most other kinds of tree fruits.

Air should be admitted only a little, at the early part of the season, and that chiefly in the middle of the day, while the sun is out, and in greater proportions, as the spring and warm weather advances, as the power of the sun will sometimes increase the heat very considerably; then also increase the admissions of air by degrees, until the middle of the day, after 
which the diminution should be also equally gradual.

Watering will likewise be necessary to the borders, when they appear dry, and sometimes over the trees, before the bloom expands, and also after the fruit is well set; but during the time the trees are in bloom, and the fruit setting, no water should be given over the branches, as that will prove very injurious to the setting of the fruit; but when the fruit begins to swell, water may be applied over the branches, once or twice a week, in fine weather, in a gentle manner, with a syringe, or those in the lower part of the house, through the fine rose of a watering pot; this should generally be done of a morning, and with soft water, either prepared, or from a pond, but rain water is at all times to be preferred.

As the fruit advances in growth, and particularly towards maturity, allow a considerable high heat from the sun, by large admissions in the middle of the day, opening in the morning, and shutting gradually, as before directed, as the sun is highly essential, both for assisting 
the swelling and colouring of the fruit, and also for producing a fine rich flavour; by this practice, peaches and nectarines will ripen in the greatest perfection, in May and June, and the late sorts in July and August.

FORCING HOUSE FOR CHERRIES, WITH ITS FURTHER USES.

Par. 37.-In large forcing establishments, a house is allotted chiefly for forcing cherries, and which is called the cherry house; this house may be constructed on the same principle as the general forcing houses, and is generally forced by fire heat, or hot water only; and the whole, or part of the bottom space, composed of proper soil for planting the trees in; formed into one or more borders, ranged the long way of the house, and the trees planted therein; the trees should be of an age for immediate bearing, and some may be trained, and planted against a trellis near the back wall, or the whole may have round heads, with a moderate share of branches, some dwarfs and others standards, planted in rows across the house, placing the tallest behind 
and lowest in front; and likewise along the front may have dwarfs planted or brought in in pots. Vines may also be planted inside or in a border outside, and treated as directed in other forcing departments. Refer to the proper paragraphs for sorts recommended; but I may here add, that the May-duke is generally the most successful, and ought to be planted more plentifully than other sorts.

The cherry house is generally set in motion (commencing moderately) about the end of January, or beginning of February; and the directions given for the management of the peach house will mainly apply to this, and ripe fruit may be expected about the end of April, or beginning of May, also many other useful articles may be produced in the house, in all vacancies on shelres, or elsewhere.

OBSERTATIONS RELATIVE TO THE SEASONS,

AND METHODS, OF FORCING GENERALLF.

Par. 38.-Haring given such instructions for forcing generally, which I know to be safe, and in the most clear manner my judgment could 
dictate, and which from a long and extensire practice, and close application, has convinced me, that what I have recommended, if properly attended to, will prove successful; I will conclude this part of the subject, by a few general remarks thereon, and which may be considered applicable, or nearly so, to the whole.

The most general time for commencing forcing, is from the middle of January to the beginning of February, although it is sometimes commenced earlier, and sometimes later; when the forcing is to be assisted with a bark bed, it is an advisable plan, to make the bed a week, or ten days, or a fortnight before the fires are commenced; in some cases, dung hotbeds are substituted; these should also be made ten or twelve days before the fires, to get: settled, or to allow the rank steam to evaporate, then add ten or twelve inches of tan at top, or in the absence of tan, some light sifted soil, in which to plunge pots, or for raising articles therein. When the fires are once commenced, either for flues or pipes, they 
should be continued every evening, and kept up till nine or ten o'clock, and left in such a manner, that it will continue to warm the house durin. the night; but this part must greatly depend on the nature of the weather, and the season of the year; and where there is no bark, or other hotbed, the heat of the flues or pipes should be revived in the morning, and continued moderately throughout the day; and where there is a bark bed, this will also be necessary on cold mornings, and likewise all day, in severe weather; as the season advances, the thermometer should be constantly watched, and the artificial heat be increased by fire, or decreased by air according to the power of the sun, thereby keeping a moderate kind beat, which is not only desirable, but absolutely required for tree fruits; the standard for artificial heat being sixty degrees, and ought not to vary after the fruit is set, more than four or five degrees under or over

The vinery is altogether different, the house may be kept at a much higher temperature, particularly when they are required to be 
brought forward very early; in that case, the heat may be kept up to the height of the pine stove; but where vines are allowed in the peach house, the same heat must content for them, which is allowed for the peach trees.

The fires shoula be continued as above directed, till April or May, or longer, to be guided generally by the ripening of the fruit; and, as the weather proves more or less favourable; and thus, as the season advances, and the power of the sun increases, lessen by degrees the heat produced by the pipes or flues.

ADMITTING AIR, WITH INSTRUCTIONS FOR WATERING IN THE DIFFERENT FORCING HOUSES.

Par. 39.-As the admission of air, and a proper mode of watering is of considerable importance in all kind of forcing, I will make a few observations thereon, being satisfied that many failures take place through neglect, or a want of knowledge on the subject.

From the commencement of the forcing, I 
would recommend fresh air to be admitted into the house every day, unless the frost is intensely severe, or the air so saturated with fog, or otherwise filled with humidity, that it is really dangerous; otherwise, if it is but five minutes in the day, with merely a crack here and there at the top, to let out a little of the confined air, it will be of service to the plants; and during the early part of the forcing, from half an hour to an hour, or from that to two, in the middle of the day, being guided by the warmth of the external atmosphere, and embracing as much as possible the opportunity when the sun shines; but still, at the early part of the forcing, the air should be admitted spar. ingly, by sliding open some of the glasses only; but, as the season advances, and the sun has proportionate influence, so should the admission of air increase from eleven till two or three; and in very warm weather, and the power of the sun is great, the house may be opened earlier in the morning, and shut later in the afternoon, and so be guided according to the 
state of the weather, but always be sure to shut close, whenever it turns suddenly cold.

Watering is another most essential thing to be attended to, for much injury is often done to the plants, through neglect, irregular, or improper waterings; the borders in the forcing house, where the trees are planted, should be moderately watered when they appear dry, also occasionally all over the trees, except while in bloom; for then it is apt to destroy the fructification, by preventing the proper action of the farina; but after the fruit is well set, repeated waterings over the branches will be beneficial. The above remarks will apply to tree fruits generally: likewise plants in pots, which may have been introduced into the forcing house, they should be watered very sparingly at first, but the watering should always be repeated immediately they appear dry; and as they advance in growth, and particularly when coming into bloom, they will require to be watered much more copiously; always use rain water for preference, and in the absence of that, use soft pond water, and it is very desirable to have a 
tank, with the water kept about the beat of the house; for by using cold water, particularly in very cold weather, it causes a great chill to the trees and plants.

PRUNING FRUIT TREES IN FORCING HOUSES, WITH INSTRUCTIONS FOR TRAINING.

Par.40.-Pruning of fruit trees in the forcing house, may be done any time after Norember, till near the time for forcing; but generally for peaches, nectarines, \&c., it is better to prune them two or three weeks before the forcing is commenced; the methods usually adopted for pruning in the open air, may serve as a guide for pruning in the forcing house. I may here remark, for the information of those who are accustomed to prune peaches indiscriminately, by cutting back all the young wood; that some sorts, particularly some of the finest varieties of French peaches, and the best bearers, are not unusually covered with bloom buds, nearly all up the young fruitbearing wood, without a leaf bud to cut to.

When such is the case, the shoots should not be shortened, which is the general practice, for 
the top bud of the shoot is sure not to be a bloom bud. I scarcely need remark, that when there is not a bud to shoot above the bloom, although the fruit may set and swell till it gets to a tolerable size, it will never come to perfection; at the same time, by cutting back a sufficient quantity of young wood, or the last year's bearers, the body of the tree may always be kept well supplied with bearing wood.

In the winter pruning, it is likewise necessary to free the trees of some of the most unfruitful wood, and such of the old that is unserviceable, to make room for the young bearing wood; and I wish particularly to impress on the minds of my readers, the necessity, I say absolute necessity, if you wish to preserve the health of the trees, of removing all little dead snags, and take care that your knife is sharp, and remove them clean until you cut to a sound place; for simple as those little snags may appear, they frequently cause the tree to canker, and the constitution of the tree (if I may use the term) to become diseased; and if any blister or canker appears, do not fear to use the knife, and make it clean 
till you come all round to sound bark; if the tree, could speak it would thank you.

Having retained a sufficient quantity of the one year old shoots on all parts of the tree, after cutting away the ill placed, let them be trained at regular distances to the trellis: such of the peaches and nectarines which it may be thought advisable to shorten the young shonts of, that are left for bearing, the usual practice is to cut them back about one-third; but it is not customary to shorten plums, cherries, nor figs, but as cherries and plums will bear for several years on the same branches, upon small side spurs, these, at the winter pruning, must not be removed, at least as long as they continue fruitful, and at this season, retain some young well-placed shoots, to supply the places of the old as they decline bearing.

The summer pruning of trained fruit trees, particularly peaches and nectarines, rests chiefly with preserving a sufficient quantity of the most regular side young shoots for fruiting the ensuing year, and the removal of the foreright shoots; and those which are ill placed, and all such which appear superfluous, and of improper strong 
growth; this pruning is best performed when the shoots are about five or six inches long; then let the young shoots which have been retained be trained in a regular manner to the trellis, \&c., and the training be repeated as the growth of the trees may render it necessary during the summer.

BLIGHTS AND INSECTS ON TREES, HOW TO PREVENT AND DESTROY IN FORCING HOUSES.

Par. 41.-Forcing houses are at times infested with small insects of various kinds, and the fruit. trees are at times seriously attacked, blighting the leaves, and causing them to crumple and shrivel, and the young shoots also frequently become stunted, which often proves very prejudicial to the fruit if not early attended to, for when they appear, they generally increase very fast.

The most effectual way to prerent and destroy them is by smoking the house with tobacco; this may be done with fumigating bellows, or occasionally smoking the house thoroughly with a smoking pot, with burning tobacco therein, having a hole in the side to blow the tobacco 
with bellows, in this way a strong thick smoke can be produced, which will greatly assist in destroying the vermin; but as many will fall to the ground apparently lifeless from suffocation, but will afterwards recover and ascend the trees again, a tolerable watering over the borders, immediately after the smoking, will effectually destroy them, also by syringing the trees it will dislodge those which may not have fallen; this system of smoking is by no means to be dreaded, on the contrary, it is beneficial to the trees, and if occasionally performed even in the absence of insects, it will assist the growth of the trees, and also promote the swelling of the fruit, and with proper care and attention the house may always be kept free, at least sufficiently free from insects, to prevent them from being seriously injurious.

THE SEASONS THE DIFFERENT VARIETIES OF FRUIT GENERALLY ATTAIN MATURITY IN FORCING HOUSES.

Par. 42.- By the foregoing practice in forcing fruit trees, the different varieties may be expected to ripen in the following order. 
Grapes, by early and powerful forcing, some may be expected in May, and a general crop in June and July, and the late kinds in August.

Peaches, nectarines, apricots, figs and plums, in May, June and July; cherries in April, and early in May; strawberries in March, and a succession continued, according as they are introduced into the house.

TREATMENT OF FRUIT TREES AFTER FORCING.

Par. 43.-After the forcing season is over, and the fruit gathered, the trees ought to be exposed to the open air as much as possible, by removing the whoie of the moveable lights both above and below, to give them the benefit of the sun, air, rains, dews, \&c., during the remainder of the summer and autumn, this will harden the young shoots, and tend greatly to strengthen the trees for the next forcing season. 


\section{CHAPTER III.}

Contains directions for growing Melons, with instruction: how to raise early Strawberries; also many useful and ornamental plants in forcing houses.

GENERAL OBSERVATIONS.

Par. 44.- In the last chapter I have laid down rules for the forcing all the leading varieties of tree fruits, with such illustrations and comments, which I think will render the practice easy to every one who has any pretensions to gardening, and which rules, if properly carried out, will be found to produce the most successful results. It is now my intention, in order to render this work as complete as possible, in 
every thing relating to forcing fruits, to furnish directions for growing melons; likewise the most approved methods of forcing strawberries; to which will be added some useful remarks, for forcing ornamental plants, in the various departments of the forcing houses; with directions for raising many useful articles for culinary purposes.

NATURE OF THE Melon PlaNt, its cUlture, AND DESCRIPTION OF THE FRUIT.

Par. 45.-The melon plant, which is one of the most tender belonging to our kitchen garden, is an annual of slender trailing growth, and upon these long slender herbaceous vines, they produce fruit remarkable for its size and richness of flavour; indeed by many it is held in quite as great estimation as the pine; therefore an account of its culture will not be contrary to the spirit of this work, and more particularly as the melon cannot be brought to anything like perfection without the assistance of hotbeds; and by the directions which will be hereafter given, the fruit can be produced in perfection in May and 
NATURE OF THE MELON PLANT, \&C. 259

June, and supplies continued till October and November.

The plants are always raised from seed; those required for the early crop are sown in winter, and for the main crops in spring; the plants must be raised in a hotbed, which is generally done in a small one first, where they remain till two, three, or four inches high, when they will be of a proper age for transplanting into the large melon frames, where they are to remain for fruiting; but where there is a hothouse with a bark bed, or other sufficient heat to raise the plants in, if a small dung hotbed is not wanted early for other purposes, the seed may be sown therein, and be transplanted direct into the fruiting frames; but the general methods will be found more fully explained in the following paragraphs, under their proper heads.

DIFFERENT TARIETIES OF THE MELON, WTTH OBSERVATIONS.

Par. 46.-All the varieties of melons may be considered exotics of very tender nature; of these, the Romana is one of the earliest and 
most plentiful bearers, and is, although small, a very good fruit. The cantaleupe melons are highly esteemed, the flavour being very superior, and greatly prized by those ford of this fruit for their extreme richness; they grow large, of a roundish form, and deeply ribbed; and although they do not bear so plentifully as some, they are generally preferred for the principal crops for private use; the green flesh, the smooth green rind, and the common ribbed, are also very fine, and the above may be considered equal, if not superior, to the other varieties for general culture; yet, as others have their admirers, I will give a list of names of those usually cultivated:

Cantaleupe Melon

Rock Cantaleupe Melon

Silver Cantaleupe Melon

Black Rock Cantaleupe Melon

Orange Cantaleupe Melon

Early Romana Melon
Green-fleshed Melon

Green Smooth Melon

Oblong Ribbed Melon

Netted Plain Melon

Netted Ribbed Melon

Large White Melon.

The fruit of the different varieties of melons varies greatly both in size and appearance, being 
round, oblong, oval, smooth-rind, depressed, ribbed, netted, carbuncled, mostly red fleshed, and some green fleshed, \&c., the whole of the varieties producing a rich and highly esteemed table fruit when ripe; the young green fruit is also used for mangoes.

SOILS PROPER FOR GROWING MELONS.

Par. 47.-The compost for growing melons in, should be prepared in the autumn, prior to its being used, or at least some considerable time before it is wanted, in order that it may be well mixed, and in proper condition to receive the young plants; for this purprse take half or two-thirds of rich light surface loam, dug fresh from a common or pasture field, the remainder of thoroughly rotted dung from old hotbeds, and rich garden mould, in about equal proportions; or if a part is rotten cow-dung, it will prove beneficial: those should be all thoroughly mixed together in a heap or ridge where it is exposed to the sun, rains, \&c., turning it over three or four times to well break, and cause it the more effectually to mix; and before placing it in the frames, take 
such quantity as may be required into a shed under cover for two or three weeks, that it may dry to a proper moisture for the hotbed.

PREPARING DUNG, \&C. FOR THE HOTBEDS FOR RAISING MELONS.

Par. 48.- Hotbeds for growing melons are generally made of stable dung, being the most easily obtained; of which prepare a sufficient quantity in proper time to have it in good order by the time the beds are required to be made, choosing that which is fresh and in a lively, steaming state, the long and short mixed up together in a heap, letting it lay for a week; then turn it over, and well mix it, and in about another week turn it over again. By this process it will properly ferment, discharge the rank steam, and become of a proper temperature to be made into a bed; and when the heat of the bed declines, and linings are required, prepare a sufficient quantity from time to time for that purpose also. Melons are likewise grown very successfully in bark hotbeds. These beds retain a 
long regular heat, choosing the tan in the same state as described for bark-bed pits.

SEED PROPER FOR SOWING.

Par. 49.-With regard to the seed of melons, it should be saved from the earliest and finest fruit, which has thoroughly ripened; and when three or four years old at the time of sowing, it generally proves more successful, as the plants raised from new seed grow very luxuriantly, in which case the fruit seldom sets so soon or freely as on those plants raised from old seed.

OBSERVATIONS ON RAISING MEIONS IN DIFFERENT WAYS; THE TIMES FOR SOWING THE SEED; REMARKS ON WATERING, AND SEASONS OF RIPENING.

Par. 50.-Speaking generally of the culture of melons, they are raised chiefly in three principal crops, although, if preferred, they may be sown more frequently, at two or three weeks interval. The first is sown in January or February, from which, ripe fruit may be expected in May and June, and sometimes as early as April; 
264 OBSERTATIONS ON RAISING MELONS, \&C.

but for a more general and certain crop, to be also cultivated in frames under lights, the end of February or beginning of March for sowing the seed proves the most successful, and the fruit will come to perfection about July and August. The third and last crop should be sown late in March or beginning of April, for planting out under hand-glasses, to produce ripe fruit in August, September, and October.

When the plants have grown too large for the hand-glasses, (in the absence of frames with lights,) oiled paper frames may be placed over them, by which means good crops of late melons are produced with proper management, which will hereafter be fully explained.

Melons in any stage of their growth are by no means fond of excessive moisture, neither to the earth or over the plants. It will cause the roots to rot, and frequently the main stem; it will likewise prevent the young fruit from setting kindly, and much wet will considerably deteriorate the flavour of the fruit, if applied while ripening. Consequently they ought to be kept at all times in a very moderate state of moisture. 
HOTBEDS FOR RAISLNG MELONS, \&c. 265

METHOD OF MAKING HOTBEDS FOR RAISING

MELON PLANTS; WITH THEIR MANAGE-

MENT THEREIN.

Par. 51.- - Having ready for sowing such kinds of melon seed as may be intended for the earliest crop, make a small hotbed for a one light frame, (a larger if required for other purposes, making the bed with fresh stable dung, about three feet or three feet and a half high. Immediately place on the frame and glasses, which will defend the bed from the weather and draw up the heat sooner than when left open, giving vent to the rank steam, by raising the glass or glasses at the upper or north end. When the bed is of a proper temperature, place the soil or compost on the top of the dung inside the frame, about five or six inches thick. Then fill two or three garden pots or more (according to the number of sorts intended to be sown) with the same sort of earth, and plunge them a little way into the earth of the bed, sowing the seed therein, and lightly covering it; likewise sow some seed in the earth of the bed, in order to embrace a 
double chance of success; but the sowing in pots should in no case be omitted, in case the heat of the bed should prove too violent; and if that should happen, the pots are easily drawn up farther from the dung, or if necessary, quite out of the earth.

When the forcing of cucumbers has commenced, there will be no necessity for preparing a hotbed for raising the melon plants, as the same mean temperature is suitable to both; and the seed may be sown either in the earth of the cucumber hed, or in pots plunged therein at the back part of the frame. In either case, when the plants have come up three or four days, and while in the lobes or seed leaf, transplant (or what is more generally termed prick) them into small pots, two plants in each, and then plunge the pots in the earth of the hotbed; or some may be pricked into the earth of the bed, but they are much better in pots, as they are ready for turning out with the whole ball into the frames, where they are intended for fruiting. But while in the seedbed be careful to cover the glasses with mats every night, admitting air 
every day more or less as the weather will permit, by raising the glasses behind, from a mere crack to a quarter of an inch, an inch or more, in proportion to the heat of the bed and external atmosphere ; shutting close when extremely cold, but in moderate weather shut by degrees. Should there be a great steam and strong heat, which is sometimes the case in the early part after the bed is made, a small portion of air may' be admitted during the night, to give vent to the rank steam, covering the aperture with a garden mat, hanging over it from the top of the glasses. This same precaution may be observed in defending the bed in the day time, when the steam and heat may render it necessary to admit fresh air, in exceeding cold weather.

When the heat of the bed has become moderate, keep the glasses close at night, but give air in favourable weather daily. Cover the glasses every evening about sun-set with garden mats, one, two, or three thick, according to the heat of the bed, uncovering in the morning, and when the earth appears dry, give light waterings; and be sure in the early stage of the bed to 
examine it daily, and if the heat appears too violent, immediately draw up the pots, until the burning heat has subsided.

The plants may remain in the first or nursery frame till they have two or three rough leaves two or three inches broad; then they will be of proper growth for ridging out into the main fruiting hotbed.

MAKING THE FRUITING HOTBEDS FOR EARLY AND GENERAL CROPS OF MELONS; WITH THEIR MANAGEMENT THEREIN COPIOUSLY LAID DOWN. •

Par. 52.-We next proceed to prepare the hotbed for fruiting the melons: this should be made a week or more before finally transplanting the plants, or what is more generally termed ridging out for fruiting, in order that the bed may be of a proper temperature to receive them.

The bed should be made on the level ground, about three feet and a half high, of stable dung properly prepared, as before directed, and of such dimensions, horizontally, as the size and number of frames will require; but three light 
AND GENERAL CROPS OF MELONS. 269

frames are to be preferred for growing melons to maturity. As soon as the bed is made a proper height with the dung, and regularly levelled, place on the frame lights; and when the violent heat has subsided, which will generally be the case from about a week to ten days, bring in the earth, (that having been already prepared as before directed,) laying it in a round heap under the centre of each light, about a foot or fifteen inches thick, covering the other part of the bed. only about three inches deep, until the heat has become more moderate.

When the hills or ridges of earth have become warm, either on the same or following day, put in the plants in the middle of the hill, removing them from the pots with the balls entire about the roots. Place two plants under each light, but some consider one plant sufficient in each hill, and particularly of the cantaleupe. When planted, give a little water round the extremities of the fibres, and then close the frames to draw up the heat; but when the steam begins to get strong, raise the lights at the back half an inch or more to give vent, and in the same manner 
give air daily to the plants; or sometimes it is also necessary, in the early stage of the bed to admit a little air during the night, if the heat is violent and the steam strong; but in this case defend the aperture, by letting a garden mat hang over it from the top, and this will also be requisite in the day time, when the winds are cold and cutting; but when the heat is moderate, the frames may be kept close at night. Cover the glasses every evening about sunset with one or more mats thick, as the heat of the bed and the atmosphere will dictate.

It is a very essential thing in early hotbed - forcing to lay dry litter round the sides, tolerably thick, which will greatly defend the beds from snow and heavy rains, and the inclemency of the weather generally. This will greatly prevent their chilling, and the heat from suddenly declining, which is often the case when this is not done, and frequently proves very injurious to the plants, and sometimes ends in the loss of the crop; but by the above precautionary protection in an early stage of the hotbed, the heat will continue regular, and of much longer duration. 
AND GENERAL CROPS OF MELONS. 271

When the bed has become of a regular kind heat, bring in more earth, laying it first near the sides of the frame to get warm; then apply it round the hills where the plants are, likewise adding more on the surface of the bed between the hills, and by two or three earthings, by degrees the whole should be earthed up even with the top of the hills, and at each earthing press the mould down close; for by having the soil made tolerably firm and of the depth recummended, it will be sufficient to nourish the plants without much watering, particularly when the soil is of a loamy nature. Nevertheless, moderate waterings will be necessary at times, when the earth becomes dry; it should be given generally at a distance from the plants, but this should be very moderate indeed while the fruit is setting, and also while ripening, for while in a young state, if watered too abundantly, it will cause the fruit to turn yellow and decay, and when approaching to maturity, it will retard its ripening and injure its flavour; therefore never water over the fruit while in a very young state, but apply the water between the runners of the plants, 
pouring it out of the spout of the watering-pot on a flat piece of tile, that it may not disturb the earth, and the tile will cause the water to spread more over the surface. But after a full crop is thoroughly set and in an advanced state of growth, occasional waterings may be given moderately over the plants; but never water over the plants in the heat of the day, while the sun shines powerfully, but either in the morning about eight or nine o'clock, or in the afternoon after three. When the runners are pushing forth, they should be stopped by pinching, or cutting off the tops of the shoots, to promote the strength of the plants, and to furnish more runners, and the new runners should also be stopped at the third joint, to get a further supply, to fill the bed with bearing vines; and as they advance in growth, train them in proper order over all parts of the bed.

It will be requisite to admit air every day, except in exceedingly cold weather, by tilting the glasses at the back, in proportion to the heat of the bed and the temperature of the atmosphere, closing the lights by degrees in the after- 
AND GENERAL CROPS OF MELONS. 273

noon; and all times when the weather changes very cold, shut close, and also every night, and more particularly when the bed is an advanced state.

The covering the glasses with mats by night may be continued, more or less, till the middle of June, to be guided by the season and the temperature of the weather, uncovering in the morning about sun-rise, or as soon after as convenient. In hot weather, when the sun appears too powerful for the plants, so as to cause them to flag, afford them a slight shade, by laying over the glasses a thin mat, or a little light litter for about three or four hours, during the great heat of the sun, in the middle of the day.

Should the plants become very crowded in the frame, by the vines becoming too numerous, thin them out by cutting away some of the weak unfruitful runners. Likewise remove decayed clusters of male bloom, but not the fresh blossoms, while the fruit is setting; and thin out the old leaves, and always remove those which become decayed. 
Also should the plants press against the glass, and the frame become much crowded towards the end of June or beginning of July, the frame may be raised at bottom a few inches, to give more room above.

When the fruit has advanced to a tolerable size, it is requisite they should be turned occasionally, which will cause them to be more regular in their growth, and assist the fruit in ripening more equally.

It is generally necessary to continue the glasses constantly on the frames till the middle or end of June, but should be raised high in hot weather. After this time they may be taken off occasionally on dry days, but should be put on generally at night; likewise the lights should always be kept on in wet or other unfavourable weather.

The later crops of melons should be protected by keeping the glasses for the most part over the plants, giving plenty of air in warm weather, and about the middle or end of August, (particularly if the season is wet and cold,) it may be requisite to line the frame and bed round 
with dry litter or waste hay; and if there is any fruit left, which is not expected to ripen till October, give an additional lining of hot dung about the middle of September. At this late season it will greatly assist the ripening of the fruit, by promoting a moderate bottom heat.

MANNER OF TREATING MELONS WHEN IN BLOOM.

Par. 53.-When the plants come into bloom, a good heat should be kept, and as regular as possible; this will greatly assist the setting of the fruit. Also, at the early season of the plants blooming, when bees and other winged insects are scarce among the flowers, impregnating the female blossoms with the male, generally proves of considerable service, by causing the fruit to set well, and swell off immediately. This is done in the same way that is usually practised in growing early cucumbers, by taking a fresh male flower, commonly called the false blossom, on the same day, both the male and female expand; take away the petal or flower leaf of the male bloom, leaving only the central part, which 
contains the farina; apply this to the centre of the female, to discharge some of the farina therein, and then withdraw the male part.

The male and female flowers are both produced on the same plant, the female always showing the young fruit at the base of the flower. As the fruit sets and begins to swell, either pinch off the runner to the third joint, or turn the point of the runner inwards. This will assist the young fruit to swell, by directing the nourishment of the plant more effectually to it; also as the fruit sets and begins to swell, place a piece of tile underneath each, to keep it from rotting, which, if neglected, it will frequently do, through the moisture arising from the earth; and if one or two fruit can be procured on each runner it will be sufficient, particularly when fine fruit is the prevailing consideration.

INSTRUCTIONS FOR RENEWING THE HEAT OF THE HOTBED BY LININGS.

Par. 54. - It is necessary, in all stages of the hotbed, to occasionally examine the heat, with the view to support a proper temperature; there- 
fore, when the heat has declined considerably, it should be renewed as speedily as possible, by applying linings of hot dung to the sides, about one foot and a half wide, and three or four inches above the dung of the bed, to allow for settling; but it is by no means a desirable plan to raise the linings much higher than the dung of the bed, for that is apt to burn the earth within the frame; the steam also will draw into the frame, and frequently proves injurious, by scalding the leaves, and perhaps kill the plants. This may be prevented, by laying several inches of earth on the top of the linings, which will not only confine the steam, but keep the heat in below. In most cases the back part is lined first, and the front in about a week after, unless the heat of the bed has become very much reduced : in that case, the lining had better be completed at once.

It will be necessary to examine the linings in their early state, to find whether the heat is too violent, for that may communicate to the bed and earth, and scorch the roots of the plants; therefore should such by chance take place, 
remove the upper part of the linings, or the whole if necessary, for a day or two, and then apply them again more moderately.

By this practice of renewing the linings as the old becomes decayed, a constant regular heat will be supported till June, which is essential, both for the growth of the plants and the swelling of the fruit.

\section{REMARKS RELATIVE TO MELONS WHILE} RIPENING.

Par. 55.-The maturity of melons will appear in different ways; - by the full size of the fruit, and in some kinds by changing yellow; but all the varieties impart a powerful rich odour; also at times the stalk, joining the base of the fruit, will crack open, apparently ready to separate from it; - all these appearances denote that the melons have arrived to a sufficient state of maturity for gathering, which should be done before the fruit is over ripe. Cut with it most of the stalk, which is attached to the fruit; or if there is no other fruit growing above on that vine, it is usual to cut a small piece of the 
runner also. In the morning, before the heat of the day, is the most preferable time for cutting the melons, while they are cool and fresh, as they are considered to eat with a more rich and agreeable flavour : lay them in a cool dry place, till they are required for table.

If melons are cut before too ripe, they will keep good for several days, when any particular occasion may render it desirable.

LATE CROPS OF MELONS UNDER HAND-GLASSES, ETC.

Par. 56.- Good late crops of melons may be produced in August, September, and October, in fine dry seasons, by being ridged out on hotbeds, under hand-glasses, raising the plants in a frame hotbed, by sowing the seed in March or beginning of April, where they should remain three or four weeks, till they have produced two or three rough leaves. Then at the end of April or beginning of May, ridge them out on large hotbeds prepared for the purpose under handglasses, at three or four feet apart, along the middle of the bed. About the end of May, or 
heginning of June, when the plants have filled the glasses, they must be raised three or four inches upon props, for the vines to run over the bed.

These crops of melons may consist of any of the varieties; but the common ribbed, oblong ribbed, netted, and the Romana, may be mostly depended on for plentiful crops, the plants being treated in a similar way to the directions given in the paragraph for the early crop.

The hotbeds for these late crops may either be made in trenches or on the level ground, but those made in April or the beginning of May it will be advisable to make on the level ground, as the heat may decline in three or four weeks; and if cold weather should ensue, it may be necessary to line the beds, to revire the heat, and by this plan they may be lined from the bottom.

The treatment of the surface of the bed to be nearly the same as directed for early forcing, both as to the hills or ridges for planting the plants in, and also as to filling up the remainder of the bed to the level of the hills by degrees; put the glasses on the hills, and when the earth 
is warm, put in the plants, removing them from the pots with the balls entire, with two plants in each, give them a moderate watering, and put down the glasses and shade them for a few days until they have made fresh roots, after which, raise the glasses a little on the south side to give air, but keep them close at nights, and cover the glasses and also the bed every night with thick garden mats, which ought to be continued till the middle of June; the plants will require occasional waterings moderately in fine weather, and when the glasses bave become crowded, they must be raised, and the runners trained out on the surface of the bed in regular order.

When the beds are made in trenches or pits, dig them out three or four feet wide, and two feet deep, fill them up with the prepared hot dung eight or ten inches above the surface, plant the plants on ridges as before directed, about twelve inches deep, and earth all over the top of the bed, and also the sides to keep in the heat, and so far extended, to make the beds six feet wide; and raising it till it is about a foot thick all over the bed, or even with the top of 
hills; in the absence of any other covering, keep the glasses over the centre of the plants, to defend the main roots and stem from heavy rains, \&c.; as the fruit advances in growth, it would be of advantage to place some of the best under the glasses, or those at a distance may be covered with spare glasses, especially when very cold or wet weather is prevalent; but if spare frames with lights are at hand, about the middle of August, and placed over these beds, it will be by far a more effectual protection, and the fruit will ripen sooner, and in greater perfection, and towards autumin the glasses can be covered with mats on cold nights.

RAISING MELONS IN OILED-PAPER FRAMES, WITH DIRECTIONS FOR MAKING THE FRAMES.

Par. 57.-Fine crops of melons are produced by growing them under oiled-paper frames; the plants being raised the same as directed for hand-glasses, and the beds prepared in the same way; they may either be covered with hand-glasses till June, or in want of handglasses the paper frames placed over them at 
once. If first protected with hand-glasses, when the glasses become filled with the runners, remove the glasses, and place over the beds the oiled-paper frames, there to remain during the summer.

The frames are formed of thin slips of wood, like pan-tile laths, or poles, similarly constructed to the roof of a house or an archway, ten feet long, by three and a half to four or five wide, and two and a half to three feet high, with two pannels made to open on one side with hinges.

The bottom of the frame is made of slight wood-work, in which the small cross rafters are fixed, a foot apart, either in a ridge form or arched, and across these small rafters, pack. thread, or strong twine is placed along the frame lengthways, putting it round each rafter about a foot apart, and others drawn across the bed between the rafters, crossing or intersecting the other lines, which will serve to strengthen the rafters, and assist in supporting the paper; then take sume strong white demy paper, and paste on the rafters in a regular and neat manner, and when dry, brush the paper all over with 
linseed oil ; this may be done with a soft painting brush, using the oil on the outside only, and that but lightly; when this has become thoroughly dry, the frames will be fit for use.

Although the oiled-paper will be sufficiently water-proof to resist the rain, and keep off the cold; it will form an agreeable shade for the plants, during the scorching rays of the sun in the height of summer, and through which protection the plants thrive exceedingly, and produce good crops of fruit, from the end of July till the beginning of October. After the frame has been placed over the plants, admit air every fine day by opening the side pannels of the frame, or if no pannels were made to open, raise the frame a few inches at bottom, and as occasion may require, give moderate waterings when the earth is dry, but be very moderate while the fruit is setting and ripening, for the reasons assigned for early crops.

I may here remark that in very heary rains or hail storms, which sometimes occur in the height of summer, it will be advantageous to spread mats over the frames, not only to pre- 
GROWING MELONS BY BARK-BED HEAT. 285

serve them from damage, but also to defend the bed as much as possible in very unfavourable weather; and by proper attention to growing late melons by this practice, not only fine crops are obtained, but the fruit (which for the most part will ripen in August and September) will also be of very good flavour. When melons are wanted for mangoes, they should be gathered while green, about a quarter or half-grown, and should be taken from the late crops, selecting those which are not likely to ripen.

GROWING MELONS BY BARK-BED HEAT.

Par. 58. - Melons grown by bark hotbed heat, are generally raised in very good perfection, sometimes superior and with less trouble than those grown on dung hotbeds, and more particularly for general crops, such as are planted in February, March, or April, as the heat of the bark is of that kind, regular nature, and also so lasting, not being subject to heat violently, or decline suddenly like dung hotbeds, but will continue a moderate heat for two or three months, and the degree of heat produced 
by the bark is exceedingly well adapted to the nature of melons.

The beds for this purpose must be made in a pit; or in a case, which may be made of post and planking, for the bark being of a loose nature, cannot be so conveniently formed into a bed without; the best plan is to make them of bricks and mortar, sunk about one-third in the ground, being in the clear in depth about three feet in front, by four behind, the width, that of a large garden frame, to place on the top, or a frame work made for the glasses, fitted to, and fixed on the pit; in the latter case, the pit may be sunk deeper, but in all cases melons ought to have about a foot of earth in depth, placed on the top of the hotbed.

Where a pit can be constructed with hot water pipes, or fire-flues internally, it will be of great advantage, by rendering moderate assistance in severe weather, particularly after the heat of the bed has considerably declined, but such is not of so much importance except for very early forcing; but for commencing in February or early in March, it will be requisite that 
the bark should be fresh but for later forcing, part of the waste bark from a hot-house, to the extent of one-third or a half, may be mixed with the new; or in want of a sufficient quantity of tan to make the bed with wholly, of the size required, a part may be tan, and a part stable dung; this may be made in a pit or without, as the dung will keep the bed in proper form, and the bark being mixed with the dung, the heat will be more durable than that of a bed made entirely of the latter.

The plants at all seasons, if practicable, ought to have been previously raised, and of proper growth, with two or three rough leaves, by the time the principal hotbed for their reception is ready, otherwise they will be deprived of the advantages of the first and main heat of the bed; but if such cannot be the case, the seed may be sown at once, where the plants are to remain; treat these beds as directed for the other hotbeds, with regard to air, water, covering, shading, \&c. 
HOW TO SAVE AND PRESERVE MELON SEED.

Par. 59.-To have good melon seed that will keep, it is of importance to select it from wellripened fruit, and it is also preferable to save it from the earliest, and those grown near the stem of the plant, as the plants raised from such seed generally prove more productive, and the fruit set better than when saved from fruit grown on an advanced part of the vine.

When the melon is cut for eating, the pulp in the centre, in which the seed is intermixed, should be preserved, and the seed afterwards washed clean from the pulp, then spread it a few days to dry and properly harden; after which, place each variety in separate packets, each packet being carefully labelled with the name of the sort, and date of the year written thereon, then deposit it in any dry place until it is wanted.

Seed saved, as above directed, will retain its vegetative qualities for several years; and, as I have before remarked, that it proves more productive when three or four years old, at 
the time of sowing, than the new seed; the instructions I have given on this subject ought to receive their due force with those melon growers who have not themselves proved the difference.

INTRODUCTORY REMARKS ON THE GROWING OF STRAWBERRIES.

Par. 60.-Strawberries, as a dessert fruit, deserve to be prominently noticed, it being generally admired for its delicious flavour, and as it can be obtained by forcing earlier than other fruits, it is a great acquisition for the dessert; and as it can be forced in every forcing department, I think I shall not be trespassing by giving rather a detailed account of its culture.

The strawberry may be brought to perfection by forcing, three months or more before its natural season for ripening in the open ground, particularly throughout the months of March, April, and May, and some (although not with so much success) much earlier; therefore, where there is convenience for forcing them in succes- 
sion, they may be obtained by the following rules until their natural season for ripening.

Although I have said that strawherries may be brought to perfection in all forcing departments, it may be as well to remark that the forcing houses are the most convenient, (including the pinery, vinery, peach-house, \&c.,) more so, and generally more successful than by forcing them in hotbeds, at the same time I intend to lay down the necessary rules for their general culture in every department of forcing.

DIFFERENT SORTS OF STRAWBERRIES PROPER FOR FORCING.

Par. 61.-Many new varieties of strawberries have been raised within the last few years which have become celebrated, some for their size and beauty, some for their great bearing, and some have reached the character of being fine-flavoured; but being acquainted with the whole of these new sorts of any nute, I nevertheless must give the preference for a general crop $i$ the old scarlet, being one of the earliest and most successful forcers we have in cultivation, 
it being an excellent bearer, and the fruit of superior quality; although I have said thus much respecting this well-known fruit, yet there are several other very fine flavoured strawberries which ought to be cultivated both for their size and beauty, and also for the sake of a variety for table, particularly those which possess a rich flavour; and as the under mentioned strawberries will force successfully, they will form a fine collection.

Keen's Imperial

Downton

Alpine
Wilmot's Superb

Roseberry

New Hautboy

The scarlet alpine is a plentiful bearer, both on the main stool, and also on the early runners of the former year; this strawberry, with the old scarlet, are decidedly two of the best for early forcing, and they produce a supply of long continuance. 
MANNER OF RAISING AND CULTURE OF STRAWBERRY PLANTS INTENDED FOR FORCING.

Par. 62.-Strawberry plants for forcing should for the most part be in pots, thirty-twos is the size generally preferred for two years old plants; at this age they attain proper strength for forcing; one year old runners are also sometimes forced, which if not very strong, will succeed in forty-eights; likewise three year old plants, being the greatest age, they ought to be admitted into the forcing departments; these generally succeed best in twenty-fours.

The runners, when taken from the motherplants in summer, may be immediately planted in pots, to remain till they are proper for forcing, or some of the late runners may be planted out in beds to remain till the following spring, or early in autumn, when they should be taken up with balls and potted, to get established by the ensuing forcing season; or for hotbed forcing some may remain to be removed with balls direct from the nursery beds, and be planted in the earth of the hotbed. 
When selecting the plants for forcing, take them from healthy bearing beds in the open ground, making choice of the first produced runners of the year, which by nature takes root in the ground at the joints; the early runners are generally of proper growth to detach for planting about May or June; but this may be done any time during the summer, or early in autumn, but the sooner they are transplanted the better; take them up with good roots, cut of the runner part from the plant, and whether planted in pots or beds, they ought to be placed in a shady situation.

The soil best suited for planting strawberries in pots, is light loam enriched with rotten dung, or any rich garden mould; if the plants are not over large, place two in a pot, watering them at planting, and continue to supply them with repeated and plentiful waterings in dry weather. As they put forth runners, cut them off to strengthen the plants for fruiting; this should be done both to those plants which are considered of sufficient strength for forcing the first year, and also those which are retained for 
the second year, placing the plants on a warm border during the winter, or in a frame, to have occasional protection in severe weather, this will keep them in good condition for forcing.

If the plants have grown very strong in the small-size pots, that they appear not likely to have room to receive sufficient nourishment to support them through, their fruiting, previous to removing them when they are to be forced, shift them with their entire balls into larger pots, from forty-eights to thirty-twos, or from thirtytwos to twenty-fours, placing a little fresh earth at the bottom of the pots, and fill up the sides thoroughly. In January, or earlier, some plants may be introduced, and a succession continued throughout February, March, and April, accord. ing as the forcing departments will admit.

FORCING STRAWBERRIES IN THF PINERY.

Par. 63.- Where there is a pinery, or any general hothouse continually in cultivation by artificial heat, some pots of strawberries may be brought in as early as December or January; but about the end of January, and any time in 
FORCING STRAWBERRIES IN THE PINERY. 295

February, is a better time to bring in a plentiful supply, as they generally prove much more successful than those brought in earlier; some may be placed over the flues, (if heated by them,) near the front and end glasses, on the front wall of the bark-bed, or if room, some may be plunged in the fore part of the bark-bed, which will considerably assist in forwarding the fruit, and also in any other convenient parts of the house near the glass, and the different successions may be brought in at two or three weeks interval, till the middle or end of April; the principal culture being, during the time they are in the forcing-house, to give them frequent waterings, not letting the earth get very dry, but while in bloom apply the water to the earth only, as watering over the blossom before the main crop of fruit is set, may prove injurious to the farina or pollen of the male, by which its fructifying properties may lose their proper effect in impregnating the pistils of the female.

As the plants put forth their runners, cut them off, in order to throw strength into the bloom and fruit, some of which may be expected to 
ripen in February, but in greater perfection and more plentiful in March and April; and by regular successions of plants, fine fruit may be obtained till the supplies in the open ground, about the end of May or beginning of June.

FORCING STRAWBERRIES IN PEACH AND OTHER FRUIT-TREE FORCING HOUSES, ETC., INCLUDING VINERIES.

Par. 64.-Forcing houses for fruit trees are admirably adapted for forcing strawberries, bringing them to great perfection; some may be introduced as soon as the house is set in motion by artificial heat, and a succession continued as directed in the vinery; and where there is a bark bed some should be plunged therein, which will forward them considerably; and about the end of January or beginning of February place some forward near the glasses, also upon shelves in different parts of the house and in any other convenient situation, thus a supply may be continued until the season for ripe strawberries in the open air. 
EORCING STRAWBERRIES IN HOT-BEDS, WITH USEFUL REMARKS.

Par. 65.--In the absence of the convenience of hot-houses for producing early strawberries they may be forced by hotbeds under frames and lights, and they will come to tolerable perfection ahout April; these hotbeds may be made of stable dung, or of tanner's bark; if convenient to make them of the latter, they are to be preferred, as the heat is more steady, kind, and durable, and generally proves more successful; but the bark hotbed must have a bricked pit, or a case of post and planking, to contain the bark in, otherwise its loose texture will make it inconvenient to form it into a bed. The bedis should be about three feet deep, width according to the size of the frames, and length to what extent may be required.

But a well constructed pit of brick-work, about four feet deep in front, by five to six feet behind, to admit of hot water pipes, or a flue along the upper part at the back, or continued all round above the top of the bark-bed, will 
be very beneficial to assist occasionally in cold weather, and more particularly when the heat of the bed becomes low; then it would prove of great advantage to the plants; these beds may be made any time, from the middle or end of January, till about the middle of March, and when the bark is of a proper moderate heat, plunge the pots therein; by this practice good crops of early strawberries will be produced.

Dung hotbeds for forcing strawberries may be made also from the end of January, in February, or March, in the same manner as is usual for making hotbeds of stable dung; set on the frames and lights, and when the bed is of a moderate heat, bring in the earth, and cuver the bed about six or seven inches deep, in which to plunge the pots; or if not in pots, to plant the plants in, which should be taken if possible immediately from the nursery bed to that of the hotbed, with as much ball about the roots as can be preserved; after the bed is planted, and a moderate watering given to the plants, put on the glasses, and gire vent to the steam arising from the bed, then cover the glasses every night 
with mats, S:c.; and when the plants are in a growing state, admit air daily when mild, and more freely when the sun shines, and especially when in bloom, and the fruit is setting. Support the heat when it declines by linings of hot dung, and treat the plants in every other respect as directed for their culture in the hothouse.

If convenient to have ten or twelve inches of bark to place on the top of the dung' hotbed instead of mould, to plunge the pots in, it will prove of advantage to the crops. On the other hand, when the plants are intended for the bark pit without pots, mould should be placed on the bark, about six inches thick, to receive the plants; although the plants will grow, and often do tolerably well, by being planted in the bark.

When the plants have not been properly prepared for forcing, as before directed, or not a sufficiency for the purposes required, some plants may be taken up from the natural beds in the open ground, and be immediately potted, or transplanted with balls direct in the hotbed. Observe, in bark-bed forcing, should the heat become very weak, take up the pots and fork up 
the tan, which will rerive the heat, and then replunge them immediately. As the plants adrance in growth, be careful to attend to the watering. They will require a greater supply to the earth while in bloom and the fruit setting; but when the fruit is ripening, very little should given, in order to preserve the rich flavour of the fruit.

Therefore in hotbeds, either of dung or tan, supplies may be proluced in succession, by introducing the plants at different times, and by occasional linings to the former, and forking up the latter, the heat may be revived to produce fruit, until the strawberries arrive at maturity in the open ground; and for the purpose of having plants which may be depended on for fruiting successfully, it is advisable to have fresh supplies prepared for forcing, as formerly described, every season, which will preclude the necessity of forcing the plants a second time, which seldom proves so successful as fresh plants.

FORCING RASPBERRIES.

Par. 66. - The raspberry as a table fruit being 
highly esteemed, and, when produced early, highly appreciated as a variety, deserves to be noticed, as they will produce good crops of early fruit of tolerable flavour, by forcing. Any of the varieties will force, but the double bearing, both red and white, and the red Antwerp, generally prove very successful.

The plants should be two or three years old, having two, three, or four canes (young shoots of the year) to each, and taken up from the open ground, in the autumn previous to the forcing, and potted in twenty-fours or sixteen size pots, letting some of the earth remain about the fibres: light rich loam or garden mould will suit for potting them in. If potted early in October, they will take fresh root almost immediately, which will greatly strengthen them by the forcing season, and cause them to set their fruit more freely, and likewise to become much finer than when potted late in the season, or inmediately previous to forcing. The plants after potting should be placed in a sheltered situation during the winter months, until they are removed to the forcing house. 
The peachery, or any other tree-fruit forcing house, or the vinery, when not too powerfully forced, will suit for forcing raspberries. The most convenient part of the house for this purpose, and where they will succeed well, is the centre, where there is no bark pit, or trees planted. Therefore in that case, in the centre space of the house plunge the pots, in cross rows, about fifteen inches plant from plant, and eighteen row from row, the canes being loosely tied together with bass. The plants may be introduced successfully about the beginning or middle of February, or earlier, if thought proper, but this fruit will have little or no flavour until the sun has sufficient power to render assistance to the ripening; and although we are subjected to severe cutting winds in March, the sun generally has great influence; at the end of which month, and throughout April and May, good fruit may be obtained.

When the potting has been omitted, as directed above, some plants may be taken up with as much earth as will remain about the roots, and be either potted immediately before forcing, or 
taken direct to the forcing house, and planted in the earth of the house, when there is a space in the centre vacant. Where there is no vacancy for plunging the pots, some may be introduced in convenient places in the lower part of the house; but they succeed decidedly better when plunged, and more particularly when potted early.

RAISING KIDNEY BEANS IN FORCING-HOUSES, ETC.

Par. 67.-Kidney beans can be brought forward in any of the forcing departments, to be fit for use in March, and a succession continued till the crops in the open ground are fit to gather, by commencing setting the seed in January, when any furcing has commenced.

The earliest crops are generally raised in twenty-fours (size pots); these should be filled within an inch and a half of the brim (well shook down) of rich light soil; then set four or five beans in each, and cover them over about an inch thick with the same sort of soil, which should be tolerably dry. Place them in the forcing house 
near the glass, or in such a part, as is most convenient. The seed will soon germinate, when a moderate watering should be given, but not before, but they will require frequent waterings after the plants have corne up; and by planting some in succession about every three weeks in smaller pots, (forty-eights or thirty-twos,) three or four beans in each, and the plants placed close together in any convenient part of the house, to be coming forward while the more early crops are arriving to maturity; and when the plants have come' up one, two, or three inches high, shift them into larger pots with their balls entire, and give them an immediate watering. Likewise some may be raised in the borders of the forcing houses, in small drills an inch deep, either length or crossways the borders, placing the beans about two inches apart, earthing them over regularly, and give waterings as directed for those in pots. By this practice good crops may be obtained throughout the spring, until full crops succeed them in the open ground. 
GROWING CUCUMBERS IN FORCING HOUSES.

Par. 68.-Cucumbers may be raised in the vinery, the peach-house, or other forcing houses. The plants should be raised by sowing the seed in a hotbed of dung or bark, in December, January, or February, and when the plants are a few days old, while in the seed leaves, prick them into small pots, (forty-eights,) three in each ; and when they have formed their rough leaves about two inches broad, turn them out of the pots with balls, and plant them into large ones, or into narrow oblong boxes, the earth being rich 'and fine, the same as is generally used for frame cucumbers. Place them near the top glasses behind, that they may not shade the trees, \&c. below; as the plants advance in growth, place sticks for them to run upon for support, and give frequent waterings. When in bloom, inpregnate the female with the farina of the male, by applying the centre of the flower (after removing the outside flower leaf) of the male, commonly called the false blossom, to the centre of the female flower, which always has the 
young fruit attached at the bottom of the flower. This is only necessary in early forcing, while the bees and other winged insects are scarce, particularly the bees, which, by flying from flower to flower to collect honey, convey the farina of the male blossoms to those of the female, which causes the fruit to set more successfully. Although the plants generally succeed better by the above treatment, the seed may be sown in large pots or boxes, to remain for fruiting; by this practice tolerably good early cucumbers are sometimes produced. It is also advisable to sow more seed occasionally, as failures will sometimes happen to these tender plants by mere accident; and by this precaution, if they are not quite so early, the disappointment will not be so great as entirely losing the early season.

EARLY LETTUCES IN FORCING HOUSES.

Par. 69.-Lettuces of different sorts, but particularly the white Cos, may be forwarded for early use in forcing houses, by planting them in the borders any time in winter; but the most successful way to have them in the best per- 
fection in such places, is to transplant them from warm borders or frames, with some earth to their roots, in January and February, when the forcing is commenced, when they will advance to a tolerably good size, and with moderately good hearts for early use.

PEAS AND BEANS IN FRUIT-TREE FORCING HOUSES.

Par. 70.-Peas and beans may be brought into bearing for early use in tree-fruit forcing houses. The early frame peas and mazagan beans are the sorts usually selected for this purpose. Some may be sown in the borders of the house in November, sowing them in drills a distance from the trees; likewise some may be sown thick in frames, or on a warm border, for transplanting into the borders of the house. These may be sown late in October, or beginning of November; and by this early sowing the plants get considerable strength by the forcing season, and are generally more productive than those sown thick in pots for transplanting. Nevertheless, some may be sown in pots to be trans- 
planted, if required, in November, December, or January, in a hotbed, (or hothouse, if any in motion,) to forward the plants by the forcing season to an inch or two high, and then transplant them into the borders of the fruit-tree forcing house, as soon as the forcing is commenced, or before; also some may be transplanted into pots, if any convenient front situation can be afforded for them in the house.

Frequent waterings will be necessary, and more so as they advance in bloom and the pods begin to appear; these may be expected to be ready for gathering in April, and sometimes sooner, from those raised very early.

RAISING EARLY, VARIOUS USEFUL ARTICLES FOR CULINARY PURPOSES, IN FORCING HOUSES.

Par.71.-Various useful things may be brought forward for early use, in the different forcing departments, when convenient to afford them room, such as green gooseberries for tarts, and currants for the same, or some to ripen, also rhubarb for the like purpose. Likewise many useful and 
FORCING DIFFERENT VARIETIES, \&C. 309

favourite herbs, such as mint, tarragon, tansey, \&c. \&c., taking up the roots from the open ground, which may be either introduced into the forcing house in pots, or be planted in any convenient place on the borders or centre of the house; also small salading may be kept in regular and corstant supply, by frequent sowings for that purpose. Chilis should likewise be brought in for early green fruit, and also to forward them for a main crop of ripe fruit ; and any other articles which are likely to be wanted should not be omitted.

OBSERVATIONS ON FORCING DIFFERENT VARIE-

TIES OF CHOICE FLOWERS IN FORCING HOUSES.

Par. 72.-Flowering plants of different varieties, consisting of bulbous, tuberous, and fibrousrooted kinds, can also be successfully admitted into forcing houses for early bloom, at any time after the forcing has comınenced, bringing in some at a time, with a view to keeping up a succession, the whole of which may be in pots, or if preferred, some may be in small neat boxes, 
made for the purpose, and neatly painted on the outside, with holes at the bottom, according to their size, to carry off the water, and filled with such soil as is suited to the sorts intended to be grown therein.

Amongst the numerous varieties which may be brought into early bloom in forcing houses, may be introduced occasionally many kinds of greenhouse plants, also roses, including moss, white Provence, (mark, I mean by white Provence the old rose unique, or Grimwood's white Provence, the wood of which is of a short, stumpy growth, on which the bloom comes amazingly strong, large, and double, and when expanded, of a beautiful white. I have named this, as it is not generally known, even among florists, that there is another sold under this name, which is a very free grower, equal to the old cabbage rose, but the bioom is by no means equal to the original white Provence).-Rose de Meux, Pompone, red and scarlet Provence, blush and crimson china, \&c. Likewise pinks, piccotees, carnations, hyacinths, jonquils, dwarf tulips, 
polyanthus, narcissus, ranunculus, anemones, bulbous and tuberous irises, stocks, mignionette, balsams, \&c. ; also many choice sorts of American plants, such as different varieties of rhododendrons, azalias, kalmias, andromedas, ledums, daphnas, \&c., with other flowering shrubs, consisting of double and single dwarf almonds, double blossom peach, double blossom cherry, Siberian and Persian lilac, syringas, and honeysuckles, with many other varieties of small growth, which taste and fancy may dictate.

I would recommend all plants of a shrubby nature to be well established in the pots, at least to have become well rooted therein, before they are brought into the forcing house; and although I am not now writing a work on botanical culture generally, (if I may use the term, yet I think I may not here digress by observing that American plants, particularly when forced, will derive great benefit from placing some sheep droppings round the top of the pot, about sufficient to cover the surface, which, by the repeated waterings, will greatly assist the plants, by the 
312 FORCING DIFFERENT VARIETIES, \&C.

juices being washed into the soil, and cause the bloom to be much finer. The sheep dung may be either removed or covered over with mould, prior to the plants being removed to the conservatory, or elsewhere, during the time of flowering.

THE END. 



$$
1
$$




\section{LIBRARY OF CONGRESS \\ ||| || || || || || || || || || || || || || || || || || |||' \\ |||||||||||||||||||||||||||||||||||||||||||| \\ 00009294910}

